


\title{
Eutectic Modification of Al-Si casting alloys
}

\author{
Jenifer Barrirero
}
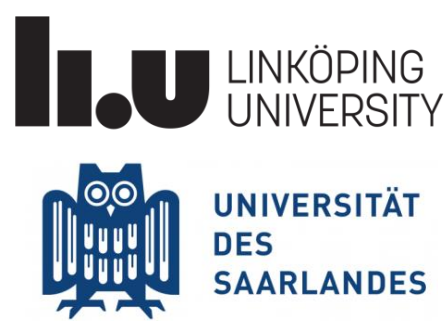

Nanostructured Materials

Department of Physics, Chemistry and Biology (IFM)

Linköpings University, Sweden 
(C) Jenifer Barrirero, 2019

ISBN 978-91-7519-007-5

ISSN 0345-7524

Printed by LiU-Tryck, Linköping, Sweden, 2019 
ahora

en esta hora inocente yo y la que fui nos sentamos en el umbral de mi mirada

Alejandra Pizarnik 


\section{Abstract}

Aluminum alloys with silicon as the major alloying element are the most widely used aluminum casting alloys. The eutectic phase in these alloys is formed by hard and brittle silicon plates in an aluminum matrix. Such silicon plates can act as crack propagation paths deteriorating the toughness of the material. To enhance ductility, silicon can be modified to a coral-like microstructure by addition of a modifying agent. Amongst the elements proposed as modifiers, only strontium, sodium and europium induce a plate-tocoral transition, while others such as ytterbium, only refine the silicon plates. The exact mechanism for the remarkable plate-to-coral change, and the reason why certain elements only refine the structure, is still not completely understood.

In this investigation, atom probe tomography and transmission electron microscopy were used to analyze and compare the crystal structure and the distribution of solute atoms in silicon at the atomic level. An unmodified alloy and alloys modified by strontium, sodium, europium and ytterbium were studied. Elements inducing silicon plate-to-coral transition were found to contain nanometer sized clusters at the defects in silicon with stoichiometries corresponding to compounds formed at the ternary eutectic reaction of each system. In contrast, the addition of ytterbium, that only refines the silicon plates, is unable to form clusters in silicon. We propose that the formation of ternary compound clusters $\mathrm{AlSiNa}, \mathrm{Al}_{2} \mathrm{Si}_{2} \mathrm{Sr}$ and $\mathrm{Al}_{2} \mathrm{Si}_{2} \mathrm{Eu}$ at the silicon / liquid interface during solidification restrict silicon growth. The formation of clusters on silicon facets create growth steps and increase growth direction diversity. The incorporation of clusters in silicon explains the high density of crystallographic defects and the structural modification from plates to corals.

The parallel lattice plane-normals $011_{\mathrm{Si}} / / 0001_{\mathrm{Al} 2 \mathrm{Si} 2 \mathrm{Eu}}, 011_{\mathrm{Si}} / / 6 \overline{7} 1 \mathrm{O}_{\mathrm{Al} 2 \mathrm{Si} 2 \mathrm{Eu}}$ and $111_{\mathrm{Si}} / /$ $6 \overline{7} 1 \mathrm{O}_{\mathrm{Al} 2 \mathrm{Si} 2 \mathrm{Eu}}$ were found between $\mathrm{Al}_{2} \mathrm{Si}_{2} \mathrm{Eu}$ and silicon, and absent between $\mathrm{Al}_{2} \mathrm{Si}_{2} \mathrm{Yb}$ and silicon. We propose a favorable heterogeneous formation of $\mathrm{Al}_{2} \mathrm{Si}_{2} \mathrm{Eu}$ on silicon. The misfit between $011_{\mathrm{Si}}$ and $0002 \mathrm{Al}_{2} \mathrm{Si} 2 \mathrm{X}$ interplanar spacings shows a consistent trend with the potency of modification for several elements such as strontium, sodium, europium, calcium, barium, ytterbium and yttrium. 


\section{Popular Summary}

Air pollution is one of the top environmental concerns. Cars are responsible for around $12 \%$ of the total $\mathrm{CO}_{2}$ emissions in Europe. One way to reduce $\mathrm{CO}_{2}$ emissions and fuel consumption is to reduce the mass of vehicles, also called light-weighting. Lightweighting also plays an important role in the developing electro-mobility branch compensating for the high weight of batteries and improving energy efficiency.

To significantly reduce the weight of a vehicle, we can focus on the materials' selection, for example, by replacing some steel or cast iron parts by light-weight aluminum parts. Aluminum has one third the density of iron allowing a reduction of up to $50 \%$ weight without compromising safety. This replacement is, however, not trivial. Strong and tough alloys based on aluminum need to be designed and optimized for this purpose.

The mechanical properties and, consequently, the performance of an alloy can be controlled and improved by designing their microscopic structure. In the aluminumsilicon (Al-Si) alloys studied in this investigation, for instance, silicon grows in aluminum in the form of hard and brittle plates that can act as crack propagation paths deteriorating the resistance to fracture of the material. To enhance ductility, the morphology of silicon can be modified to a coral-like structure by adding a modifying agent. Amongst the several elements that have been proposed as potential modifiers, only strontium, sodium and europium induce the plate-to-coral transition, while other elements such as ytterbium, only refine the silicon plates. Although this modification has been used at the industrial practice in the last decades, the exact underlying mechanism for the remarkable plate-to-coral change, and the reason why certain elements only refine the structure, is still not completely understood. This lack of knowledge hinders the control of the microstructure homogeneity in more complex alloys such as $\mathrm{Al}-\mathrm{Si}-\mathrm{Mg}$ and $\mathrm{Al}-\mathrm{Si}-\mathrm{Mg}-\mathrm{Cu}$.

The reason why this structural modification has not been completely understood, in spite of almost 100 years of heavy investigation, is that the key of the effect lies at an extremely small length-scale. Only now with the possibility of combining two characterization methods with spatial, structural and chemical resolutions down to the atomic scale, we are capable of gaining further understanding. Atom probe tomography and transmission electron microscopy among other methods, were used in this investigation for a detailed study of the distribution of atoms in the silicon crystal of Al-Si alloys. In alloys containing 
elements that transform the silicon structure from plates to corals (strontium, sodium and europium), groups of atoms with fixed compositional relationships, were found inside the silicon crystal. In contrast, with the addition of ytterbium, which only refines the silicon plates, no clusters of atoms in silicon were found. We propose that the formation of clusters during the solidification of the casting parts restrict the silicon growth. These clusters lead to increased growth direction diversity, explaining the formation of a coral-like structure.

This new understanding contributes to the future control of the microstructure evolution of complex alloys at the industrial practice and the further enhancement and optimization of aluminum casting parts. 


\section{Populärvetenskaplig sammanfattning}

Luftföroreningar är en av de viktigaste miljöfrågorna. I Europa står bilar för ungefär 12\% av det totala utsläppet av $\mathrm{CO}_{2}$. Ett sätt att minska bränsleförbrukning och $\mathrm{CO}_{2}$-utsläpp är att minska fordonets massa, så kallade lättviktskonstruktioner. Lättviktskonstruktioner spelar också en viktig roll för elektrifieringen av transportsektorn genom att kompensera för batteriernas vikt och öka energieffektiviteten.

Vikten på ett fordon kan signifikant minskas genom materialvalen, t.ex. kan vissa ståloch gjutjärnskomponenter bytas mot lättviktskomponenter i aluminium. Aluminiums densitet är ca en tredjedel av järns vilket möjliggör en viktsreduktion på 50\% utan att tumma på säkerheten. Detta byte av material är dock inte trivialt. Höghållfasta och sega legering av aluminium måste designas och optimeras för detta ändamål.

De mekaniska egenskaperna och följaktligen prestandan hos en legering kan kontrolleras och förbättras genom design av dess mikrostruktur. Till exempel, i de legeringar mellan aluminium och kisel (Al-Si) som studerats i denna avhandling så växer kislet in i aluminium och bildar hårda och spröda plattor som kan verka som spricktillväxtvägar som lättare ger upphov till materialbrott. För att öka segheten så kan kislets morfologi ändras till en koralliknade morfologi genom att tillsätta en modifierare. Av de många ämnen som föreslagits som möjliga modifierare är det endast strontium, natrium och europium som inducerar den eftertraktade övergången från plattor till koraller medans andra ämnen så som ytterbium endast förfinar kiselplattorna.Trots att denna modifiering har använts industriellt de senaste årtiondena så är fortfarande de underliggande mekanismerna för denna remarkabla förändring av plattorna inte förstådd. Avsaknaden av denna kunskap hindrar att oss från att kunna kontrollera mikrostrukturen hos mer komplexa legeringar så som Al-Si-Mg och Al-Si-Cu.

Orsaken till denna strukturförändring är ännu inte förstådd, trots nästan 100 år av studier. Det beror på att nyckeleffekterna återfinns på en extremt liten längdskala. Endast nu är det möjligt att kunna studera detta genom att kombinera två karakteriseringsmetoder som tillsammans ger nödvändig spatial, strukturell och kemisk upplösning, dvs på atomär nivå. Atomsond och transmissionselektronmikroskopi, jämte andra metoder, användes i denna avhandling för detaljerade studier av atomernas placering i kiselkristallerna i Al-Si legeringar. I legeringar innehållande ämnen som modifierar Si-strukturen (strontium, natrium och europium) hittades endast dessa 
ämnen grupperade till små områden i kiselkristallen med en och samma sammansättning, s.k. kluster. Det står i kontrast till de ämnen som enast förfinanade kiselplattorna där sådana kluster inte kunde hittas. Vi föreslår att bildandet av kluster under framställningsprocessen av de gjutna detaljerna begränsar tillväxten av kiselkristaller. Dessa kluster leder till en större variation i tillväxtriktning som också förklarar bildandet av en koralliknande struktur.

Denna nya förståelse bidrar till en framtida kontroll av mikrostrukturutvecklingen av gjutna komplexa aluminiumlegeringar så att förbättrade och optimerade lättviktdetaljer kan framställas industriellt. 


\section{Vereinfachte Zusammenfassung}

Die Luftverschmutzung ist eines der größten Umweltprobleme. Pkw sind für rund $12 \%$ der gesamten $\mathrm{CO}_{2}$-Emissionen in Europa verantwortlich. Eine Möglichkeit, den Kraftstoffverbrauch und damit den $\mathrm{CO}_{2}$-Ausstoß zu reduzieren, besteht darin, die Masse der Fahrzeuge zu reduzieren, was auch als Leichtbau bezeichnet wird. In der zunehmend an Bedeutung gewinnenden Elektromobilitätsbranche spielt der Leichtbau ebenfalls eine wichtige Rolle, da er das hohe Gewicht der Batterien kompensieren und damit die Energieeffizienz verbessern kann.

Eine deutliche Reduzierung des Fahrzeuggewichts ist durch eine geeignete Materialauswahl möglich, indem beispielsweise einige Stahl- oder Eisengussteile durch leichte Aluminiumteile ersetzt werden. Aluminium hat ein Drittel der Dichte von Eisen, was eine Gewichtsreduzierung von bis zu 50\% ermöglicht, ohne die Sicherheit zu beeinträchtigen. Dieser Ersatz ist jedoch nicht trivial, da feste und zähe Legierungen auf Aluminiumbasis für diesen Zweck entwickelt und optimiert werden müssen.

Die mechanischen Eigenschaften und damit die Leistungsfähigkeit einer Legierung können durch die Gestaltung ihrer Mikrostruktur, dem Gefüge, kontrolliert und verbessert werden. In den in dieser Untersuchung untersuchten Aluminium-Silizium (AlSi) -Legierungen liegt Silizium beispielsweise in Form von harten und spröden Platten im Aluminium vor, die als Rissausbreitungspfade fungieren können und die Bruchfestigkeit des Materials beeinträchtigen. Um die Duktilität zu erhöhen, kann die Morphologie des Siliziums durch Zugabe eines sogenannten Veredelungsmittels in eine korallenartige Struktur überführt werden. Unter den zahlreichen Elementen, die als potenzielle Veredelungselemente vorgeschlagen wurden, erzeugen nur Strontium, Natrium und Europium den Übergang von einer plattenförmigen $\mathrm{zu}$ einer korallenförmigen Morphologie, während andere Elemente wie Ytterbium nur die Siliziumplatten verfeinern. Obwohl diese Veredelung in den letzten Jahrzehnten in der industriellen Praxis angewendet wurde, ist der genaue zugrunde liegende Mechanismus für diese bemerkenswerten Morphologieänderung und der Grund, warum bestimmte Elemente die Struktur nur verfeinern, noch nicht vollständig verstanden. Dieses fehlende Wissen behindert die Kontrolle der Mikrostrukturhomogenität bei komplexeren Legierungen wie beispielsweise $\mathrm{Al}-\mathrm{Si}-\mathrm{Mg}$ und $\mathrm{Al}-\mathrm{Si}-\mathrm{Mg}-\mathrm{Cu}$. 
Der Grund, warum diese Morphologieänderung trotz fast 100-jähriger intensiver Forschung nicht vollständig verstanden wurde, ist, dass sich die Ursache des Effekts auf einer extrem kleinen Längenskala abspielt. Erst heute sind wir durch die Kombination zweier Charakterisierungsmethoden mit räumlichen, strukturellen und chemischen Auflösungen bis in den atomaren Bereich in der Lage, dieses Verständnis zu erweitern. Die Atomsondentomographie und die Transmissionselektronenmikroskopie wurden in dieser Untersuchung unter anderem für eine detaillierte Untersuchung der Atomverteilung in der Siliziumphase in Al-Si-Legierungen eingesetzt. In Legierungen mit Veredelungselementen die eine korallenförmige Morphologie des Siliziums erzeugen (Strontium, Natrium und Europium), wurden in der Siliziumphase Atomcluster mit festem Verhältnis der Zusammensetzung gefunden. Im Gegensatz dazu wurden bei der Zugabe von Ytterbium, das die Siliziumplatten nur verfeinert, keine Atomcluster im Silizium gefunden. Wir schlagen vor, dass die Bildung von Clustern während der Erstarrung der Gussteile das Siliziumwachstum behindert. Diese Cluster führen zu einer erhöhten Vielfalt der Wachstumsrichtungen und erklären damit die Bildung einer korallenartigen Struktur.

Dieses neue Verständnis trägt zur zukünftigen Steuerung der Mikrostruktur komplexer Legierungen in der industriellen Praxis und zur weiteren Verbesserung und Optimierung von Aluminiumgussteilen bei. 


\section{Preface}

This thesis is the result of the Joint European Doctoral Program in Advanced Materials Science and Engineering - DocMASE. The work was accomplished in the Chair of Functional Materials at the University of Saarland, Saarbrücken, Germany; and in the group of Nanostructured Materials at the Department of Physics, Chemistry and Biology (IFM) of Linköping University, Linköping, Sweden.

The work was supported by the Erasmus Mundus program of the European Commission (DocMASE), the EU funding in the framework of the project AME-Lab (European Regional Development Fund C/4-EFRE-13/2009/Br). The atom probe was financed by the German Research Society (DFG) and the Federal State Government of Saarland (INST 256/298-1 FUGG). 


\section{Included papers}

\section{Paper I.}

Comparison of segregations formed in unmodified and Sr-modified Al-Si alloys studied by atom probe tomography and transmission electron microscopy.

Barrirero J., Engstler M., Ghafoor N., de Jonge N., Odén M., \& Mücklich F. Journal of Alloys and Compounds, 611, 410-421 (2014). https://doi.org/10.1016/j.jallcom.2014.05.121

\section{Paper II.}

Cluster formation at the $\mathrm{Si}$ /liquid interface in $\mathrm{Sr}$ and $\mathrm{Na}$ modified $\mathrm{Al}-\mathrm{Si}$ alloys.

Barrirero J., Li J., Engstler M., Ghafoor N., Schumacher P., Odén M., \& Mücklich F. Scripta Materialia, 117, 16-19 (2016). https://doi.org/10.1016/j.scriptamat.2016.02.018

\section{Paper III.}

Eutectic modification by ternary compound cluster formation in $\mathrm{Al}-\mathrm{Si}$ alloys.

Barrirero J., Pauly C., Engstler M., Ghanbaja J., Ghafoor N., Li J., Schumacher P., Odén M., \& Mücklich F. Scientific Reports 9, 1-10 (2019). https://doi.org/10.1038/s41598019-41919-2

\section{Paper IV.}

Nucleation and Growth of Eutectic Si in Al-Si Alloys with Na Addition.

Li J. H. H., Barrirero J., Engstler M., Aboulfadl H., Mücklich F., \& Schumacher P. Metallurgical and Materials Transactions A, 46(3), 1300-1311 (2014). https://doi.org/10.1007/s11661-014-2702-6

\section{Paper $V$.}

Phase selective sample preparation of Al-Si alloys for Atom Probe Tomography.

Barrirero J., Engstler M., Odén M., Mücklich F. Practical Metallography, 56(2), 76 - 90 (2019) https://doi.org/10.3139/147.110557 


\section{My contribution to the papers}

\section{Paper I.}

I was responsible for the planning of the project, prepared the samples for SEM / FIB, EBSD, APT and TEM. I performed the APT and EBSD measurements and analyses and participated in the TEM analysis. I wrote the first draft of the paper and was in charge of the submission and revision processes.

\section{Paper II.}

I was responsible for the planning of the project, prepared the samples for SEM / FIB, APT and TEM. I performed the APT measurements and analyses and participated in the TEM analysis. I wrote the first draft of the paper and was in charge of the submission and revision processes.

\section{Paper III.}

I was responsible for the planning of the project, prepared the samples for SEM / FIB, EBSD, APT and TEM. I performed the APT and EBSD measurements and analyses and participated in the TEM. I wrote the first draft of the paper and was in charge of the submission and revision processes.

\section{Paper IV.}

I prepared the samples for APT. I performed the APT measurements and analyses. I contributed to the writing of the paper.

\section{Paper $V$.}

I developed the method, prepared the samples, and applied it successfully in my work. I wrote the first draft of the paper and was in charge of the submission and revision processes. 


\title{
Other papers not included in the thesis
}

\author{
Barrirero J, Engstler M, Mücklich F. Atom Probe analysis of Sr distribution in AlSi \\ foundry alloys. In: Light Metals 2013 - TMS. ; 2013:291-296. \\ doi:10.1002/9781118663189.ch50.
}

Liang S-M, Engstler M, Groten V, Barrirero J, Mücklich F, Bührig-Polaczek A, SchmidFetzer R. Key experiments and thermodynamic revision of the binary Al-Sr system. $J$ Alloys Compd. 2014;610:443-450. doi:10.1016/j.jallcom.2014.05.018.

Mücklich F, Engstler M, Britz D, Barrirero J, Rossi P. Why We Need All Dimensions to Solve Both Very Old and Very New Questions in Materials at the Micro-, Nano- and Atomic Scales. Pract Metallogr. 2015;52(9):507-524. doi:10.3139/147.110360.

Li JH, Barrirero J, Sha G, Aboulfadl H, Mücklich F, Schumacher P. Precipitation hardening of an $\mathrm{Mg}-5 \mathrm{Zn}-2 \mathrm{Gd}-0.4 \mathrm{Zr}$ (wt. \%) alloy. Acta Mater. 2016;108:207-218. doi:10.1016/j.actamat.2016.01.053.

Shulumba N, Hellman O, Raza Z, Alling B, Barrirero J, Mücklich F, Abrikosov I A, Odén M. Lattice Vibrations Change the Solid Solubility of an Alloy at High Temperatures. Phys Rev Lett. 2016;117(20):205502. doi:10.1103/PhysRevLett.117.205502.

Yalamanchili K, Wang F, Aboulfadl H, Barrirero J, Rogström L, Jiménez-Pique E, Mücklich F, Tasnadi F, Odén M, Ghafoor N. Growth and thermal stability of TiN/ZrAlN: Effect of internal interfaces. Acta Mater. 2016;121:396-406. doi:10.1016/j.actamat.2016.07.006.

Menezes CM, Bogoni N, Barrirero J, Aboulfadl H, Mücklich F, Figueroa CA. Influence of the surface chemistry-structure relationship on the nanoscale friction of nitrided and post-oxidized iron. Surf Coatings Technol. 2016;308:220-225. doi:10.1016/j.surfcoat.2016.07.095.

Roa JJ, Aboulfadl H, Barrirero J, Turon-Vinas M, Mücklich F, Anglada M. Chemical segregation in a 12Ce-ZrO 2 /3Y-ZrO 2 ceramic composite. Mater Charact. 2017;132:8391. doi:10.1016/j.matchar.2017.07.045.

Calamba KM, Pierson JF, Bruyère S, Febvrier AL, Eklund P, Barrirero J, Mücklich F, Boyd R, Johansson Jõesaar MP, Odén M. Dislocation structure and microstrain evolution during spinodal decomposition of reactive magnetron sputtered heteroepixatial c-(Ti o.37, $\left.\mathrm{Al}_{0.63}\right) \mathrm{N} / \mathrm{c}-\mathrm{TiN}$ films grown on $\mathrm{MgO}(001)$ and (111) substrates. J Appl Phys. 2019;125(10):105301. doi:10.1063/1.5051609.

El Azhari I, Barrirero J, García J, Soldera F, Llanes L, Mücklich F. Atom Probe Tomography investigations on grain boundary segregation in polycrystalline Ti(C,N) and Zr(C,N) CVD coatings. Scr Mater. 2019;162:335-340. doi:10.1016/j.scriptama t.2018.11.041. 
Calamba KM, Barrirero J, Johansson Jõesaar MP, Bruyère S, Boyd R, Pierson JF, Le Febvrier A, Mücklich F, Odén M. Growth and high temperature decomposition of epitaxial metastable wurtzite $\left(\mathrm{Ti}_{1-\mathrm{x}}, \mathrm{Al}_{\mathrm{x}}\right) \mathrm{N}(\mathrm{OoO1})$ thin films. Thin Solid Films. 2019; 137414. doi.org/10.1016/j.tsf.2019.137414 


\section{Acknowledgements}

First and foremost, I would like to express my gratitude to my two supervisors, Prof. Frank Mücklich and Prof. Magnus Odén.

Prof. Frank Mücklich is a leadership role model for me. I have learned from his ever positive approach and communication skills. I would like to thank him for his trust and unrestricted access to all I needed to fulfill this research.

Prof. Magnus Odén is an inspiring scientist, I learned from his experience and confidence. I would like to thank him for the fruitful discussions, academic guidance, personal advice and endless support.

I am especially grateful to Michael Engstler for believing in me, always finding a solution to whatever came up and accompanying me during all these years.

I thank all the co-authors of the publications included in this thesis. This work would not have been possible without their contributions. Thank you to Christoph Pauly for giving me insight on materials characterization and for the fruitful discussions, and to Michael Engstler, Flavio Soldera, Andrés Olguín and Pranav Nayak for proof reading the manuscript of the thesis.

Thank you to the colleagues at the Chair of Functional Materials at Saarland University and the Nanostructured Materials group at Linköping University that made all these years such an enjoyable time.

I thank the Erasmus Mundus Joint European Programme for giving me the possibility of performing my doctoral studies in two countries and working in multi-cultural international environments.

I am very grateful to Andrés Olguin for holding me in his embraces and encouraging me to go forward in difficult times.

I am particularly grateful to Roberto Tannchen who stood wholehearted by my side helping me to sail through the storm.

Thank you to Corinna Markmann for her inspiring light.

I thank my parents Carmen Caffaratti and Domingo Barrirero for their love and unconditional support. Thanks to my brother Exe Barrirero for teaching me with his strength and determination. Thanks to Caro Rey for her openness, sweetness and peace. 
I am extremely grateful to all my dearest friends who are the biggest treasure that I have in this life: Pauli Kuschnir, María Laura Cenci, Anne Villamil, Moni Echeverry, Marian De Giovanni, Prisi Zanetti, Pauli Sierra, Anita Barbotti, Cele Karchesky, Juli Trivelli, Gaby Fertonani, Celi Bratovich, Hisham Aboulfadl, Fede Benedetto, Marco Francesconi, Oscar Deccó, Feli Giussani, Almila Özügürler, Micha Agthe, Tiny Walther, Gonza Schierloh, Eugenia Dalibon, Naureen Ghafoor, Nina Shulumba, Ana Chaar, Fei Wang, Gustavo Barrirero, Lucía Campo, Nico Souza, Flora Kiss, Fede Lasserre, Ire Morales, Agus Guitar, Gyöngyi Andras, Flavio Soldera, Fede Miguel, Seba Suárez. 


\section{Acronyms and symbols}

\begin{tabular}{|c|c|}
\hline A & Solidification interface area \\
\hline APT & Atom Probe Tomography \\
\hline $\mathrm{AR}$ & Atomic Resolution \\
\hline $\mathrm{BSE}$ & Back-Scattered Electrons \\
\hline$\Delta \mathrm{HF}$ & Enthalpy of fusion \\
\hline$\Delta \mathrm{SF}$ & Entropy of fusion \\
\hline EBSD & Electron Backscattered Diffraction \\
\hline EDX & Electron Dispersive X-ray \\
\hline ETD & Everhart Thornley Detector \\
\hline FIB & Focused Ion Beam \\
\hline G & Temperature gradient \\
\hline HR & High Resolution \\
\hline $\mathrm{HV}$ & High Voltage \\
\hline IIT & Impurity Induced Twinning \\
\hline IPF & Inverse Pole Figure \\
\hline $\mathrm{L}$ & Latent heat of fusion per unit volume \\
\hline LEAP & Local Electrode Atom Probe \\
\hline$\mu \mathrm{XRF}$ & Micro X-Ray Fluorescence \\
\hline $\mathrm{PF}$ & Pole Figure \\
\hline q & Total rate of heat extraction \\
\hline $\mathrm{R}$ & Ideal gas contant \\
\hline SE & Secondary Electrons \\
\hline SEM & Scanning Electron Microscopy \\
\hline SIMS & Secondary Ions Mass Spectroscopy \\
\hline TEM & Transmission Electron Microscopy \\
\hline ToF & Time-of-Flight \\
\hline TTL & Through The Lens \\
\hline UHV & Ultra-High Voltage \\
\hline $\mathrm{V}$ & Average interface velocity \\
\hline V & Growth rate \\
\hline $\mathrm{vCD}$ & Low voltage - high Contrast Detector \\
\hline VF & Volume Fraction \\
\hline $\mathrm{Z}$ & Atomic number \\
\hline$\alpha$ & Jackson's factor \\
\hline$\eta$ & Nearest neighbors at a growing solid/liquid interface \\
\hline$v$ & Coordination number \\
\hline$\xi$ & Orientation factor \\
\hline
\end{tabular}




\section{Content}

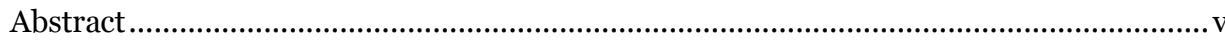

Popular Summary …................................................................................................. vii

Populärvetenskaplig sammanfattning ...........................................................................ix

Vereinfachte Zusammenfassung....................................................................................

Preface

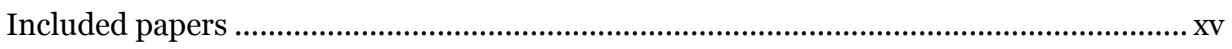

My contribution to the papers .................................................................................... xvii

Other papers not included in the thesis......................................................................... xix

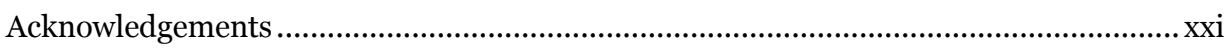

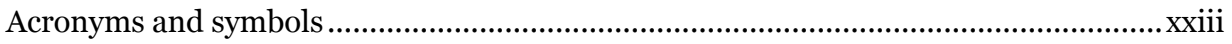

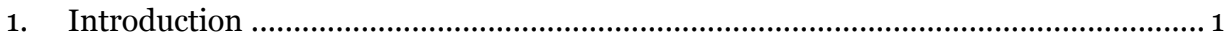

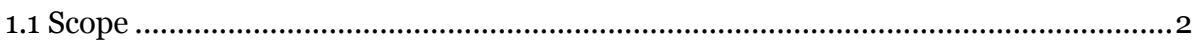

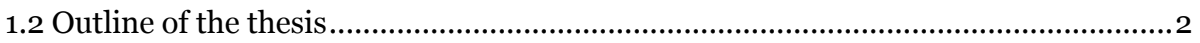

2. Aluminum casting alloys ................................................................................

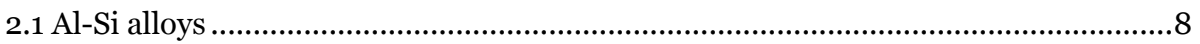

3. Eutectic solidification .........................................................................................11

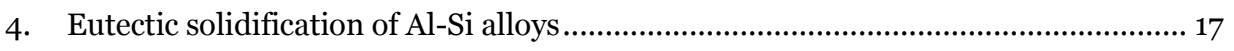

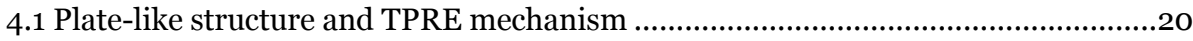

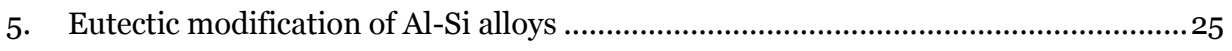

5.1 Enhancement of mechanical Properties .................................................................25

5.2 Elements modifying eutectic silicon and their effect on the microstructure...........28

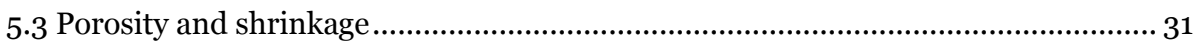

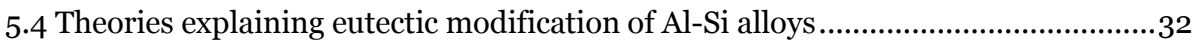

5.4.1 Early theories for eutectic modification............................................................ 32

5.4.2 Modification effect on eutectic growth .......................................................... 35

5.4.3 Modification effect on eutectic nucleation .......................................................39

5.4.4. Recent developments...............................................................................46

6. Sample preparation and Characterization .......................................................... 47 
6.1 Al-Si alloys

6.1.1 $\mathrm{Al}-7 \mathrm{wt} \% \mathrm{Si}$

6.1.2 $\mathrm{Al}-5 \mathrm{wt} \% \mathrm{Si}$

6.2 Scanning electron microscopy - SEM ............................................................48

6.2.1 Secondary electron imaging - SE .................................................................48

6.2.2 Backscattered electron imaging - BSE ..........................................................49

6.2.3 Energy dispersive X-ray spectroscopy - EDX................................................50

6.2.4 Electron backscattered diffraction - EBSD ................................................. 51

6.3 Focused ion beam - FIB ............................................................................... 53

6.3.1 Sample preparation for TEM .......................................................................5

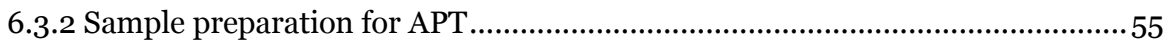

6.4 Transmission electron microscopy - TEM ….....................................................56

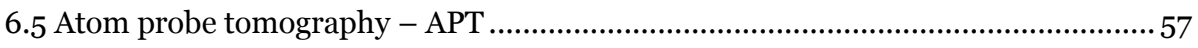

6.5.1 Working principle and experimental setup ....................................................57

6.5.2 Data reconstruction, visualization and analysis..........................................6 60

6.5.3 Trajectory aberrations and local magnification effects ...................................61

7. Summary of included papers and contribution to the field ...................................6 63

Paper I. Comparison of segregations formed in unmodified and $\mathrm{Sr}$-modified $\mathrm{Al}-\mathrm{Si}$ alloys studied by atom probe tomography and transmission electron microscopy...64 Paper II. Cluster formation at the $\mathrm{Si} /$ liquid interface in $\mathrm{Sr}$ and $\mathrm{Na}$ modified $\mathrm{Al}-\mathrm{Si}$

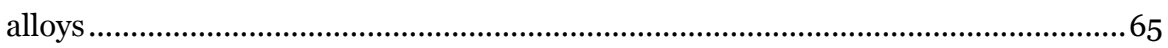

Paper III. Eutectic modification by ternary compound cluster formation in $\mathrm{Al}-\mathrm{Si}$ alloys.

Paper IV. Nucleation and growth of eutectic Si in Al-Si alloys with Na addition ......66

Paper V. Phase selective sample preparation of Al-Si alloys for atom probe tomography .66

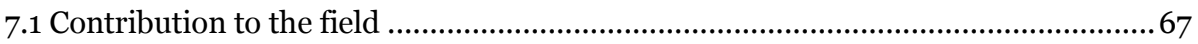

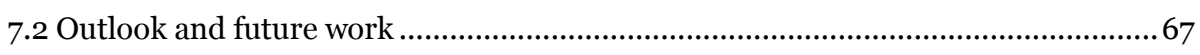

7.2.1 APT analysis of modified Al-Si eutectic phase ..................................................68

7.2.2 Calculation of phase diagrams and simulations .............................................68 
7.2.3 Correlative characterization of the solidification front

.69

7.2.4 Interaction of modifying elements in Al-Si alloys with magnesium and iron...69

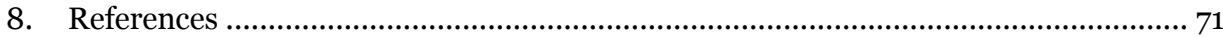

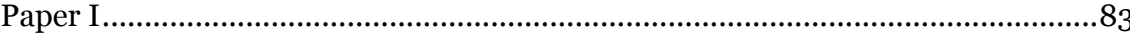

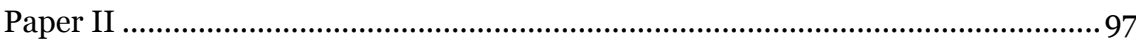

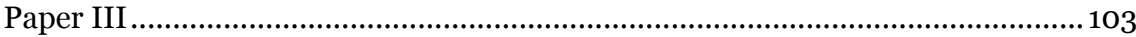

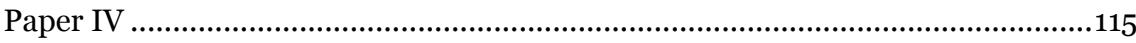

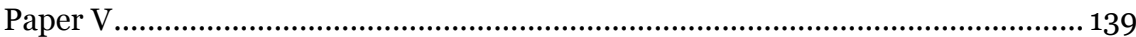




\section{Introduction}

Improving the design of structural alloys is a never-ending task as industrial applications continuously demand increased performance. Aluminum alloys are used in a wide range of applications due to their attractive low density in comparison to steels, which offers the possibility to design light-weight components.

Aluminum alloys with silicon as the major alloying element are the most widely used for casting applications. Their excellent castability and high strength-to-weight ratio makes them an appealing material for the automotive industry [1]. Al-Si alloys have an irregular eutectic phase formed by faceted silicon in a non-faceted aluminum matrix [2-4]. During the solidification of this phase, several microstructures and growth modes can be obtained depending on the temperature gradient and cooling rate $[5,6]$.

In the solidification processes generally used in industry, such as sand casting or die casting, eutectic silicon grows in the form of plates, also known as flakes. Since silicon plates are hard and brittle and, often act as easy paths for cracks, a microstructural modification towards rounded silicon branches is desirable [7]. Almost 100 years ago, a peculiar phenomenon was patented by Pacz [8], who found that the addition of low concentrations of alkaline fluorides, particularly sodium fluoride changed the silicon structure in these alloys from plate-like to fibrous or coral-like. This modification significantly improves ductility and therefore, it is industrially used nowadays [7]. However, challenges in its application are found when the composition of the alloy gets more complex.

In general, industrially relevant $\mathrm{Al}-\mathrm{Si}$ alloys contain ternary and quaternary elements such as magnesium and/or copper. The addition of these elements can make the alloy heat treatable and improve its strength and machinability [1]. All of these alloys benefit from the modification of the eutectic microstructure, but in the case of ternary and quaternary alloys, the change is often inhomogeneous showing well-modified regions and non-modified regions with coarse silicon parts. Inhomogeneities in the microstructure are detrimental for the properties of the alloys and hinder its further development. The lack of understanding of the fundamental mechanism underlying eutectic modification impedes further improvement of these alloys. 
During the last decades, several alkaline earth and rare earth metals were investigated and two groups of elements were differentiated based on their effects: (1) elements which change the silicon morphology into corals such as sodium [9,10], strontium [11,12] and europium [13]; and (2) others which only refine the plate-like silicon or can only partially change the silicon structure such as calcium [14,15], yttrium [16], ytterbium [17,18], barium [19] and most rare-earths [20]. The reason why these elements behave differently is still unknown.

\subsection{Scope}

The aim of this thesis is to widen our understanding of the eutectic modification in $\mathrm{Al}-\mathrm{Si}$ alloys. Several investigations have been performed regarding this topic, however, no systematic research revealed and compared the three-dimensional distribution of the atoms in the silicon phase. I seek to analyze, for the first time ever, atomically resolved chemical information in these alloys by atom probe tomography (APT) and propose a model for the multiplication of crystal defects in silicon and its morphological change.

The study will focus on three cases:

- Al-Si alloy with no addition of any modifier as a reference for the identification of changes and characteristics related to addition of a modifier agent.

- Alloys with addition of the three most powerful modifiers known to date: sodium, strontium and europium. By studying and comparing the solute distribution in eutectic silicon in these alloys, it is possible to pinpoint the common characteristics to further understand the plate-to-coral transition.

- An alloy with ytterbium addition, where the silicon plate structure is refined without corals formation, to understand the differences with coral-forming elements.

\subsection{Outline of the thesis}

This thesis contains a background about aluminum and Al-Si alloys highlighting their relevance, classification and general applications in chapter 2. An introduction to eutectic solidification of irregular systems in general and, of Al-Si alloys in particular is given in chapter 3 and 4 respectively. Chapter 5 presents a literature review about eutectic modification. Chapter 6 goes through the sample preparation and characterization methods used during this investigation. Chapter 7 gives a summary of the papers 
included in the thesis and the contribution to the field, together with an outlook and suggestions for further work. Finally, the outcome of the thesis is presented in five scientific papers. 


\section{Aluminum casting alloys}

Several useful properties make aluminum the base metal of choice for engineering solutions. It is light weight, with a density of approximately one-third that of steel; it has high electrical and heat conductivities; good corrosion resistance and can be used in wrought and casting applications. Its high recyclability also plays an important role with a remelting process out of scrap requiring only about $5 \%$ of the energy needed to extract the same amount of primary metal from the bauxite ore $[1,21]$.

Aluminum is the most abundant metallic element, the third most abundant element in earth's crust and the second most industrially used after iron. Surprisingly, its existence was not acknowledged until the beginning of the $19^{\text {th }}$ century and it took almost until the end of the century to develop an economically viable production route [21]. Although its short history of about 200 years in comparison to thousands of years of iron use, aluminum metallurgy evolved extremely fast to cover a wide range of applications. The constant growth in the importance of aluminum is tightly related to the increasing demands for mass reduction in vehicles to improve fuel consumption and lower $\mathrm{CO}_{2}$ emissions $[1,21]$.

Pure aluminum has low strength and has to be alloyed for use in structural applications. The major alloying elements are copper, manganese, magnesium, silicon and zinc. The mechanical, physical and chemical properties of these alloys are determined by their composition and microstructure. Depending on the composition, manufacturing processes and mechanism of properties development, alloys can be classified into wrought or casting alloys and further into heat treatable or not heat treatable alloys. The most important difference between wrought and casting composition is the alloy's castability. Wrought parts are casted in round or rectangular cross sections with a uniform solidification front. On the contrary, casting compositions are able to achieve dimensionally accurate near-net-shape parts with complex geometries and designed properties, in order to fulfill specified requirements [1]. The good castability of aluminum castings is related to their relative high fluidity, low melting point, short casting cycles and relatively low tendency for hot cracking [22]. Since the present work focuses on the eutectic modification of casting alloys, only this type will be further described. Aluminum castings present a wide range of compositions with great versatility in the achievable properties (Table 2.1). 
The most common classification of aluminum castings is based on the major alloying elements. Although no international standard nomenclature is available, the designation given by the Aluminum Association of the United States is well known [23]. This designation has four numeric digits separated by a period between the third and fourth. Table 2.2 shows the main categories defined by the first digit based on the major alloying constituent. The second and third digits do not have any significance but are unique to each alloy. The fourth digit describes whether it is casting (o) or ingot $(1,2)$. For fine variations in the composition limits, a letter preceding the numbers is added $(\mathrm{A}, \mathrm{B}, \mathrm{C})$.

Table 2.1: Range of mechanical properties for aluminum casting alloys [1]

\begin{tabular}{|l|l|}
\hline Tensile strength & $70-505 \mathrm{MPa}$ \\
\hline Yield strength & $20-455 \mathrm{MPa}$ \\
\hline Elongation & $<1-30 \%$ \\
\hline Hardness & $30-150 \mathrm{HB}$ \\
\hline Electrical conductivity & $18-60 \% \mathrm{IACS}$ \\
\hline Thermal conductivity & $85-175 \mathrm{~W} / \mathrm{m}{ }^{*} \mathrm{~K}$ at $25^{\circ} \mathrm{C}$ \\
\hline Fatigue limit & $55-145 \mathrm{MPa}$ \\
\hline Coefficient of linear thermal expansion at $20-100^{\circ} \mathrm{C}$ & $(17.6-24 \cdot 7) \times 10^{-6} /{ }^{\circ} \mathrm{C}$ \\
\hline Shear strength & $42-325 \mathrm{MPa}$ \\
\hline Modulus of elasticity & $65-80 \mathrm{GPa}$ \\
\hline Specific gravity & $2.57-2.95$ \\
\hline
\end{tabular}

Table 2.2: Casting alloys designation of the Aluminum Association (ANSI H35.1) [23]

\begin{tabular}{|l|l|}
\hline $1 \mathrm{xx} . \mathrm{x}$ & pure aluminum (99\% or greater) \\
\hline $2 \mathrm{xx} \cdot \mathrm{x}$ & aluminum-copper alloys \\
\hline $3 \mathrm{xx} \cdot \mathrm{x}$ & aluminum-silicon + copper and/or magnesium \\
\hline 4xx.x & aluminum-silicon \\
\hline $5 \mathrm{xx} \cdot \mathrm{x}$ & aluminum-magnesium \\
\hline 7xx.x & aluminum-zinc \\
\hline 8xx.x & aluminum-tin \\
\hline 9xx.x & aluminum + other elements \\
\hline $6 \mathrm{xx} \cdot \mathrm{x}$ & unused series \\
\hline
\end{tabular}

Table 2.2 summarizes the most relevant composition families for aluminum castings. Some of their remarkable characteristics and applications are [1]: 
- Aluminum-copper alloys primarily fulfill requirements of strength and toughness. They exhibit high strength and hardness at room and elevated temperatures. Mostly used in the aerospace industry.

- Aluminum-silicon-copper alloys exist in a wide range of compositions. Copper is added to improve strength and machinability, while silicon contributes to the castability. They dominate the market for powertrain components such as engine blocks, cylinder heads or pistons.

- Aluminum-silicon binary alloys have excellent fluidity, castability and corrosion resistance, but limited strength and poor machinability. They show low specific gravity and coefficients of thermal expansion. In hypoeutectic alloys, the strength, ductility and castability can be improved by modification of the eutectic phase.

- Aluminum-silicon-magnesium alloys combine remarkable casting characteristics, outstanding properties after heat treatment, good corrosion resistance and low level of thermal expansion. Eutectic modification is also used for these alloys to increase elongation.

- Aluminum-magnesium are binary alloys with moderate to high strength and toughness with excellent corrosion resistance. They have good weldability, machinability and an attractive appearance. They are used to produce highpressure die cast automotive steering wheels and structural components.

- Aluminum-zinc-magnesium have the particularity of naturally aging, showing full strength after approximately 30 days at room temperature. Their machinability and corrosion resistance is good in general, but they often show poor castability.

- Aluminum-tin are alloys used for bearing applications. The light weight and good heat dissipation are beneficial characteristics. Alloys with 5.0 to 7.0 wt\% Sn are often used when low friction, low compressive and fatigue strengths and good resistance to corrosion are needed.

The steady increase in the production of aluminum responds in a great part to its light weight. The reduction in weight by the use of aluminum alloys in automotive designs, improves the efficiency of energy consumption without compromising performance and safety, with a minimal impact on costs [21]. Castings in the transport sector are used in applications such as engine blocks, cylinder heads, pistons, wheels or suspension components, just to mention some examples. In addition to the automotive sector, aluminum alloys are also used in aerospace applications, construction, machinery, packaging, cooking utensils, and housing for electronics or pressure vessels.

All casting manufacturing methods can be applied to cast aluminum alloys. The choice of the most convenient method depends on the size, complexity of the design and number 
of parts to be manufactured per year $[1,21]$. The three most important methods are die casting, permanent mold and sand casting. Figure 2.1 shows application sectors and their relative percentages for these three casting processes.

High pressure die casting accounts for more than $50 \%$ of aluminum castings produced [21]. It is a fast near-net shape manufacturing process well suited for large production volumes. High cooling rates are desirable to get short manufacturing cycles. This method enables the fabrication of dimensionally accurate parts with excellent surface finish [22]. The tooling and automation costs are rather high, but they are compensated by the production volume.

Permanent mold and sand castings are used for thicker wall products or for parts requiring internal hollow sections that strictly need a sand core to be fabricated (e.g. cylinder heads) [21]. These two methods show slower cooling rates than the high pressure die casting and therefore, for $\mathrm{Al}-\mathrm{Si}$ parts manufactured by these methods, the modification of the eutectic phase treated in this thesis is used to refine the structure and improve strength, ductility and machinability [22]

(a) High pressure die casting

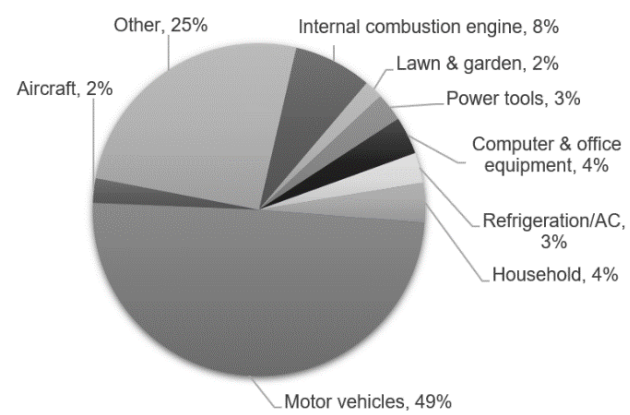

(b) Permanent mold and sand casting

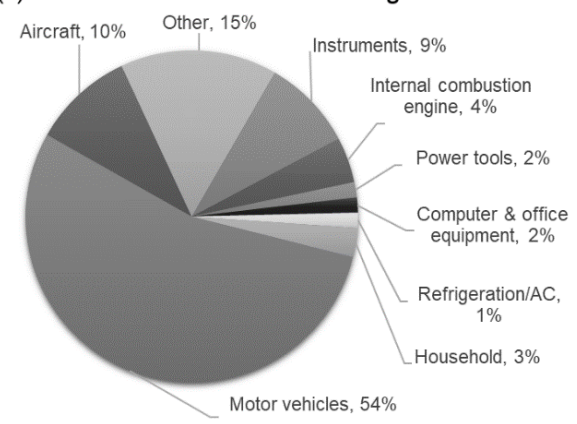

Figure 2.1: Applications for aluminum cast products separated by casting process, data collected from [24].

\subsection{Al-Si alloys}

$\mathrm{Al}-\mathrm{Si}$ alloys are the most widely used aluminum castings, especially in automotive applications. Silicon provides good castability with improved fluidity, elevatedtemperature resistance to cracking and good feeding characteristics [1]. The amount of silicon depends on the desired properties but also on the casting process used to 
manufacture the part. Processes that need higher heat flux use higher silicon content to improve fluidity, which in turn assists the filling of narrow cavities and intricate designs. Good castability is associated with alloys of reduced solidification range. Addition of silicon also reduces the specific gravity and the coefficient of thermal expansion. Commercial alloys may contain silicon from hypoeutectic concentrations to hypereutectic with up to about $30 \mathrm{wt} \% \mathrm{Si}[1]$.

Binary Al-Si alloys have low density, are weldable and resistant to corrosion although sometimes difficult to machine. Binary alloys often range between 5 to 12 wt\%. Some applications include architectural panels, marine components, cooking utensils, tire molds and, medical and dental equipment. Besides the binary Al-Si, alloys with additional elements such as $\mathrm{Al}-\mathrm{Si}-\mathrm{Cu}, \mathrm{Al}-\mathrm{Si}-\mathrm{Mg}$ and $\mathrm{Al}-\mathrm{Si}-\mathrm{Cu}-\mathrm{Mg}$ are extremely relevant for industrial applications (Figure 2.2). The addition of copper to Al-Si results in good castability, higher strength and hardness, and improved machinability; but it reduces ductility and resistance to corrosion. Typical applications are in transmission cases, engine blocks, gear blocks and cases, fuel pumps and cylinder heads. Al-Si-Mg, which include the very well-known 356.0 and A356.0, have outstanding casting properties and good corrosion resistance. The remarkable combination of tensile and physical properties that can be obtained by heat treatments, makes them appealing for aerospace, machinery, automotive and military applications. Some examples of parts produced by these alloys are automotive space frames and wheels, pump and compressor bodies, cylinder heads, impellers or missile bodies.

Finally, in some cases, the addition of both, copper and magnesium, to $\mathrm{Al}-\mathrm{Si}$ is advantageous. These alloys have excellent strength and hardness, with some sacrifice in ductility and corrosion resistance. Optimal properties are achieved after heat treatment. The alloy most commonly used for pistons in passenger cars and light trucks belongs to this category (332.0-T5 / Al-9.5 wt\% Si-3 wt\% Cu- 1 wt\% $\mathrm{Mg}$ ), showing a good combination of mechanical and physical properties at elevated temperatures including low thermal expansion. Other applications of $\mathrm{Al}-\mathrm{Si}-\mathrm{Cu}-\mathrm{Mg}$ are found in crankcases, structural aerospace components, air compressor pistons or compressor cases [1]. 


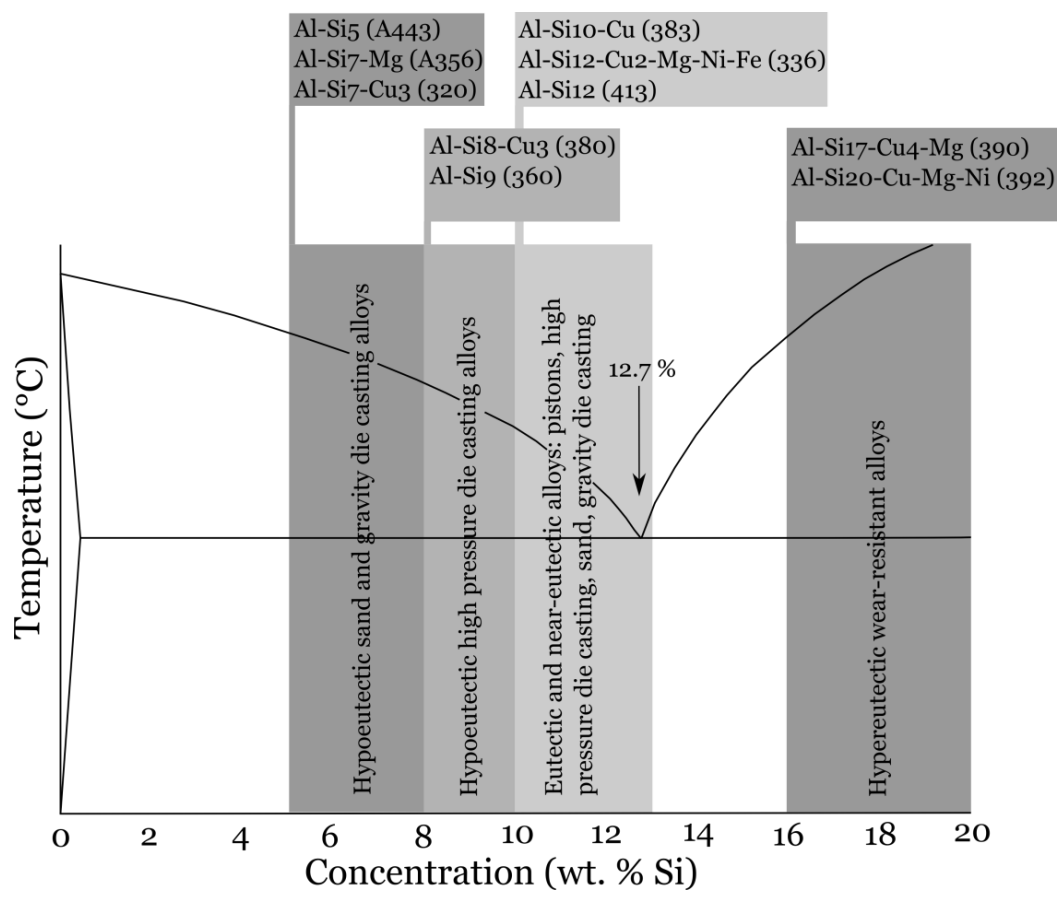

Figure 2.2: Schematic of the Al-Si phase diagram with some of the most common casting alloys. Adapted from [25].

All these general-purpose alloys may be subjected to modification of the eutectic silicon phase morphology. Ultimately, the commercial use of these materials depends on the control of the microstructure of the silicon phase. The detailed study of this modification is the focus of this thesis and will be further explained in the next sections. 


\section{Eutectic solidification}

The microstructure of an alloy is influenced by the solidification conditions and the composition. Generally speaking, two basic growth morphologies exist during alloy solidification: dendritic and eutectic [26]. Depending on the composition on a phase diagram, one can find (a) a pure substance that can solidify in a planar or dendritic manner; (b) solid-solution dendrites; (c) dendrites with interdendritic eutectic; and (d) eutectic (Figure 3.1).

The design of casting alloys requires good castability to get small hot tearing, low shrinkage and good mold filling $[1,22]$. The best castability is given by pure metals, or by alloys with near eutectic compositions [26]. Multicomponent systems with an invariant eutectic point have a long history in the casting of components. These systems offer relatively low temperature melting when mixing pure elements enabling the fabrication of near-net shape parts of high performance [27]. Near eutectic compositions have a short freezing range offering better fluidity than long freezing range.

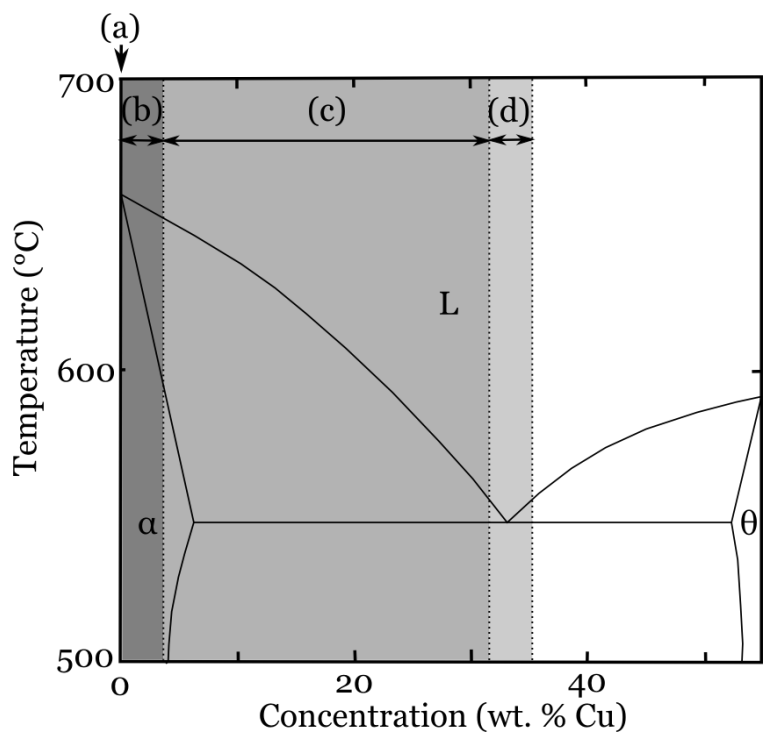

Figure 3.1: Representation of part of the $\mathrm{Al}-\mathrm{Cu}$ system between aluminum and $\theta\left(\mathrm{Al}_{2} \mathrm{Cu}\right)$. Letters in the diagram highlight different microstructures depending on the composition:

(a) planar or dendritic solidification of a pure component; (b) solid-solution dendrites; (c) dendrites plus interdendritic eutectic; (d) eutectic. (Adaptation from [26]) 
During solidification of a binary eutectic, two solid phases form cooperatively from the liquid. There are numerous morphologies in which eutectic phases may evolve depending on the growth characteristics of the individual phases [28,29]. Eutectic structures can be classified depending on the entropy of fusion of the components, which is the difference of entropy between the liquid and the solid phases at the melting point. Jackson et al [30] proposed a parameter, $\alpha$, to evaluate this:

$$
\alpha=\frac{\eta}{v} \frac{\Delta H_{F}}{R T_{M}}=\xi \frac{\Delta S_{F}}{R}
$$

where $\xi$ is the orientation factor defined as the ratio between the number of nearest neighbors for a growth unit at the solid / liquid interface of the crystal ( $\eta$ ) and the coordination number (v); $\Delta \mathrm{H}_{\mathrm{F}}$ the enthalpy of fusion (or latent heat of fusion); $\mathrm{T}_{\mathrm{M}}$ the melting temperature; $\mathrm{R}$ the ideal gas constant and $\left(\Delta \mathrm{S}_{\mathrm{F}} / \mathrm{R}\right)$ the dimensionless entropy of fusion. According to this factor, related to the roughening transition of a crystal surface, phases with $\alpha>2$ (high entropy of fusion) grow in a faceted manner with an atomically smooth interface, while phases with $\alpha<2$ (low entropy of fusion) grow isotropically showing no facets and atomically rough interface. Based on this, eutectic structures can be broadly classified into regular (or normal) and irregular (or anomalous). Regular eutectics are formed by two non-faceted phases (low entropies of fusion), while irregular eutectics have one faceted phase with a high entropy of fusion. Aluminum-silicon, for example, presents an irregular faceted / non-faceted eutectic, with a metallic aluminumrich phase with $\alpha<2\left(\Delta \mathrm{S}_{\mathrm{F}} / \mathrm{R}=1.35\right)$ and a faceted silicon $\alpha>2\left(\Delta \mathrm{S}_{\mathrm{F}} / \mathrm{R}=7.15\right)$ [11].

Another difference that distinguishes regular and irregular eutectics is that the former generally occurs for symmetric phase diagrams with a symmetric eutectic coupled zone (Figure 3.2 (a)). The coupled zone represents the solidification conditions under which the two eutectic phases can grow together with similar velocities [31]. For two nonfaceted phases, both phases have a similar undercooling and therefore, the coupled zone is symmetric. Differently, in an irregular system where one phase is faceted, its growth and consequently, that of the eutectic phase will need a higher undercooling. Dendrites of the non-faceted phase can grow faster and they can grow even at eutectic composition. Because of this reason, pure eutectic microstructures can be obtained only at hypereutectic compositions forming an asymmetrical coupled zone (Figure 3.2 (b)) [32].

A further finer classification can be done if the volume fraction $\left(\mathrm{V}_{\mathrm{F}}\right)$ of the solute phase is considered. When the minor phase in a regular eutectic has a $V_{F}$ smaller than $30 \%$, the structure will be rod-like; and when the $\mathrm{V}_{\mathrm{F}}$ is higher than that, a lamellar structure will form. For irregular eutectics, when $\mathrm{V}_{\mathrm{F}}<30 \%$, the faceted phase grows with a rod-like or 
fibrous morphology, while for $\mathrm{V}_{\mathrm{F}}>30 \%$, branched flakes or acicular structures are generally present. Figure 3.3 shows a schematic of the classification considering Jackson's factor $(\alpha)$ and $V_{F}[26]$.

(a) Symmetric phase diagram and coupled zone

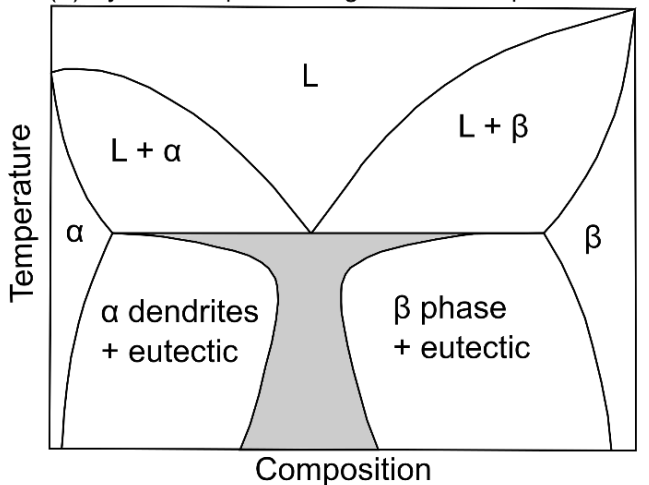

(b) Asymmetric phase diagram and coupled zone

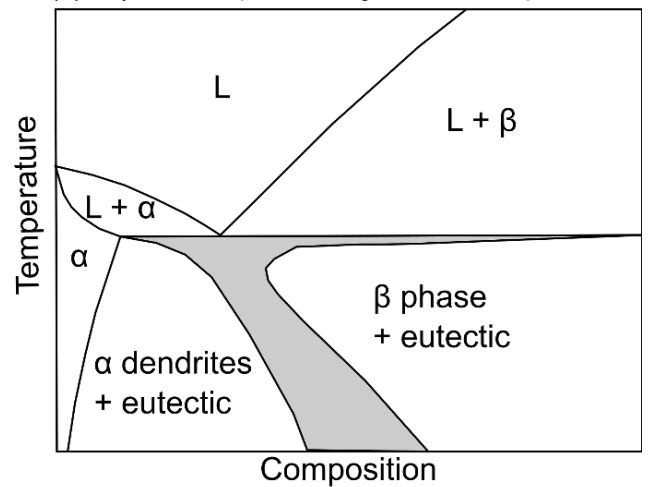

Figure 3.2: Representation of the coupled zones for: (a) eutectic system with regular structure and (b) eutectic system with irregular structure. Adapted from [32].

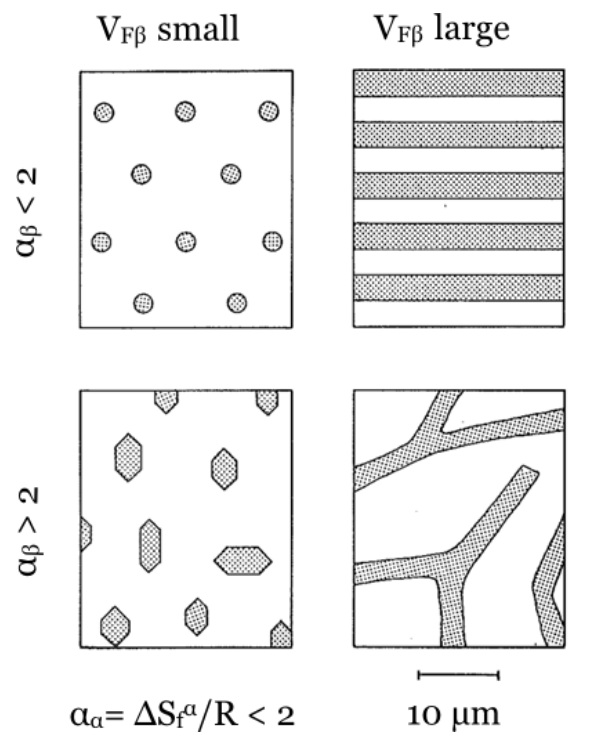

Figure 3.3: Schematic of the four broad categories of eutectic structures based on Jackson's factor, $\alpha$; and volume fraction $\left(\mathrm{V}_{\mathrm{F} \beta}\right)$. The top part shows the regular structures: rod (left) and lamellar (right); and at the bottom, the irregular structures: fibrous (left) and lamellar (right) . Reproduced from [26]. 
In general, rod-like or fibrous structures are formed for small $V_{F}$ of one phase because the interfacial area decreases with decreasing $V_{F}$ of the fibers, while it is constant for lamellae. The interfacial area of fibers is smaller than that of lamellae at $\mathrm{V}_{\mathrm{F}}$ smaller than $30 \%$ [26]. These criteria are approximated, and lamellae can also form for lower $V_{F}$ if the specific interfacial energy is strongly anisotropic. Such is the case of the irregular Al-Si system, where the silicon phase represents only about $11 \%$ of the eutectic structure, but still forms a plate-like silicon structure. Irregular eutectics can present a wide range of morphologies, depending on the solidification conditions [29].

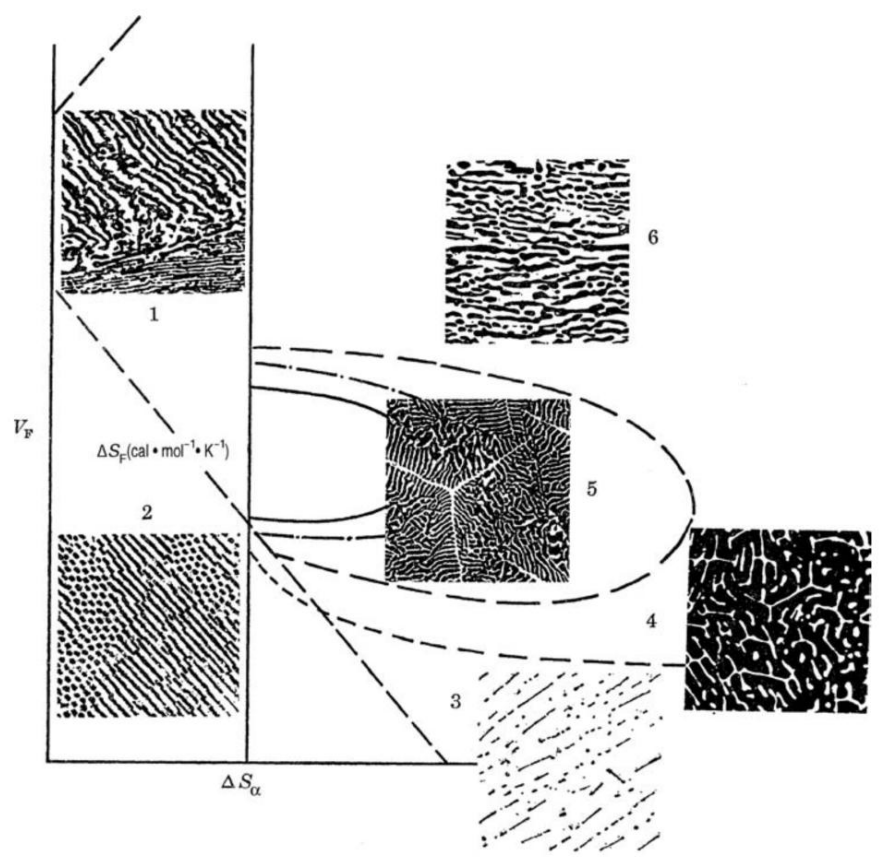

Figure 3.4: Classification of eutectic morphologies as a function of the entropy of fusion $\left(\Delta \mathrm{S}_{\mathrm{a}}\right)$ and volume fraction $\left(\mathrm{V}_{\mathrm{F}}\right)$ for a growth rate of $5 \times 10^{-4} \mathrm{~cm} / \mathrm{s}$. Six regions are shown corresponding to: (1) regular lamellar; (2) regular rod; (3) broken lamellar; (4) irregular; (5) complex regular; and (6) quasi regular. Reproduced from [28].

The $\alpha$ factor has considerable success in predicting whether a eutectic structure would grow in a normal or anomalous manner. However, since the eutectic structure grows from solution at a considerably lower temperature than the melting point of its pure constituents, the tendency to facet may be higher. Then, the Jackson's factor can be recalculated for the growth from solution by replacing the latent heat of fusion of the separate constituent by the latent heat of fusion of the solid solution and the melting temperature by the eutectic temperature [33]. Based on this improvement, Croker et al. 
[28] developed a more detailed classification of eutectic structures. In this approach, an entropy of solution of $23 \mathrm{~J} /(\mathrm{mol} . \mathrm{K})$ was found as the transition value between nonfaceting and faceting behavior. Due to the difficulty in calculating the orientation factor $(\eta / v)$ for complex structures, it is advantageous to use this entropy of solution instead of the $\alpha$ factor. Systems with an entropy of solution $\Delta \mathrm{S}<23 \mathrm{~J} /(\mathrm{mol} . \mathrm{K})$ present a normal growth, while $\Delta \mathrm{S}>23 \mathrm{~J} /(\mathrm{mol} . \mathrm{K})$ are anomalous. The structures in each group, particularly the anomalous, depend on the $V_{F}$ and the growth velocity. Figure 3.4 shows a schematic of the structures in the different regions for a growth rate of approximately $5 \mathrm{x}$ $10^{-4} \mathrm{~cm} / \mathrm{s}$ as presented by Croker et al. [28].

Regions (1) and (2) show regular lamellar structure and rod structure, respectively. Because of the increased surface energy anisotropy towards higher faceting tendency, the boundary $\mathrm{V}_{\mathrm{F}}$ between regions 1 and 2 becomes smaller when $\Delta \mathrm{S}$ rises.

Anomalous structures show a wider variety of morphologies. They can be broadly divided into four types:

(3) broken lamellar or sometimes fibrous $\left(\mathrm{V}_{\mathrm{F}}<10 \%\right)$;

(4) irregular phases with a number of morphological types which may coexist. This is the region for the Al-Si eutectic structure.

(5) complex regular, array of regular plates or fibers over small areas and generally surrounded by a spine. This structure grows with macrofaceted cellular projections at the solid/liquid interface ( $V_{F}$ higher than approximately 20\%)

(6) quasi-regular structure. Sheets or fibers of a non-faceted minor phase in a matrix of the faceted phase

The transitions between regions in figure 3.4 are not sharp and, in the case of anomalous eutectic structures, they also depend on growth rate. The Al-Si eutectic is an example of this dependence on solidification conditions. 


\section{Eutectic solidification of Al-Si alloys}

The Al-Si phase diagram has a simple eutectic point with two solid solution phases: aluminum (fcc) and silicon (diamond cubic). The eutectic reaction occurs at $12.2 \pm 0.1$ at\% $\mathrm{Si}$ and $577 \pm 1^{\circ} \mathrm{C}$ [34]. The maximum solubility of silicon in aluminum at the eutectic temperature is 1.5 at\%, and decreases to 0.05 at $\%$ at $300{ }^{\circ} \mathrm{C}$. The solubility of aluminum in silicon is extremely low at about $0.04 \pm 0.02$ at\% [35]. Figure 4.1 shows the phase diagram of the Al-Si system as presented by [34] with the metastable extensions of the liquidus and solidus lines.

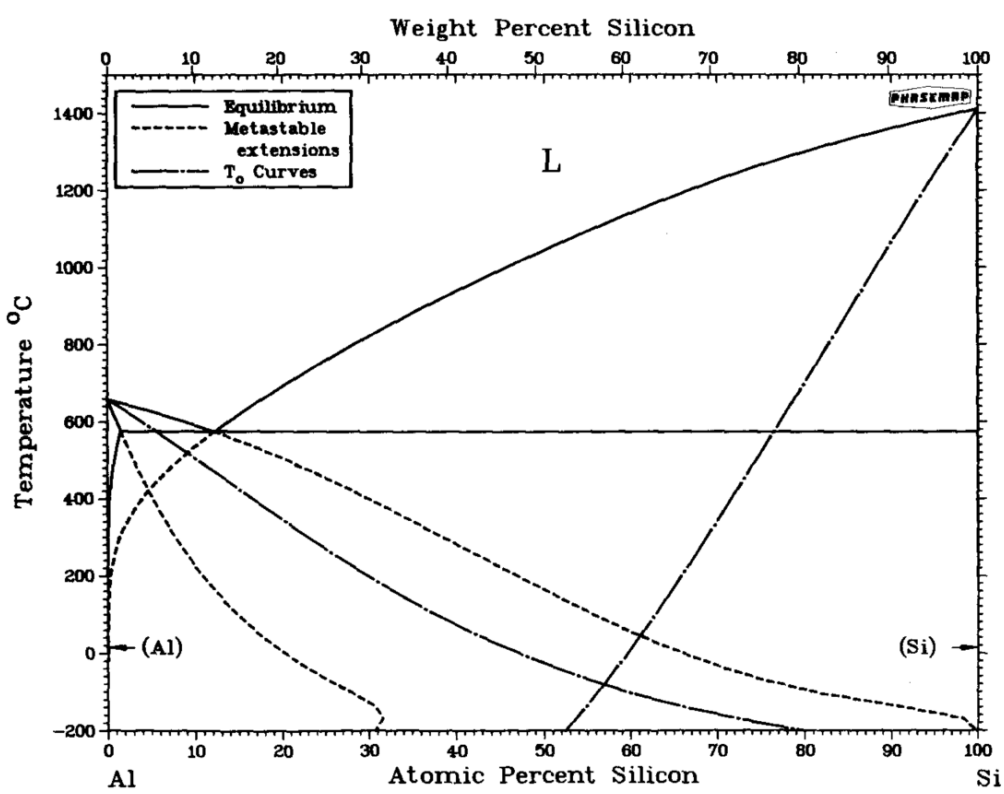

Figure 4.1: Equilibrium phase diagram of the Al-Si system with the extensions of the metastable liquidus and solidus lines. Reproduced from [34].

The formation temperature of the eutectic phase in this system is cooling rate dependent. At high cooling rates, the eutectic temperature is depressed and the eutectic point is shifted towards higher silicon concentrations [36]. This behavior is explained by the presence of an asymmetric coupled zone (introduced in section 3). Since silicon is a nonmetal that grows anisotropically in a faceted fashion forming directed covalent 
bonds, it needs a higher undercooling than the non-faceted aluminum phase and a growth asymmetry arises for changing solidification rates.

The irregular or anomalous Al-Si eutectic system formed by faceted silicon and nonfaceted aluminum can grow with a variety of morphologies depending on the solidification conditions. Silicon is capable of several crystal growth mechanisms in metal solutions. These mechanisms were rationalized and classified by Day and Hellawell $[5,6]$. Figure 4.2 depicts four distinctive regions as a function of temperature gradient (G) and growth rate $(\mathrm{V})$.
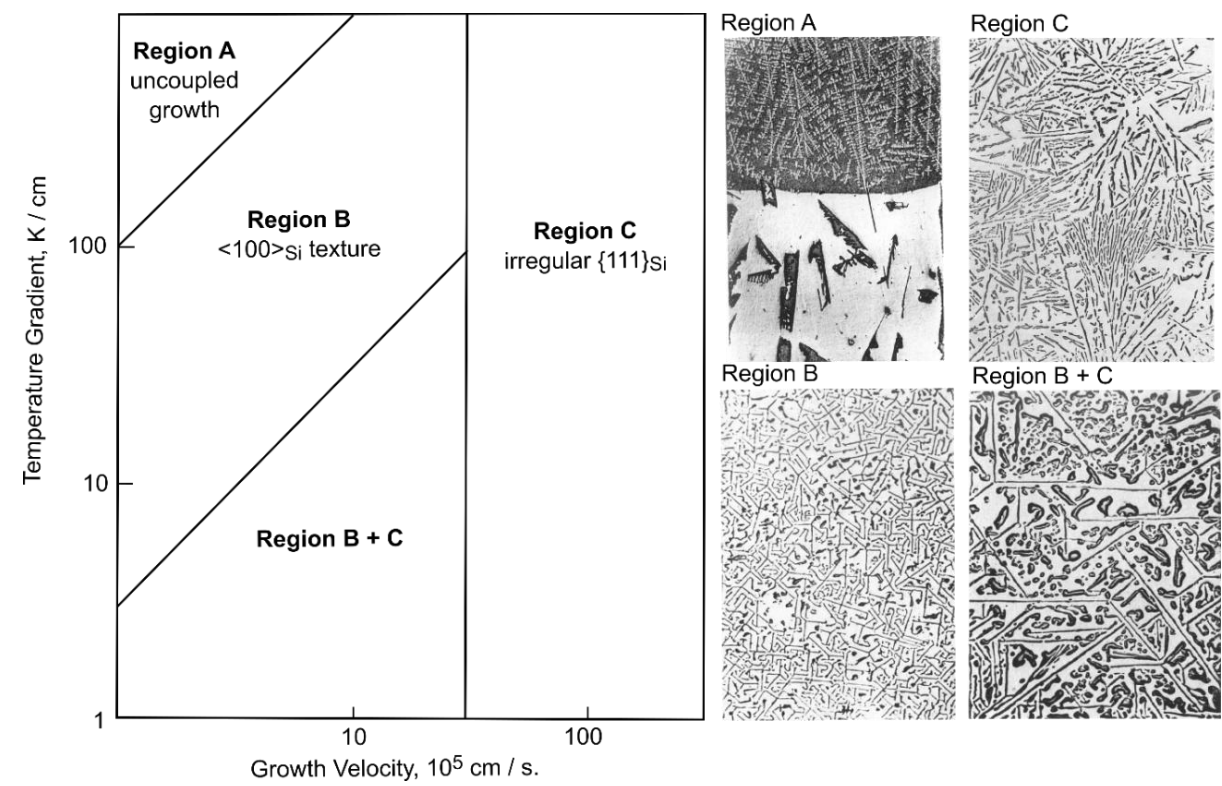

Figure 4.2: Classification of eutectic microstructures in Al-Si alloys as rationalized and presented by [5]

- Region A: the two eutectic phases grow independently showing a long-range-diffusion front at high $\mathrm{G} / \mathrm{V}$. The solidification front is formed by a planar metal liquid interface with uncoupled massive silicon crystals projecting forward into the liquid. The silicon crystals were showed to be interconnected and twinned in $\{111\}$ planes. Several silicon particles in this region show elongation in the $<110>$ or $<211>$ orientations.

- Region B: eutectic growth with a lower G/V than region A presenting short-range diffusion. Silicon shows a variety of morphologies with highly preferred $<100>$ texture. Two of the most common forms found in this region are thin plates with $\{100\}$ faces closed at the growing end by $<110>$ edges; and corrugated crystals with $\{111\}$ faces with the axis of corrugation being the $<110>$. Silicon plates are inclined with a variety of 
angles that account for twin configurations. For these structures to be stable, the aluminum must wet the $\{100\}$ external surfaces up to the aluminum-silicon-melt junction as shown in figure $4 \cdot 3$ (a).

- Region C: irregular plate-like silicon structure. This structure occurs when the growth rate is increased above a critical value where a very large undercooling is produced. Silicon flakes grow faster in the $<112>$ orientation and project ahead of the solidification interface forming a non-isothermal front. They have $\{111\}$ growth habit and contain flat twins across the plates that allow a variety of orientations. This type of growth presents a wide range of inter-particle spacing as a result of the rigid growth anisotropy.

- Region B+C: shows a gradual transition between $<100>$ texture and the $\{111\}$ growth habit. This transition in the morphology of the microstructure is the result of the change of growth mechanism of the faceting phase. Figure 4.3 shows the $<100>$ texture of region B with facets on the $\{111\}$ crystal faces. This type of morphology can occur only if the metal phase wets the $\{100\}$ external faces of the silicon crystal up to the solid / liquid interface, that is, if the growth takes place with an iso-thermal solidification front. For decreasing $\mathrm{G} / \mathrm{V}$, the silicon phase starts to project ahead of the solidification front in a non-isothermal front and the rapidly growing $\{100\}$ grow laterally giving rise to a transition structure. If the $\mathrm{G} / \mathrm{V}$ decreases even further because of an increase in $\mathrm{V}$, the irregular structure of region $\mathrm{C}$ is formed by close packed $\{111\}$ faces at the external walls of the plates and at the growing end.

(a) Region B $<100>$ si texture

(b) Region C \{111\}si growth habit
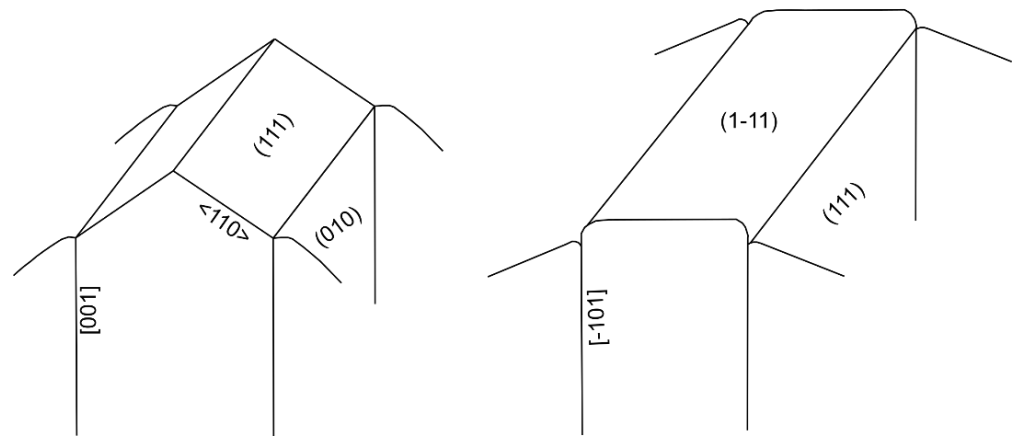

Figure 4.3: Simplified schematic view of the crystallography of eutectic silicon growing in regions B and C. Reproduced from [5].

- Region D: for higher freezing velocities in the range of 0.2 to $1 \mathrm{~mm} / \mathrm{sec}$., there is a further transition in the microstructure called sometimes chill- or quench-modification 
in literature [5,37]. Silicon appears as continuous irregular fibers with rounded crosssection similar to the modified structure obtained by the addition of impurity elements.

In the case of such a high cooling velocity, it is proposed that the kinetic undercooling increases sharply and eventually, an inversion at the solidification front occurs such that the silicon grows behind the metal phase [37]. This change in the front will also affect the liquid diffusion.

Some differences in the twinning of silicon in this structure has been reported. There is evidence showing some twinning mostly parallel to silicon growth axes [37,38], other showing non-faceted silicon with no twins [39,40], and considerable higher twinning density than in region $\mathrm{C}$ [41].

\subsection{Plate-like structure and TPRE mechanism}

The irregular plate-like structure from region C (Figure 4.4) corresponds to the solidification conditions most generally found in typical unmodified industrial casting processes and therefore, this type of growth deserves closer attention.
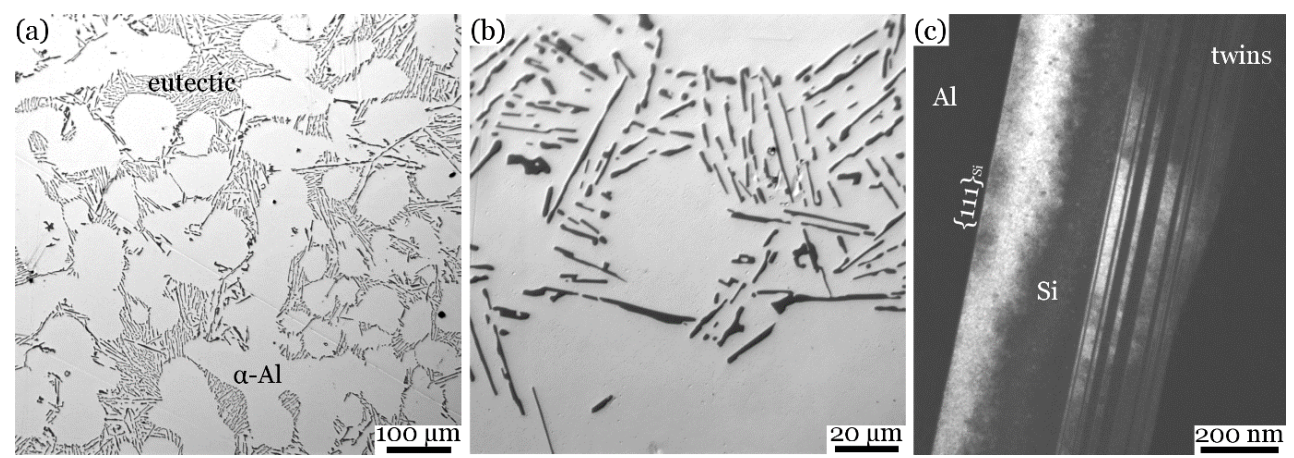

Figure 4.4: Alloy microstructure of Al-7 wt\% Si. (a, b) Optical microscopy images showing $\alpha$-aluminum dendrites and plate-like eutectic. (c) Dark field TEM image showing repeated parallel twinning on $\{111\}_{\text {Si }}$ planes in agreement with the TPRE growth mechanism.

As shown in figure 4.3 (b) and 4.4 (c), the growth rate of silicon in region $\mathrm{C}$ will be limited by the nucleation rate on the slow growing $\{111\}$ faces. One way the crystal increases its nucleation rate is by the presence of coherent twin planes across the silicon plates. In 1960, Wagner [42], and Hamilton and Siedensticker [43] thoroughly explained the faceted growth mechanism of germanium crystals in contact with a supercooled melt, 
which was later also well-accepted for silicon growth. This is called the twin plane reentrant edge (TPRE) mechanism and it is based on the formation of twin planes through the germanium or silicon lamella, generating self-perpetuating grooves that function as nucleation and growth sites. The growth on grooves is assumed to be rapid because steps are generated at the center of the grooves. The authors showed that germanium growth occurs readily if the crystal contains at least two parallel twin planes [42]. Figure 4.5 (a) shows a crystal with two twin planes bounded by $\{111\}$ faces at the growth interfaces. These twinned crystals form re-entrant corners with an angle of $141^{\circ}$, and ridges with an angle of $219^{\circ}$ enabling rapid growth in <211> orientations as shown in figure 4.5 (a). Considering the three <211> preferred growth orientations, six re-entrant corners are formed. Figure 4.5 (b) shows examples of nucleation events on two of these corners (sites I) and the further generation of new re-entrant corners with an angle of $109.5^{\circ}$ between $\{111\}$ planes (sites II). The simultaneous existence of two self-perpetuating re-entrant corners ensures the permanent presence of steps for a continuous growth in preferred sites.

(a)

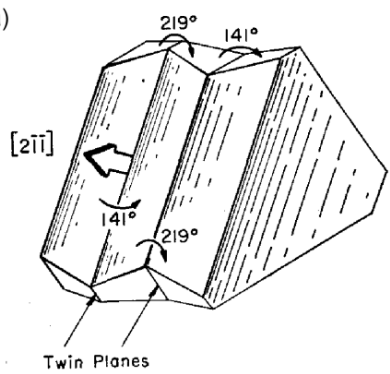

b)

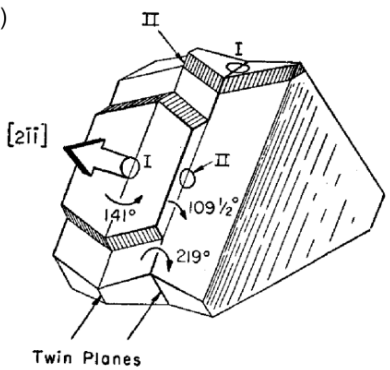

Figure 4.5: Schematic diagram of the twin plane re-entrant edge (TPRE) mechanism. (a) Re-entrant corners $\left(141^{\circ}\right)$ and ridges $\left(219^{\circ}\right)$ formed by the presence of twin planes. (b) View of the growth after nucleation in two "type I" sites, which perpetuate nucleation by the formation of "type II" corners. Reproduced from [43].

Shamsuzzoha et al [44] confirmed the TPRE mechanism and showed that all active $\{111\}$ twin planes are cozonal or coplanar, i.e. parallel to a single $<110>$ zone axis (Figure 4.4(c)). The growth of the silicon under these conditions is purely two-dimensional. To maintain an approximately constant average inter-plate spacing, repeated branching and direction changes occur by multiple twinning. Kobayashi and Hogan [45] explained branching by a $70.5^{\circ}$ change in direction due to twinning at the bounding $\{111\}$ plane. Figure 4.6 (a) shows a representation of a horizontal plate formed by the twinned crystals $\mathrm{A}$ and $\mathrm{B}$, and a branch containing the twinned crystals B and C. In this example, crystal B commenced the branching nucleating on $\mathrm{A}$, and the $\mathrm{C}$ crystals formed subsequently. 
Repeated branching such as in figure 4.6 (b) allow for changes in the silicon growth in almost any angle while retaining the $<211>$ direction and the $\{111\}$ surface planes.
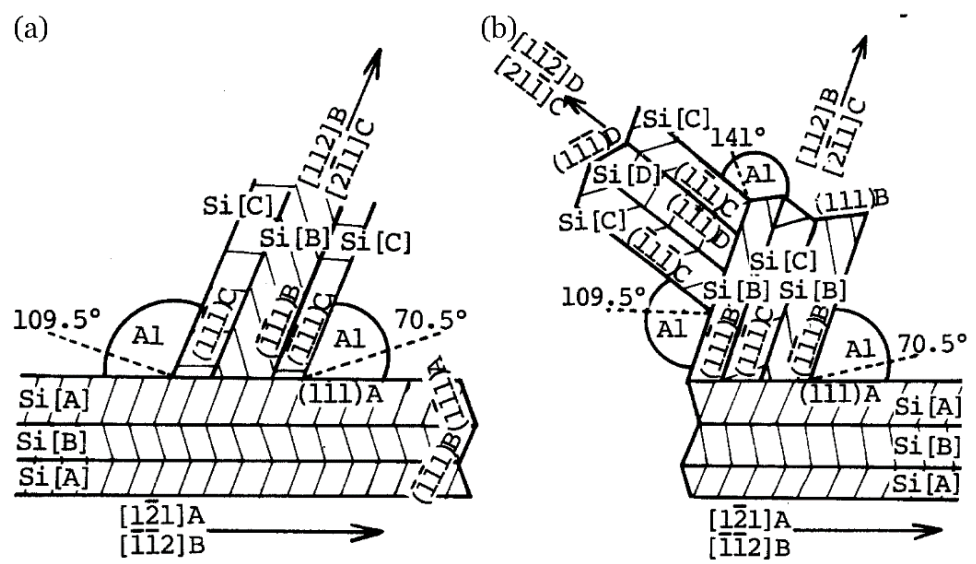

Figure4.6: Schematic representation of the high-angle branching of the eutectic silicon plate structure. (a) $70.5^{\circ}$ branching by the formation of a twinned crystal on a $\{111\}_{\mathrm{Si}}$ surface plane. (b) Repeated branching by twinning allowing for almost any growth direction [45].

Shamsuzzoha and Hogan [46] showed a further mechanism for the adjustment of the inter-plate spacing called "displacement twinning". Figure 4.7 gives a schematic representation showing two mutually twinned crystals (C and D) that stop their original growth while a new twin is formed laterally on the external $\{111\} \mathrm{D}$ face. A crystal on the $\mathrm{C}$ orientation protrudes and growth continues in the $<121>$ direction parallel to the original by the formation of two further twin events with self-perpetuating grooves. Repeated displacements result in branching in any arbitrary angle.

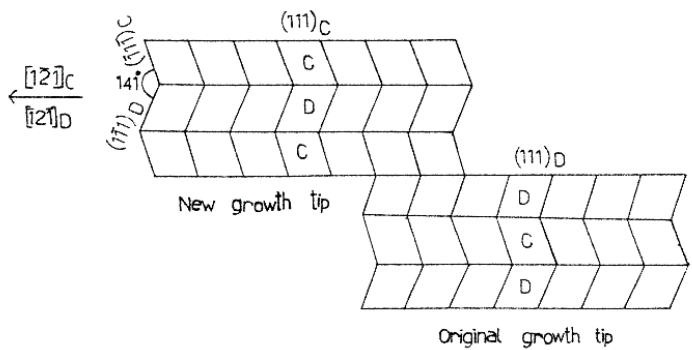

Figure 4.7: Schematic representation of displacement twinning [46]

Recently, a thorough analysis of the silicon plate-like growth done by EBSD supports the TPRE model [47]. However, in this study the authors show that, microscopically, the 
silicon plates elongate in a $<110>$ direction rather than the $<112>$ assumed in the model. They argue that a zigzag paired <112> growth from parallel twinning planes result in $<110>$ growth habit. They explain this by an alternate disappearance and creation of $141^{\circ}$ re-entrants, schematically shown in Figure 4.8.
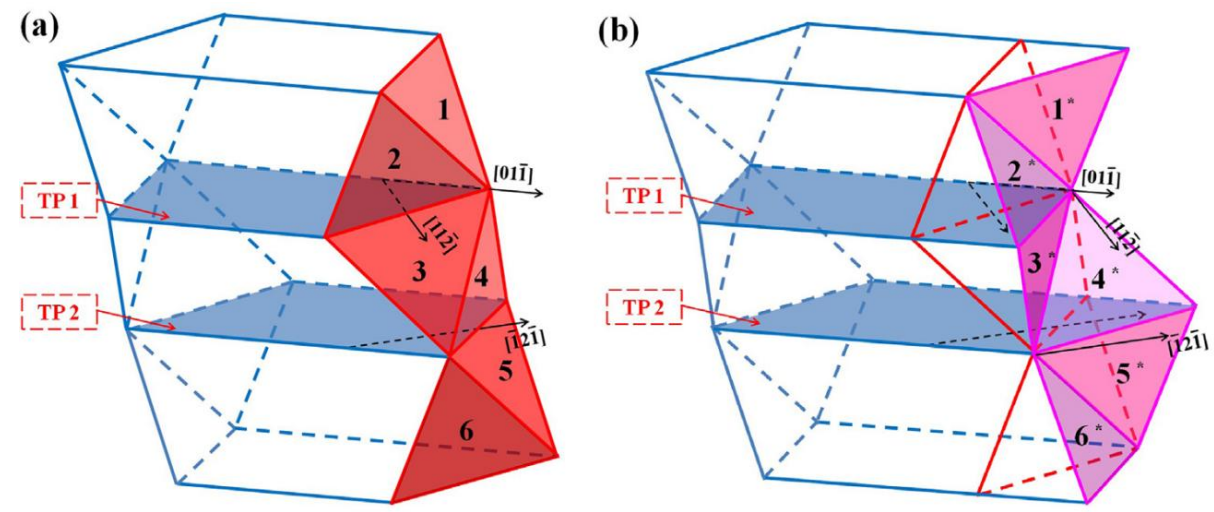

Figure 4.8: Silicon plate with two twin planes TP1 and TP2. (a) Two $141^{\circ}$ re-entrants are shown between faces 2 and 3 , and between 4 and 5 , while two $219^{\circ}$ ridges complete the structure between 1 and 4, and between 3 and 6. (b) Further growth causes the disappearance and subsequent creation of $141^{\circ}$ re-entrants that result in a $<110>$ growth extension. [47]

TPRE mechanism was shown experimentally for germanium crystals $[42,48,49]$. Figure 4.4 (c) shows several parallel twin boundaries crossing through the silicon plate and parallel to the outer $\{111\}_{\text {Si }}$ plate bounding planes. This evidence is in favor of the TPRE mechanism for silicon plate growth. It is however not possible to ensure that this mechanism is the main responsible for the plate-like growth. Lu and Hellawell [39,40] for example, showed that the spacing between twins might be too wide to be determining for the kinetics of molecular attachment and stated that the TPRE mechanism might be just incidental. Kitamura et al [50] argue that the TPRE mechanism was developed for perfect crystals without considering the influence of dislocations and therefore, its relevance is questionable. Although it is not completely elucidated, whether just twins or the presence of twins plus dislocation is responsible for unmodified silicon growth, in any case, twins show to readily form and aid the growth of silicon. 


\section{Eutectic modification of Al-Si alloys}

Al-Si alloys are commercially relevant not only because of their good castability, strength-to-weight ratio or corrosion resistance, but also because the silicon microstructure can be modified by the addition of low concentrations of certain elements [7]. This modification is used to enhance properties such as ductility and toughness in these alloys and because of this, it was the subject of hundreds of studies since its discovery in 1921 [8].

\subsection{Enhancement of mechanical Properties}

Unmodified silicon adopts a plate-like structure for industrial solidifying conditions (Figure $5.1(\mathrm{a}, \mathrm{c})$ ) [51,52]. The coarse, hard and brittle silicon plates diminish the alloy's ductility. The facets of the silicon plates are often on the cleavage plane $\{111\}$ and therefore, cracks propagate easily across them [37]. The unmodified alloys' elongation is often no more than a few percent and toughness is deteriorated [53,54]. In contrast, the modified silicon structure shows a fine interconnected coral-like structure formed by fibers with rounded cross-section (Figure $5.1(b, d)$ ) [51,52,55]. This transformation of the silicon structure improves the elongation significantly [7,56,57]. Table 5.1 shows the modification effect on the tensile yield strength, ultimate tensile strength and elongation of some representative alloys.

The mechanical properties of $\mathrm{Al}-\mathrm{Si}$ castings strongly depend on the form, size and distribution of silicon in its eutectic phase. When comparing modified and unmodified alloys, the modified structure showed a reduced amount of fractured silicon particles under the same testing conditions. This is related to the lower aspect ratio and particle size of modified silicon [54]. Larger and longer particles are more prone to cracking rapidly at low strains in coarse structures, in contrast to finer structures where the progression of particles' cracking is more gradual [58-60]. High sphericity of silicon particles is favorable to the resistance of interface debonding and plastic deformation of the aluminum matrix [61]. Fractography shows a direct relationship between the size and aspect ratio of the silicon particles and the dimples implying that the elongation of silicon particles is transmitted to the dimples and the cross-section area of the silicon particles directly influences the fracture surface geometry [62]. The mechanical properties of hypoeutectic Al-Si castings are also influenced by the grain size and the secondary 
dendrite arm spacing (SDAS). The combination of eutectic modification together with grain refiners and small SDAS were shown to exert a significant improvement of tensile [63-65] and impact properties $[53,60,66]$.
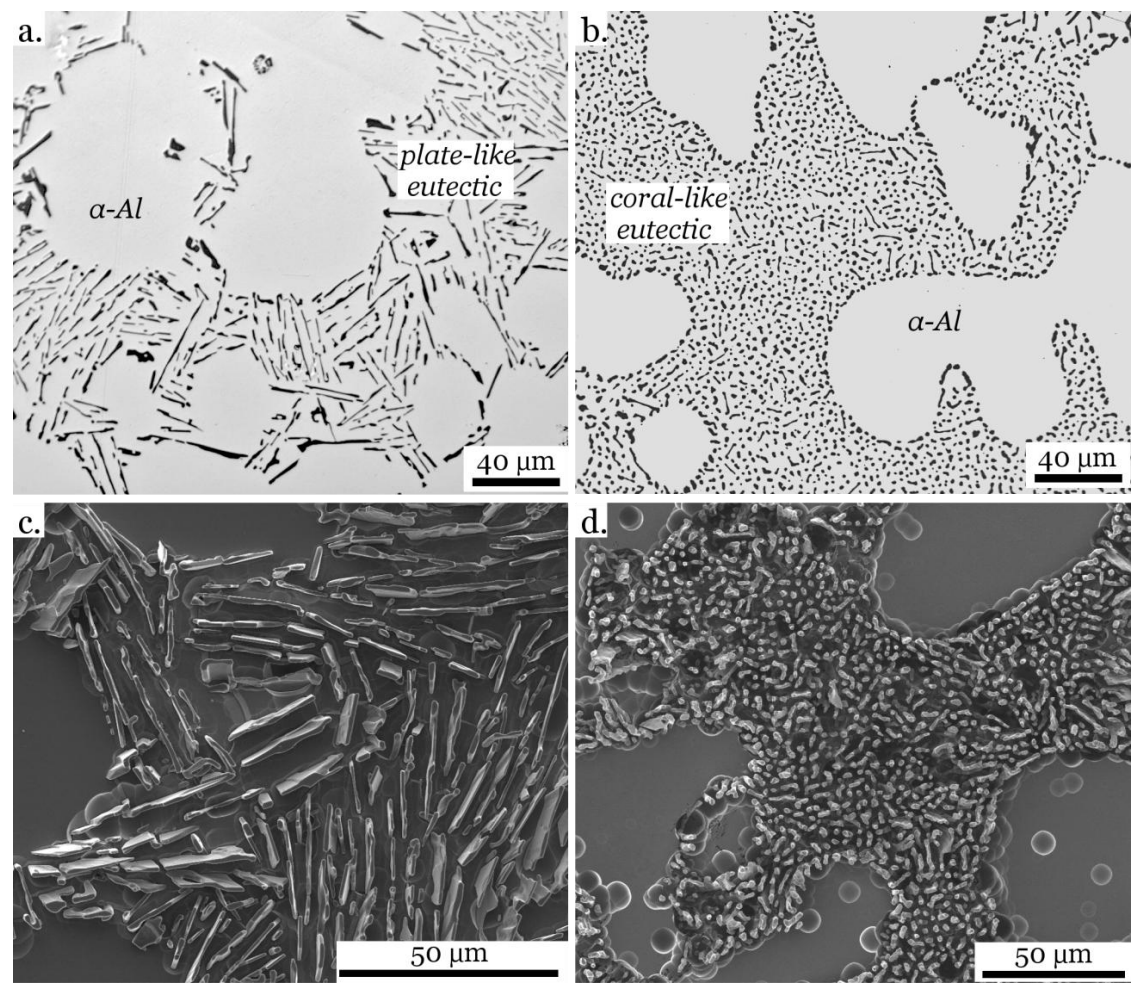

Figure 5.1: Comparison between unmodified and modified microstructure in an $\mathrm{Al}-7$ wt\% Si alloy. Both images show primary $\alpha-\mathrm{Al}$ dendrites surrounded by eutectic phase. (a,c) $2 \mathrm{D}$ and $3 \mathrm{D}$ images of unmodified eutectic silicon plates in an aluminum matrix. (b,d) Modified eutectic phase by the addition of 150 wt ppm Sr. 2D and 3D images of the silicon coral-like structure.

In industrial practice, ductility can also be improved by heat treatment producing a "thermal modification". During the heat treatments of $\mathrm{Al}-\mathrm{Si}$ alloys, the spheroidization of silicon crystals is a time consuming part of the process. Silicon plates first break up into smaller parts, then coarsen and become spherical. If the chemical modification studied in this thesis is combined with a heat treatment, the time needed for the spheroidization can be reduced in half. The reduction in cost by shortening the heat treatment can be 
about 10 times the cost of strontium addition and the throughput of the furnaces doubled $[67,68]$.

Table 5.1: Comparison of mechanical properties for unmodified and modified cast alloys as presented in reference [69]

\begin{tabular}{|c|c|c|c|c|c|}
\hline $\begin{array}{l}\text { Alloy and } \\
\text { temper }\end{array}$ & Product & $\begin{array}{l}\text { Modification } \\
\text { treatment }\end{array}$ & $\begin{array}{l}\text { Tensile } \\
\text { yield } \\
\text { strength } \\
\text { (MPa) }\end{array}$ & $\begin{array}{c}\text { Ultimate } \\
\text { tensile } \\
\text { strength (MPa) }\end{array}$ & $\begin{array}{c}\text { Elongatio } \\
\text { n (\%) }\end{array}$ \\
\hline \multirow{4}{*}{$13 \% \mathrm{Si}$} & \multirow{2}{*}{$\begin{array}{c}\text { Sand cast test } \\
\text { bars }\end{array}$} & None & $\ldots$ & 124 & 2.0 \\
\hline & & Na-modified & $\ldots$ & 193 & 13.00 \\
\hline & \multirow{2}{*}{$\begin{array}{c}\text { Permanent } \\
\text { mold test } \\
\text { bars }\end{array}$} & None & $\ldots$ & 193 & 3.6 \\
\hline & & Na-modified & $\ldots$ & 221 & 8.0 \\
\hline \multirow[b]{2}{*}{359.0} & \multirow{2}{*}{$\begin{array}{l}\text { Permanent } \\
\text { mold test } \\
\text { bars }\end{array}$} & None & $\ldots$ & 180 & 5.5 \\
\hline & & $0.07 \% \mathrm{Sr}$ & $\cdots$ & 210 & 12.0 \\
\hline \multirow{4}{*}{ 356.o-T6 } & \multirow{2}{*}{$\begin{array}{c}\text { Sand cast test } \\
\text { bars }\end{array}$} & None & 208 & 289 & 2.0 \\
\hline & & $0.07 \% \mathrm{Sr}$ & 238 & 293 & 3.0 \\
\hline & \multirow{2}{*}{$\begin{array}{l}\text { Bars cut from } \\
\text { chilled sand } \\
\text { casting }\end{array}$} & None & 213 & 284 & 4.4 \\
\hline & & $0.07 \% \mathrm{Sr}$ & 218 & 291 & 7.2 \\
\hline \multirow{2}{*}{$\begin{array}{c}\mathrm{A} 356.0- \\
\text { T6 }\end{array}$} & \multirow{2}{*}{$\begin{array}{c}\text { Sand cast test } \\
\text { bars }\end{array}$} & None & 179 & 226 & 4.8 \\
\hline & & $0.01 \% \mathrm{Sr}$ & 207 & 297 & 8.0 \\
\hline \multirow{2}{*}{$\begin{array}{c}\mathrm{A} 444.0- \\
\mathrm{T} 4\end{array}$} & \multirow{2}{*}{$\begin{array}{c}\text { Permanent } \\
\text { mold test } \\
\text { bars }\end{array}$} & None & $\ldots$ & 151 & 24.0 \\
\hline & & $0.07 \% \mathrm{Sr}$ & $\ldots$ & 149 & 30.0 \\
\hline \multirow{6}{*}{ A413.2 } & \multirow{2}{*}{$\begin{array}{c}\text { Sand cast test } \\
\text { bars }\end{array}$} & None & 112 & 137 & 1.8 \\
\hline & & $\begin{array}{c}0.005-0.05 \% \\
\mathrm{Sr}\end{array}$ & 108 & 159 & 8.4 \\
\hline & \multirow{2}{*}{$\begin{array}{c}\text { Permanent } \\
\text { mold test } \\
\text { bars }\end{array}$} & None & 125 & 168 & 6.0 \\
\hline & & $\begin{array}{c}0.005-0.08 \% \\
\mathrm{Sr}\end{array}$ & 125 & 191 & 12.0 \\
\hline & \multirow{2}{*}{$\begin{array}{l}\text { Test bar cut } \\
\text { from auto } \\
\text { wheel }\end{array}$} & $0.05 \% \mathrm{Sr}$ & 121 & 193 & 10.6 \\
\hline & & $0.06 \% \mathrm{Sr}$ & 126 & 193 & 12.8 \\
\hline
\end{tabular}

Apart from the modification of the eutectic microstructure, the addition of strontium was also reported to have an effect on iron-rich intermetallics. Iron is a common impurity in commercial alloys which often cannot be avoided. Several iron-rich intermetallics with different compositions and morphologies such as the needle/plate-like $\beta\left(\mathrm{Al}_{5} \mathrm{FeSi}\right)$, Chinese script $\alpha\left(\mathrm{Al}_{8} \mathrm{Fe}_{2} \mathrm{Si}\right.$ or $\left.\mathrm{Al}_{15}(\mathrm{Fe}, \mathrm{Mn})_{3} \mathrm{Si}_{2}\right), \pi\left(\mathrm{Al}_{8} \mathrm{Mg}_{3} \mathrm{FeSi}_{6}\right)$ or $\delta\left(\mathrm{Al}_{4} \mathrm{FeSi}_{2}\right)$ can be formed in Al-Si alloys and they are generally detrimental to the mechanical behavior of the alloy $[70-75]$. The $\beta$-phase $\left(\mathrm{Al}_{5} \mathrm{FeSi}\right)$ is brittle and cracks propagate along the boundary of its needle morphology [76]. Manganese is often added to the alloy to inhibit the formation of coarse $\beta$ phase and replace it by the less harmful $\alpha$ phase which is more compact, but strontium addition was also reported to lower the volume fraction of Fe- 
intermetallics and refine the needle-shaped $\beta\left(\mathrm{Al}_{5} \mathrm{FeSi}\right)$ making it shorter and thinner $[72,76,77]$. Samuel et al [78] noted the dissolution of $\beta$ in the aluminum matrix and an enhanced effect when magnesium and strontium are added together by the additional transformation of $\beta$ to $\pi$ phase. In wrought aluminum alloys of the $6 x x x$ series, addition of strontium was reported to promote the formation of the $\alpha$ phase instead of $\beta$, leaving more excess silicon available for the precipitation of $\mathrm{Mg}_{2} \mathrm{Si}$ during aging and, therefore, enhancing its mechanical properties [79].

\subsection{Elements modifying eutectic silicon and their effect on the microstructure}

Sodium was the first element extensively studied as a modifier [5,9,10,40,80-85]. It has a powerful effect and only around $50 \mathrm{ppm}$ are enough to show full modification. The main challenge of adding sodium is its high vapor pressure and consequent tendency to fade $[7,11,40]$. This makes the amount of effective added sodium difficult to control and therefore not so convenient for industrial practice. For this reason, since the $1970 \mathrm{~s}$ strontium replaced sodium and its effect on Al-Si was increasingly studied [11,12,38,8688]. Strontium is generally added in the form of Al-Sr master alloys [7,89,90] with almost no loss during solidification. Detailed information on the effect of sodium and strontium is reviewed in section 5.4 .

On 1987, in the search for a systematic that could explain the modification of silicon, Lu and Hellawell [40] introduced the impurity induced twinning mechanism. This model considered that elements with an appropriate size would force the silicon growth to miss one close packed position and create a twin. Based on this assumption, several elements such as barium, calcium, yttrium and most rare-earths were proposed as potential modifiers. Since then, several investigations were carried out on the effect of these elements in Al-Si alloys. Calcium was found to modify the silicon structure but with a weaker effect than sodium or strontium [14-16,19,91-94]. Ludwig et al [14,15,94] concluded that a fully coral silicon structure cannot be achieved with calcium additions of up to $300 \mathrm{ppm}$, but a strong refinement of the silicon plates is observed. Besides silicon refinement, calcium was found to refine detrimental iron intermetallics in Al-Si alloys [95-97] and to improve elongation and impact strength, but often deteriorate ultimate tensile strength due to porosity and formation of $\mathrm{Al}-\mathrm{Si}$-Ca intermetallics. Abdollahi and Gruzleski [98], and Ludwig et al [94] observed that silicon modification with calcium only refines the silicon plate structure in alloys solidified with low cooling rates and achieves fibrous silicon for higher cooling rates. 
Barium addition can produce a full modification of the silicon plates [16,19,40,91]. However, a relatively high amount of modifier is needed in comparison to sodium or strontium. Knuutinen et al [16] showed that full modification needs additions of at least 890 ppm Ba to occur, while lower additions produce only partial modification or only refinement of the silicon plates.

Rare earths were also tested as possible modifiers [20]. From all of them, only europium showed the ability to transform the silicon plates into corals, while all others showed only a refinement of the silicon plates (Figure 5.2). Besides, much lower concentrations of europium ( $~ 600 \mathrm{ppm}$ in an $\mathrm{Al}-10 \mathrm{wt} \% \mathrm{Si})$ are enough for silicon modification compared to the amount of the other rare-earths elements needed just to refine the structure (1.3 to 3.0 wt\%) [20]. Alloys modified by europium show similar characteristics as strontium modified alloys. Some of the characteristics of this modification are: high density of crystallographic defects in silicon, formation of pre-eutectic and eutectic $\mathrm{Al}_{2} \mathrm{Si}_{2} \mathrm{Eu}$ intermetallic phases, and improved ultimate tensile strength and elongation [13,56,99].

The question that remains unanswered is: why do the other rare earths only refine eutectic silicon and cannot form silicon corals. Similarly to europium, alloys with ytterbium also form $\mathrm{Al}_{2} \mathrm{Si}_{2} \mathrm{Yb}$ phases [18]. However, Nogita et al [17] showed by micro Xray fluorescence $(\mu-\mathrm{XRF})$ that, while europium is present in the silicon phase like in the case of strontium [100], ytterbium is not. Ytterbium was tested in a wide range of concentrations from o to $6400 \mathrm{ppm}$ in an A356.0 alloy and every composition showed only an increasingly refined silicon plate structure [16]. The absence of ytterbium in the silicon phase was pointed as one possible explanation for the lower density of twins in silicon [18]. 

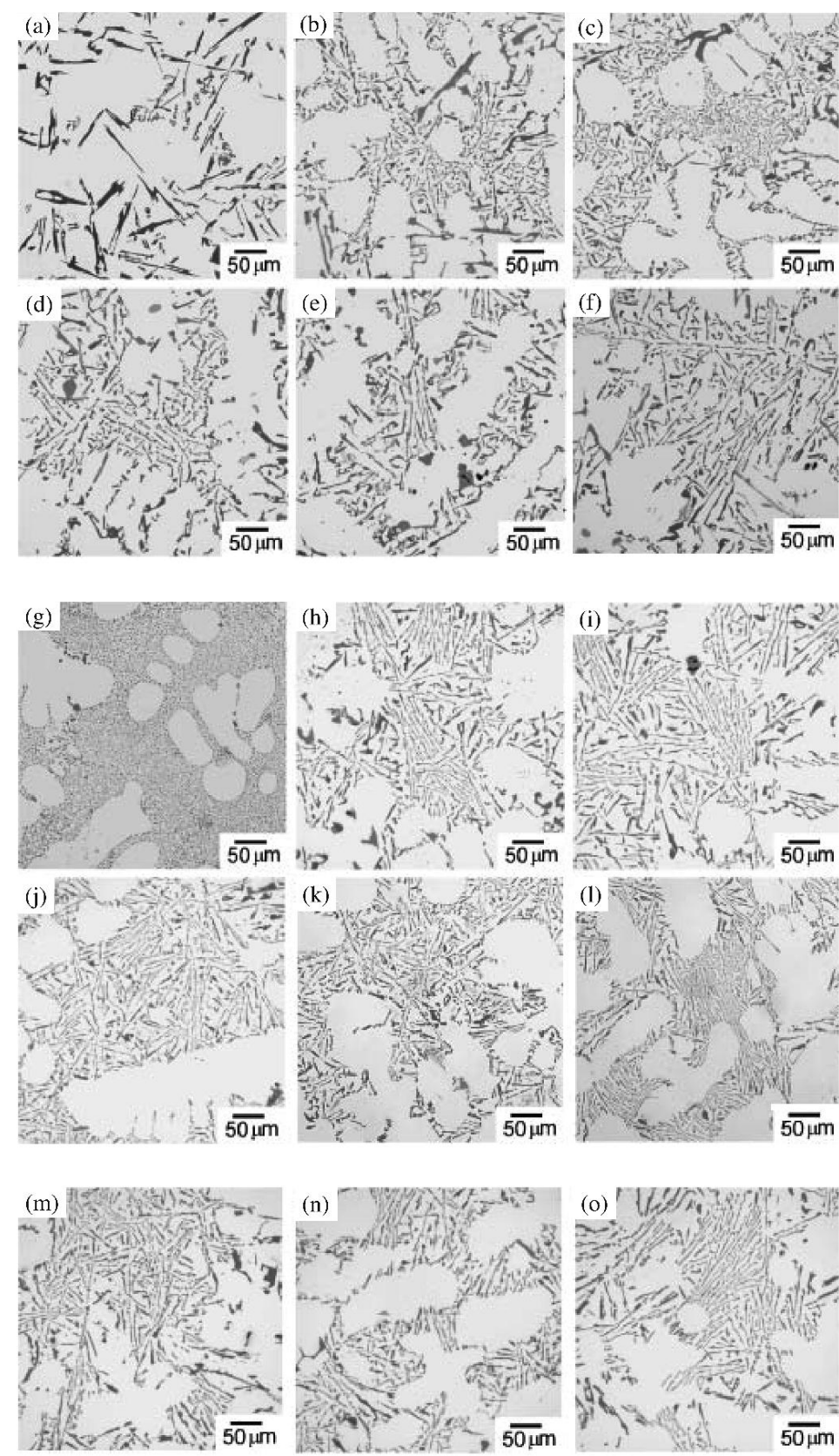

Figure 5.2: Optical micrographs of Al-Si alloys with addition corresponding to the maximum modification for each element: (a) unmodified, (b) $17300 \mathrm{ppm} \mathrm{La,} \mathrm{(c)} 19700$ ppm Ce, (d) 17200 ppm Pr, (e) 14800 ppm Nd, (f) 19700 ppm Sm, (g) 600 ppm Eu, (h) 30300 ppm Gd, (i) 25300 ppm Tb, (j) 14300 ppm Dy, (k) 18700 ppm Ho, (l) 17900 ppm Er, (m) 12900 ppm Tm, (n) 13900 ppm Yb, (o) 12700 ppm Lu [20]. 


\subsection{Porosity and shrinkage}

A downside of the addition of a modifying agent to Al-Si castings is the alteration of the amount, size and distribution of porosity. A considerable percentage of scrap is caused by undesirable casting defects such as porosity and shrinkage. Low elongation, loss of tensile strength or poor fatigue strength are some of the problems related to porosity and / or shrinkage [101]. An increased level of porosity is often reported for modified alloys and several approaches to find an explanation to this behavior can be found in literature [102-106]. A decrease of hydrogen solubility in the liquid was reported in strontium modified alloys [107]; degassing the melt after strontium addition was suggested to decrease the content of hydrogen [108]. Emadi et al [107,109] showed lower surface tension and higher viscosity of the liquid, as well as a higher volume shrinkage due to increased solid density. Inclusions such as strontium oxides $\left(\mathrm{Al}_{2} \mathrm{OSr}_{3}\right)$ [105] and strontium-containing intermetallics $\left(\mathrm{Al}_{2} \mathrm{Si}_{2} \mathrm{Sr}\right)$ [110] were suggested to act as sites for heterogeneous nucleation of pores.

In alloys with a significant volume fraction of eutectic phase, porosity was showed to be redistributed from centrally located irregular and interconnected pores in unmodified alloys, to well dispersed and rounded pores in strontium and sodium modified alloys $[103,104,111]$. The redistribution of the porosity was explained by an alteration of the solidification mode. As it will be presented in more detail in section 5.4.3, eutectic grains in hypoeutectic unmodified alloys, which nucleate near the tip of primary dendrites, are very numerous and small; in contrast, few and very large eutectic grains nucleate independently from the dendrites in modified alloys. An "isolation" model was proposed by McDonald et al [103] to account for the effect of the solidification mode on porosity. Pores are showed to form after a significant amount of solidification has occurred. The authors argue that during solidification, liquid pools will become trapped and isolated from the riser when eutectic grains impinge each other. After isolation, no feeding will occur and solidification shrinkage leads to pore formation. In the unmodified alloy, the massive number and small size of the eutectic grains will allow a good permeability of the liquid until the last stage of solidification. Very small pools may form, but porosity will mainly concentrate at the center of the casting. In contrast, the dramatic decrease in number and increase in size of the eutectic grains in the modified alloys, cause the isolation of well distributed relatively large pools of liquid where rounded pores will form due to shrinkage. The impact of solidification mode on interdendritic flow was also evaluated for additions of barium, calcium, yttrium and ytterbium to Al-Si alloys [102]. Significant differences were found in the distribution of porosity in the castings that support the effect of solidification modes on the permeability of the mushy zone. On the 
one hand, barium and ytterbium showed nucleation of independent eutectic grains that reduced the flow paths causing small, rounded and well distributed pores similarly to strontium. While on the other hand, the eutectic phase with calcium and yttrium evolved from the surface of the casting towards the center of the hot spot and the freezing of the central path caused the formation of porosity in the center such as in unmodified alloys.

The amount of silicon plays a role on porosity in hypoeutectic and eutectic alloys. Higher silicon contents decrease the volume fraction of primary aluminum dendrites, leaving more space for feeding during a longer time. In this sense, near-eutectic $\mathrm{Al}-12.5 \mathrm{wt} \% \mathrm{Si}$ alloy shows less porosity than Al- 7 wt\% Si [106]. The combination of casting design together with the feeding efficiency, given by the solidification modes and the silicon content, influences the amount of porosity in these alloys [111]. Based on this knowledge, casting design can be used to promote directional solidification towards the feeder in order to get sounder castings of increased integrity [102,106].

\subsection{Theories explaining eutectic modification of Al-Si alloys}

Several conflicting theories have been proposed through the years showing the complexity and controversy of the subject [112]. In spite of 100 years of research, the underlying phenomena for modification are still not fully understood.

\subsubsection{Early theories for eutectic modification}

Shortly after the discovery of the eutectic modification in 1921 [8], one of the first explanations considered the ternary system as a key factor. Otani [80] suggested a ternary monotectic reaction in alloys modified by sodium. He proposed that, during solidification, aluminum and silicon solid phases are formed simultaneously with a small amount of a $\beta$-liquid rich in sodium. If this very small amount of $\beta$-liquid is just ignored, the invariant reaction may be taken as equivalent to the binary eutectic reaction and, as the reaction proceeds, the $\beta$-liquid gradually accumulates contiguous to the crystal hindering the free growth. Also during the 1920s, Gwyer and Phillips [113] suggested a condition of transient stability, where formation of aggregates of colloidal dimensions in the nanometer range would play an important role. Ransley and Neufeld [81] corrected the Al-Si-Na phase diagram to show that the system had a ternary eutectic instead of a monotectic reaction and found the formation of a ternary compound [AlSiNa]. At that time, they pointed out that the idea of a colloidal dispersion would provide an adequate explanation if it were assumed that this [AlSiNa] compound is the hindering agent. Later development of the ternary phase diagram of the Al-Si-Na [114] and Al-Si-Sr [115] 
systems confirmed ternary eutectic reactions forming ternary compounds instead of a $\beta$ liquid.

In 1949, Thall and Chalmers [82] proposed a model to explain eutectic modification based on the balance of interfacial tensions during solidification. They assumed that aluminum is the leading phase during eutectic solidification. This assumption was based on the statement that the rate of advance of the solidification interface depends on the balance between the heat flow from the liquid to the solid and the latent heat evolved during solidification. Based on this, the higher thermal conductivity and the lower the latent heat of fusion, the faster the interface will advance. Because aluminum has considerably higher thermal conductivity and lower latent heat than silicon, it was concluded that the aluminum / liquid interface would freeze in advance more rapidly than the silicon / liquid interface. The second assumption made by the authors is that a small amount of added sodium reduces the surface energy between solid aluminum and solid silicon, which in turn increases the interfacial angle $\theta$ (Figure 5.3). They suggested that this reduction of surface energy causes the aluminum phase growing ahead of the solidification front to enclose the silicon crystal and, therefore, the silicon particle will be "sealed off" from the liquid and will need to re-nucleate repeatedly. Despite the logical train of thought of the authors, it was later showed that the silicon phase is the leading phase during eutectic solidification and silicon grows in a continuous manner instead of constantly re-nucleating $[5,116,117]$.

(a)

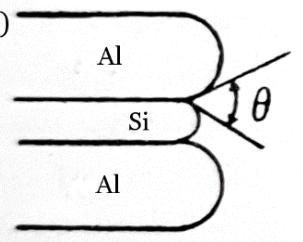

(b)

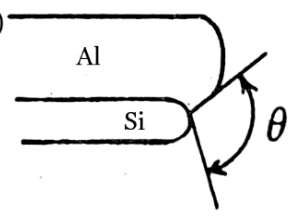

(c)

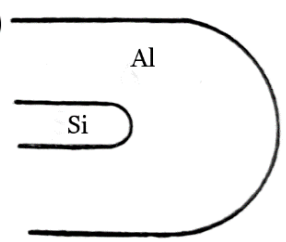

Figure5.3: Eutectic growth proposed by Thall and Chalmers: (a) Alloy with no modification. Aluminum grows in advanced of silicon. Interfacial angle $\theta$ between the growing aluminum and silicon phases. (b) Modified alloy with a reduced surface energy between the phases that translates into a larger interfacial angle $\theta$. (c) Because of the reduced surface energy, aluminum encloses silicon which will need to re-nucleate [82].

Following the idea of Thall and Chalmers [82], Davies and West [9,84] studied interfacial energies in deeper detail. The interfacial angle between solid silicon and the melt was shown to be equal to the grain boundary energy in silicon in an unmodified alloy. For the sodium modified melt, no typical angles were found and the angle depended on the crystallographic orientation of the silicon substrate. This showed that, even though a 
lower surface tension was found for sodium modified alloy in comparison to unmodified [84], the change in interfacial energy cannot determine the interface profile during solidification. The authors claimed that sodium modifies the crystal habit of silicon by being incorporated into certain crystallographic facets. They showed the restriction of fast-growing crystal faces in the presence of sodium (Figure 5.4), which reduces the growth rate of the eutectic phase to that of the slowest facets in silicon. To the best of our knowledge, Davies and West [9] were the first to propose the progressive poisoning of silicon facets by sodium atoms, explaining the supercooling of the melt as the increased driving force needed by the crystal to further grow. They also concluded that the modification is found for elements with sufficient affinity for silicon to form ternary compounds confirming the early idea $[80,81]$ that the ternary system plays a crucial role for modification.

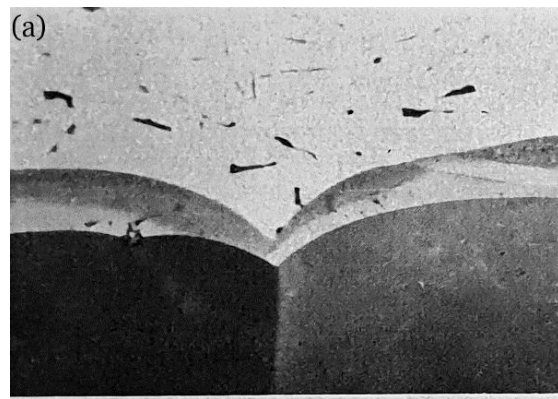

(c)

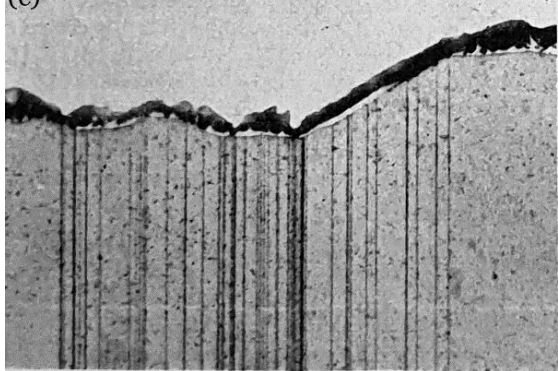

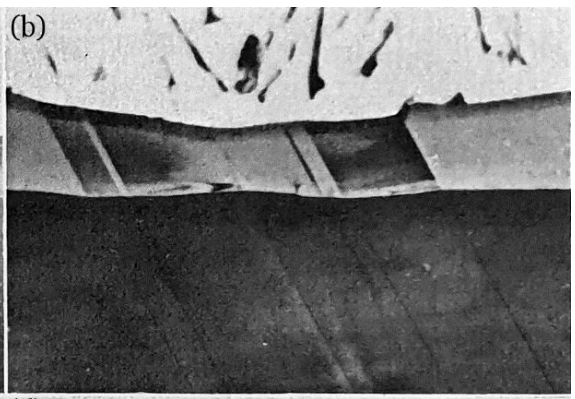

(d)

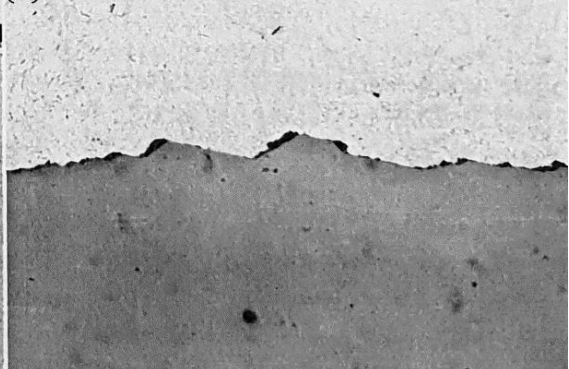

Figure 5.4: Dihedral angles at the interface between polycrystalline silicon and eutectic (Dash etch). (a) Grain boundary without sodium. (b) Twin boundaries without sodium. (c) Grain boundary and twins in presence of sodium. (d) Silicon growth layer with sodium. Apparent restriction to certain crystal faces [9]. ${ }^{1}$

Around 1970, Day and Hellawell [5,6] agreed with the proposal of the poisoning of silicon by sodium reporting that sodium poisons re-entrant $\{111\}$ twin grooves characteristic for

${ }^{1}$ Magnifications reported in the original publication are: (a) x450, (b) x45O, (c) x450, (d) x240. Note possible small deviations from these values due to print size. 
the growth of plate-like silicon in region C (Figure 4.2). They explained that the selective adsorption of sodium retards silicon growth and increases undercooling.

From the early theories mentioned above, two hypotheses stand out:

(i) the ternary system $\mathrm{Al}-\mathrm{Si}-\mathrm{X}(\mathrm{X}=$ modifier $)$ and the formation of ternary phase/s play an important role to understand modification; and

(ii) the modifier restricts silicon growth by poisoning certain crystallographic facets.

In the following decades, hypothesis (i) was abandoned because of lack of proof and great attention was put on (ii) to understand silicon growth and its restriction. Next section presents a brief summary on this topic.

\subsubsection{Modification effect on eutectic growth}

Similar to Davies and West [9], and Day and Hellawell [5,6], several other studies based their models and explanations on the silicon growth restriction due to the presence of the modifier at the growth front [11,118-120]. During the 1970s and 1980s, even though some studies still used sodium to modify Al-Si alloys, more and more investigations focused on strontium modification because of strontium's low tendency to volatilize. Strontium was proven to segregate preferentially into silicon in the eutectic phase [87].

Steen and Hellawell [118] analyzed eutectic growth and reported that strontium interfered with facet formation on $\{111\}$ silicon planes and increased the frequency of twinning events. They suggested that the effect of sodium and strontium is to inhibit the growth on planes other than $\{111\}$ by selective adsorption of the impurity element poisoning other faces. This situation leads to faceting of other planes implying that the original plane is no longer the most slowly growing and crystal growth becomes more isotropic. Hanna et al [119] suggested that the inhibition of molecular attachment on the most rapidly growing sites would increase the undercooling until growth could occur in less advantageous planes.

Jenkinson and Hogan [11] as well as Steen and Hellawell [118] concluded that modification occurs due to a limited diffusion process at the solidification front, caused by accumulation of the impurity element at the solid-liquid interphase up to a concentration where the undercooling and growth profile are affected. If the solubility of silicon in the melt is reduced, the attachment of silicon to the crystal surface is also reduced until silicon and aluminum growth velocities are equalized and both phases form by an isothermal continuous growth. 
The isotropic growth front in modified alloys was shown in several studies $[10,85,86,119]$ by comparing the shape of the solidification front in unmodified and sodium-modified eutectics. While unmodified eutectic has an irregular solidification front with silicon growing ahead, the sodium-modified alloy shows a very smooth one. In 1981, Flood and Hunt [85] emphasized that not only the growth of silicon was affected by the addition of sodium, but also the nucleation. From the imaging of quenched samples, these authors arrived at the conclusion that in an unmodified alloy, nucleation can occur on dendrites ahead of the main eutectic front, but when sodium is added these nucleation events are inhibited and growth occurs in a smooth front (Figure 5.5). Some years later, Hanna et al [119] polished successive layers on similarly quenched samples and showed that, in the unmodified alloy, eutectic colonies do not necessarily originate as nucleation events in the liquid, but are connected to the main growth front by outlying extensions of flake silicon. Although the conclusion of a restricted nucleation given by Flood and Hunt [85] was rebutted, their analysis still holds. In their study, the growth front of the sodium modified alloy was 18 times smaller than the growth front of the unmodified alloy. Because the rate of heat extraction from the solidification front should be similar for both alloys, the average interface velocity of the modified alloy must be much greater. The authors suggested that the higher interface velocity due to the smaller interface area, accounted for the refinement of the microstructure and consequent smaller spacing between silicon branches.
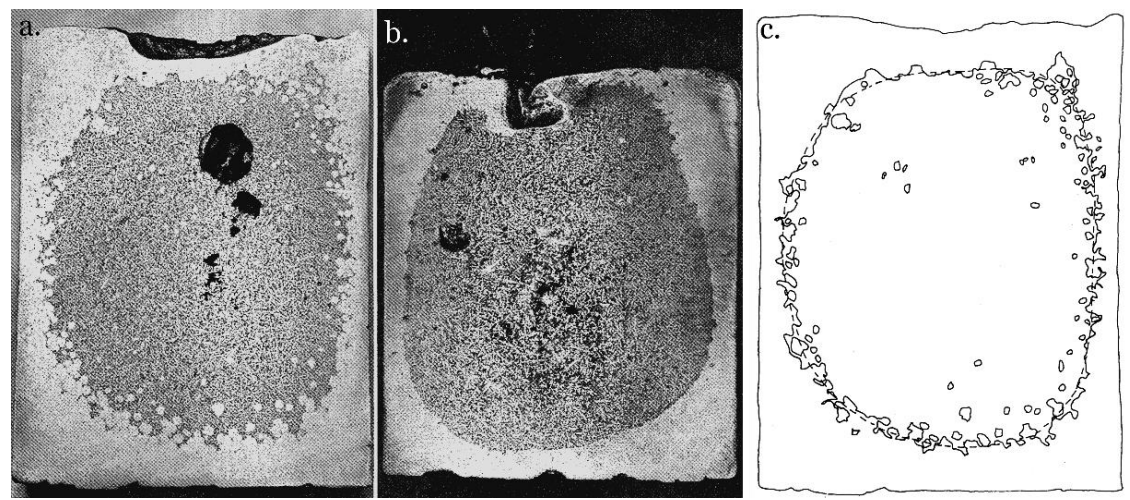

Figure 5.5: Solid / liquid interfaces after quenching molds during solidification: (a) Unmodified Al-Si eutectic alloy; (b) Sodium modified Al-Si eutectic alloy; (c) solid line showing the solid / liquid interface in (a) and dashed line showing the expected smooth interface [85].

The reason for the change in morphology of the solidification front remained unclear and the next step forward to understand eutectic modification came with the development 
and increasing popularity of transmission electron microscopy (TEM). Modified silicon revealed a remarkably imperfect crystallography with a massive increase in the twin density [12]. TEM imaging and diffraction were extensively used to study the presence of twins and to understand whether they are important or incidental for the growth of silicon and the modification process $[38,39,88,121]$. Frequent twinning in the silicon crystal was proposed to enable an isotropic growth by allowing repeated changes of growth orientation $[12,38-40,88]$.

Shamsuzzoha and Hogan [12,38,88], and Jenkinson and Hogan [11] performed TEM studies on silicon fibers modified by strontium and showed that modified silicon has fiber axes in the $<100>$ and $<110>$ orientations and exhibit multiple $\{111\}$ twinning from at least two $\{111\}$ planes simultaneously. The high twin population allows frequent branching and flexible growth. This permits the axes of the corals to change and maintain the necessary inter-coral distance. Similarly, Lu and Hellawell [39,40] showed that silicon in a sodium modified alloy is heavily twinned with the silicon fibers having a principal axis along a $<100>$ direction, with the four twin systems involved and side branches extending in <211> directions at an angle of $35.3^{\circ}$ to the principal axis. They observed that modified fibers have rough or microfaceted external surfaces, and that multiple steps and grooves are expected at the solid / liquid front as twins emerge.

Shamsuzzoha and Hogan [12] postulated that the increased twin density is the result of sodium or strontium adsorption on $\{111\}$ Si surfaces lowering the $\{111\}$ twin energy. Based on TEM images, they proposed a zigzag growth model. Figure 5.6 (a) shows how the local

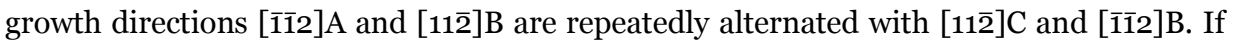
twins are nucleated such that each growth segment is of equal length, the resultant fiber axis will be [oōi] in terms of the common B orientation. Figure 5.6 (b) shows a similar case but in this case the fiber axis is [110] in terms of A. The difference between figure 5.6 (a) and (b) is given by the twin alternative configurations forming angles of $70.5^{\circ}$ and $109.5^{\circ}$ between the crystals, respectively. The $<100>$ and $<110>$ fiber orientations are extreme cases. The fiber axis can vary anywhere between $<100>$ to $<112>$ to $<110>$ if the lengths of the crystal segments are unequal. Based on this model, Shamsuzzoha and Hogan [12] also explained the branching of the fibers as an extension of the same mechanism with the twin configuration governed by the local diffusion conditions. 

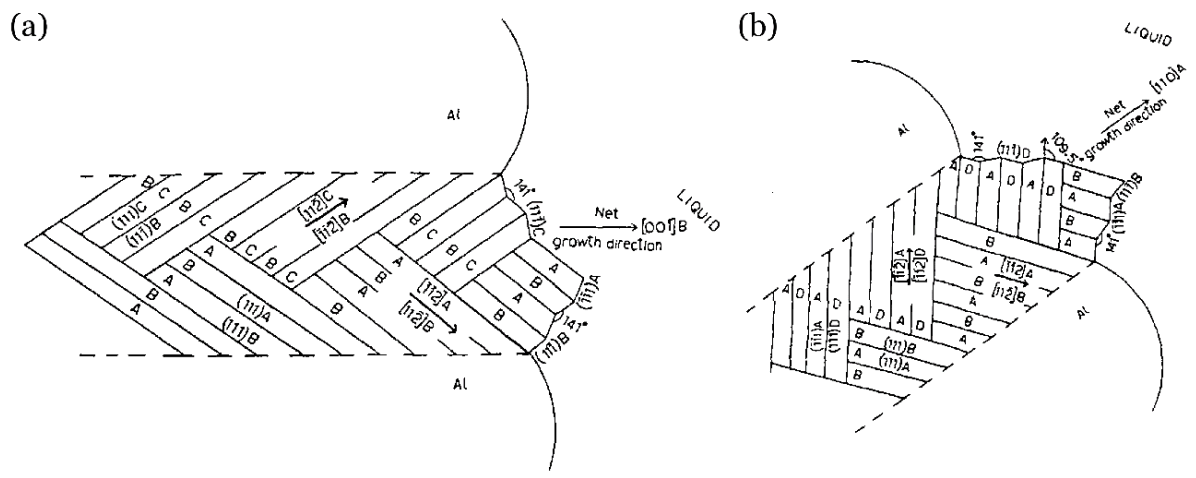

Figure 5.6: Schematic representation of the "zigzag" growth in a strontium modified alloy. Orientation relationships in a fiber with effective [0ōi] (a)and [110] (b) growth axes [12]

Following the idea of the adsorption of the modifying element on $\{111\}_{\mathrm{Si}}$ facets, in 1987 , Lu and Hellawell [40] proposed the impurity induced twinning (IIT) model. In this model, the authors looked for a common trait that could explain which elements modify the eutectic silicon. They considered in detail the possible relevance of the atomic radius of the modifying agent by calculating what would be a suitable size of the impurity atom to change the $\{111\}$ stacking sequence and promote the formation of a twin when adsorbed on the solid-liquid interface. The authors assumed silicon growth by extension of step sources across the $\{111\}$ planes. The modifier "poisons" the growth by the accumulation of adatoms at those steps. Figure 5.7 shows a 011 projection where an impurity atom of appropriate size forces the next silicon atom to miss one regular close packed position and so, continue in the alternative stacking sequence creating a twin. The geometrical calculation of the necessary hard sphere size to fulfil this condition resulted in a radius ratio of $\mathrm{r}_{\text {(modifier) }} / \mathrm{r}_{\text {(silicon })} \approx 1.646$. Table 5.2 shows a line between ytterbium ( $\mathrm{Yb}$ ) and lanthanum (La) for this "ideal" ratio and a cross (x) for elements that were reported to have some kind of influence on the eutectic phase.

At the time when the impurity induced twinning (IIT) model was proposed, there were no characterization methods with enough chemical resolution to prove the hypothesis by direct observation. This model was considered a valid explanation for the formation of twin in the silicon phase although there were incongruencies with experimental evidence. Sodium, for example, is much more effective than calcium $[14,15]$ although it has a larger difference from the "ideal"; and ytterbium and lanthanum only refine the silicon plates instead of forming the beneficial coral structure seen with sodium or strontium additions [16-18,20]. Factors other than the atomic radius -such as melting points, vapor 
pressures or oxide formation-, were also qualitatively considered by Lu and Hellawell [40], but they were rather inconclusive.

Table 5.2: Possible modifying additions in order of atomic radii as proposed by Lu and Hellawell [40]

\begin{tabular}{|c|c|c|c|c|c|c|c|}
\hline Element & $\begin{array}{l}\text { At. Rad } \\
r(\AA)\end{array}$ & $\begin{array}{l}r / \\
r s i\end{array}$ & $\begin{array}{l}m p \\
(\mathrm{~K}) \\
\end{array}$ & $\begin{array}{l}V P \text { at } 1000 \mathrm{~K} \\
\text { (atm.) }\end{array}$ & $\begin{array}{c}-\Delta G \text { Oxide } \\
(\mathrm{kJ} / \mathrm{mol} \\
1000 \mathrm{~K})\end{array}$ & $\frac{\begin{array}{c}K \\
{[\mathrm{MO}][\mathrm{Al}]}\end{array}}{\left[\mathrm{Al}_{2} \mathrm{O}_{3}\right][\mathrm{M}]}$ & Effect \\
\hline Cs & 2.63 & 2.37 & 301 & 1.675 & 156 & & \\
\hline $\mathbf{R b}$ & 2.44 & 2.08 & 311 & 1.451 & 185 & & \\
\hline $\mathrm{K}$ & 2.31 & 1.97 & 336 & 0.732 & 209 & & \\
\hline $\mathrm{Ba}$ & 2.18 & 1.85 & 998 & $5 \cdot 10^{-5}$ & 482 & 20 & $\mathrm{x}$ \\
\hline $\mathrm{Sr}$ & 2.16 & 1.84 & 1042 & $1 \cdot 10^{-3}$ & 480 & 15 & $\mathrm{x}$ \\
\hline $\mathrm{Eu}$ & 2.02 & 1.72 & 1095 & $1.8 \cdot 10^{-4}$ & $\sim 500$ & & $\mathrm{x}$ \\
\hline $\mathrm{Ca}$ & 1.97 & 1.68 & 1112 & $2.6 \cdot 10^{-4}$ & 509 & $4 \cdot 10^{2}$ & $\mathrm{x}$ \\
\hline $\mathrm{Yb} r^{*}$ & 1.93 & 1.65 & 1097 & $5.6 \cdot 10^{-3}$ & $\sim 500$ & $1.5 \cdot 10^{2}$ & $?$ \\
\hline $\mathrm{La}$ & 1.87 & 1.59 & 1193 & $10^{-6}$ & 487 & & $\mathrm{x}$ \\
\hline $\mathrm{Na}$ & 1.86 & 1.58 & 371 & $0.2^{10}$ & 367 & $2.7 \cdot 10^{-5}$ & $x x$ \\
\hline $\mathrm{Ce}$ & 1.83 & 1.56 & 1071 & $10^{-16}$ & 497 & & $\mathrm{x}$ \\
\hline Pr & 1.82 & 1.55 & 1204 & $10^{-13}$ & 524 & & $x$ \\
\hline Nd & 1.82 & 1.55 & 1283 & $10^{-11}$ & 452 & & $\mathrm{x}$ \\
\hline $\mathrm{Sm}$ & 1.81 & 1.54 & 1345 & $10^{-5}$ & 510 & & \\
\hline $\mathrm{Y}$ & 1.81 & 1.54 & 1796 & $10^{-15}$ & 506 & & \\
\hline Gd & $\begin{array}{l}1.01 \\
1.79\end{array}$ & 1.52 & 1584 & $10^{-14}$ & & & \\
\hline $\mathrm{Tb}$ & 1.77 & 1.51 & 1633 & & & & \\
\hline Mo & 1.76 & 1.50 & 1743 & $10^{-10}$ & & & \\
\hline $\mathrm{Er}$ & 1.75 & 1.49 & 1795 & $10^{-11}$ & & & \\
\hline $\mathrm{Li}$ & 1.52 & 1.29 & 454 & $10^{-3}$ & 560 & & \\
\hline $\mathrm{Al}$ & 1.4310 & 1.22 & 933 & $5.3 \cdot 10^{-11}$ & 457 & comparison & \\
\hline $\mathrm{Si}$ & 1.1755 & 1.00 & 1683 & $8.9 \cdot 10^{-17}$ & 354 & & \\
\hline
\end{tabular}

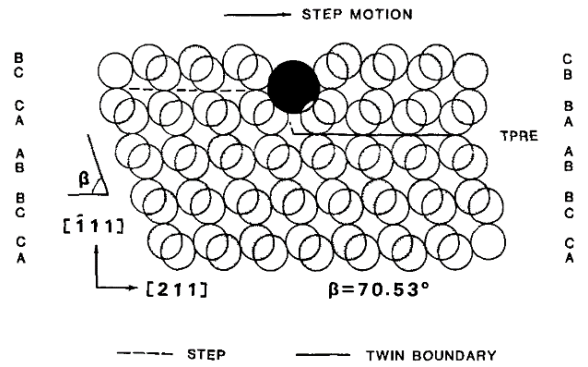

Figure 5.7: Schematic showing the impurity induced twinning model on a 011 plane projection. Impurity atom (modifying agent) with an appropriate size would promote the formation of a twin by forcing silicon to grow on the alternative $\{111\}$ stacking sequence [40].

\subsubsection{Modification effect on eutectic nucleation}

The addition of a modifying element also influences the nucleation of the eutectic phase in Al-Si alloys. The study of the cooling curves during solidification shows a depression of the nucleation temperature $\left(\mathrm{T}_{\mathrm{N}}\right)$, minimum temperature before recalescence $\left(\mathrm{T}_{\text {Min }}\right)$ and growth temperature $\left(\mathrm{T}_{\mathrm{G}}\right)$ in modified alloys (Figure 5.8) [119,122-124]. Thermal analysis 
is routinely used to study the effect of modification on nucleation and growth enabling the identification of phase formation. This analysis is made by the combination of the cooling curve (temperature over time) and its first derivative showing the solidification rate of the alloy. The nucleation temperature $\left(\mathrm{T}_{\mathrm{N}}\right)$ of the eutectic phase is defined as the point where the first silicon crystals are formed and start to grow releasing latent heat. This temperature is identified by a change in the slope of the cooling curve that can be clearly identified by the first derivative of the cooling curve [16]. The minimum temperature ( $\mathrm{T}_{\mathrm{Min}}$ ) shows the point where the latent heat due to eutectic growth equals the heat flow out of the system. This depends on the cooling rate and the heat capacity of the system [18]. After this point, the release of latent heat is higher than the heat extraction from the system and the temperature rises until the growth temperature is reached $\left(\mathrm{T}_{\mathrm{G}}\right)$. The growth temperature corresponds to the nearly horizontal part of the eutectic arrest and is defined as the maximum reaction temperature after recalescence [123]. The difference $\Delta \mathrm{T}=\mathrm{T}_{\mathrm{G}}-\mathrm{T}_{\mathrm{Min}}$ is known as the recalescence of the eutectic arrest. Thall and Chalmers [82], and Hanna et al [119] showed depressions of $\approx 6 \mathrm{~K}$ in the nucleation and growth temperatures of sodium modified alloys. They also showed a depression of primary silicon nucleation in modified hyper-eutectic alloys, while primary aluminum remains unchanged. They concluded that the depression in the nucleation of the eutectic phase is predominantly related to a change in the nucleation of the silicon phase. Another distinctive characteristic of the modified alloy is that, while the eutectic arrest is depressed, the melting temperature remains almost unaffected $[82,83,119]$. The difference between melting and freezing temperatures was shown to be dependent on the amount of modifier in the sample. Higher concentrations of the modifier in an alloy result in higher differences between melting and freezing temperatures [83]. Thall and Chalmers [82] pointed out that when the modifier content was very low, the eutectic solidification took place in two stages: the first at the normal temperature and the second at a lower temperature characteristic of a modified alloy. Several studies have confirmed the depression of the eutectic reaction temperatures for additions of strontium [100,122124], calcium [14-16], barium [16], europium [13,17,56], yttrium [16] and rare earth metals $[16-18,20]$ 


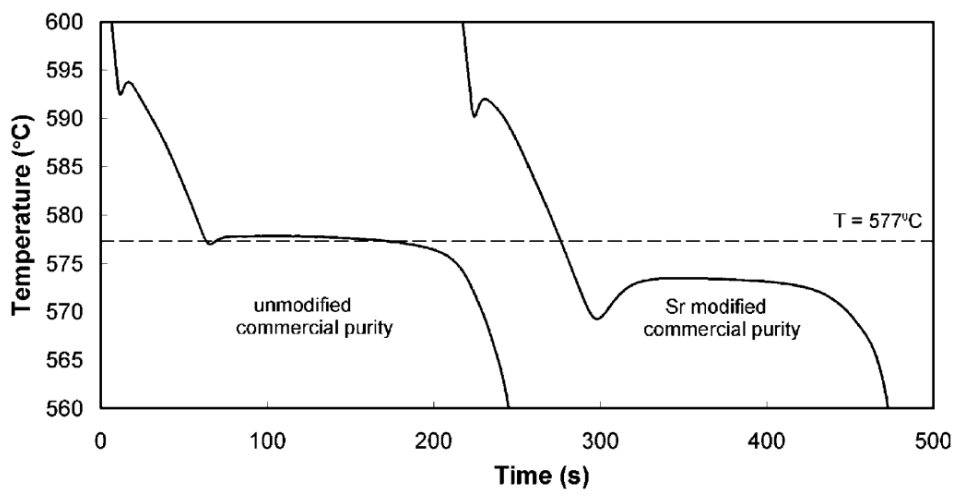

Figure 5.8: Comparison of cooling curves from unmodified and Sr-modified hypoeutectic $\mathrm{Al}-10 \mathrm{wt} \% \mathrm{Si}$ alloys with commercial purity. The primary aluminum reaction presents almost no change, while the eutectic reaction is depressed to lower $\mathrm{T}_{\mathrm{N}}, \mathrm{T}_{\mathrm{Min}}$ and $\mathrm{T}_{\mathrm{G}}$ and higher recalescence [123]

Thermal analyses of Al-Si alloys clearly depict a retarding effect of the eutectic nucleation by the addition of modifying elements. However, for a complete analysis of the eutectic nucleation, it is essential to consider the role of phosphorus. Phosphorus is deliberately added in hypereutectic $\mathrm{Al}-\mathrm{Si}$ alloys to refine primary silicon by an increased silicon nucleation on aluminum phosphide (AlP) $[7,125,126]$. Contrarily, in the eutectic phase, silicon is coarsened in the presence of phosphorous [123,127,128]. Phosphorus content also affects the modification of the eutectic silicon and larger modifier concentrations are needed in alloys with higher phosphorus levels [7,125]. Thus, the control of the phosphorus content is a major key to ensure the reproducibility of the modification treatment.

The Al-Si-P ternary system and particularly the $\mathrm{L} \rightarrow(\mathrm{Al})+\mathrm{Si}+$ AlP ternary reaction was calculated showing a phosphorus concentration threshold value between zero and 7.4 ppm for all hypoeutectic compositions [129,130]. For Al-7 wt\% Si-P with phosphorus contents higher than $3.7 \mathrm{ppm}$, AlP forms prior to eutectic silicon acting as nucleation sites. For phosphorus contents lower than $3.7 \mathrm{ppm}$ this is not possible, with silicon starting its precipitation before AlP [131]. Ludwig et al [128] showed that increasing the phosphorus concentration from 2 to $3 \mathrm{ppm}$ resulted in a transition from nucleation on the mold walls with planar front and a strong dependence of the thermal gradient, to nucleation in the vicinity of the primary aluminum dendrites with a dramatic increase in the number of grains. 
Because the threshold level of phosphorus that exert a significant difference in eutectic nucleation is extremely low and the presence of further impurities also play a role on nucleation, the entrained droplet experiment is often used to study nucleation kinetics in these alloys [13,127,132-134]. In this setup, impurities can be isolated and clean heterogeneous nucleation can be studied. The technique consists of two stages: first, the alloy is rapidly solidified by melt spinning to produce a microstructure consisting of finely dispersed eutectic droplets embedded in a higher melting point aluminum matrix; and subsequently, the low melting point eutectic droplets are re-melted and slowly cooled in a thermal analyzer to record the solidification characteristics of the eutectic phase. The advantage of this setup is that impurities segregate into a small number of droplets, leaving a large number of droplets where clean nucleation conditions can be studied. The nucleation undercooling can then be quantified by differential scanning calorimetry (DSC). A DSC is a thermal analysis technique that shows the change of heat capacity of a material as a function of temperature. In the case of Al-Si eutectic, the DSC curve shows normally two exotherms: one first sharp peak that corresponds to the solidification of eutectic droplets at the grain boundaries, and a second broader peak at lower temperature that corresponds to the entrained droplets. The undercooling of this second exotherm is related to the ability of heterogeneous nucleation in clean conditions. Ho and Cantor [127] used this method in 1995 to show a strongly increased undercooling when the content of phosphorus was decreased to less than $2 \mathrm{ppm}$ in Al-3 wt\% Si. Commercial purity alloys (up to $10 \mathrm{ppm}$ P) showed centrally located particles containing aluminum and phosphorus consistent with AlP and increasingly higher nucleation undercoolings with decreasing amount of phosphorus [122,124,128]. Insufficient number of AlP particles to effectively nucleate silicon heterogeneously causes a strong reduction in the number of eutectic grains and considerable refinement of the microstructure (Figure 5.9 (a,b)) [123,127]. The refinement is explained by the higher solidification front interface velocity derived from the low number of nucleation events. Given a constant rate of heat extraction, the inverse relationship between the solid-liquid interface velocity and surface area of the eutectic grains results in a finer eutectic structure [122,123,128]. The addition of modifying elements to commercially pure alloys was shown to have a comparable effect than decreasing the phosphorus content (comparison of Figure 5.9 (a, $\mathrm{b}$ and $\mathrm{c}$ )). In alloys with sodium addition, DSC analyses showed increased undercooling for eutectic nucleation. A possible explanation is the formation of the competing phase $\mathrm{Na}_{3} \mathrm{P}$ that consumes phosphorus, decreasing AlP nucleation sites. Similarly, other competing phases were proposed in alloys with other modifiers such as $\mathrm{Sr}_{3} \mathrm{P}_{2}[133,134]$ or YbP [18]. However, no direct evidence of these phases was ever shown. 
The effect of strontium was extensively studied in literature depicting a density of eutectic grains two orders of magnitude lower than in the equivalent unmodified alloy $[122,124]$ and the size of the eutectic grains at least one order of magnitude larger $[123,135]$. The local structure of strontium was shown to be that of $\mathrm{Al}_{2} \mathrm{Si}_{2} \mathrm{Sr}$ by means of synchrotron based extended X-ray absorption fine structure (EXAFS) spectroscopy [136]. Several studies proposed the poisoning or removal of AlP by the formation of $\mathrm{Al}_{2} \mathrm{Si}_{2} \mathrm{Sr}$ [122,124]. Pre-eutectic $\mathrm{Al}_{2} \mathrm{Si}_{2} \mathrm{Sr}$ surrounding a P-rich particle was shown by EDX analysis on a TEM sample [137]. The formation of pre-eutectic $\mathrm{Al}_{2} \mathrm{Si}_{2} \mathrm{Sr}$ was corroborated by DSC and Scheil simulation with Thermo-Calc [133,134]. Eiken et al [131] showed a critical threshold of strontium of $80 \mathrm{ppm}$ in hypoeutectic alloys with $7 \mathrm{wt} \% \mathrm{Si}$ and $5 \mathrm{ppm}$ P. If the strontium content is lower than $80 \mathrm{ppm}$, AlP solidifies before eutectic silicon. However, for higher strontium contents, the $\mathrm{Al}_{2} \mathrm{Si}_{2} \mathrm{Sr}$ phase precipitates before eutectic silicon and after AlP, leaving a solidification sequence $\mathrm{L} \rightarrow(\mathrm{Al}) \rightarrow \mathrm{AlP} \rightarrow \mathrm{Al}_{2} \mathrm{Si}_{2} \mathrm{Sr} \rightarrow \mathrm{Si}$. This calculation agrees with the postulate that $\mathrm{Al}_{2} \mathrm{Si}_{2} \mathrm{Sr}$ can nucleate on AlP particles reducing silicon's nucleation potential. DSC analysis of Al-5 wt\% $\mathrm{Si}$ modified with 500 ppm $\mathrm{Eu}$ also showed the formation of pre-eutectic $\mathrm{Al}_{2} \mathrm{Si}_{2} \mathrm{Eu}$ phases suggesting the possibility of poisoning of AlP also in this system [13].

As an alternative for AlP nucleation sites of the eutectic phase, Shankar et al [138] proposed that eutectic silicon nucleates on $\beta$-( $\mathrm{Al}, \mathrm{Si}, \mathrm{Fe})$ phases forming ahead of primary aluminum dendrites. The addition of strontium increases the viscosity of the eutectic liquid ahead of the $\alpha$-aluminum dendrites [139]. Since the viscosity is proportional to the surface tension, the authors argue that the presence of strontium changes the wetting angle between the eutectic liquid and the $\beta$-( $\mathrm{Al}, \mathrm{Si}, \mathrm{Fe})$ particles. If the viscosity is sufficiently high, the eutectic phases cannot nucleate at the eutectic temperature and significant undercooling of the melt occurs. However, Lu and Dahle [72] and Li et al [134] could not find evidences suggesting that $\beta$ needles nucleate eutectic silicon. On the contrary, it was proven by Cho et al [137] that both, pre-eutectic $\beta-\mathrm{Al}_{5} \mathrm{FeSi}$ and eutectic silicon, nucleate on phosphorus-rich nuclei. Higher phosphorus contents cause an increase in the nucleation temperature of $\beta-\mathrm{Al}_{5} \mathrm{FeSi}$ suggesting that this iron-rich intermetallic nucleates at lower undercooling because of the larger number of phosphorus-based nuclei. The Al-Si eutectic nucleation frequency decreases further when the iron concentration in the alloy increases. This means that the AlP particles are consumed by both, $\mathrm{Al}_{2} \mathrm{Si}_{2} \mathrm{Sr}$ and $\beta-\mathrm{Al}_{5} \mathrm{FeSi}$, before eutectic solidification. Shankar et al [139] showed a depression of the eutectic nucleation temperature for higher iron content that supports these results. The inter-relationship between strontium and iron on eutectic nucleation events shows that eutectic growth undercooling is not an exclusive characteristic of strontium modification, but is strongly related to the presence of 
additional impurities in commercial alloys as it was stated before by McDonald et al [123] based on the analysis of cooling curves.

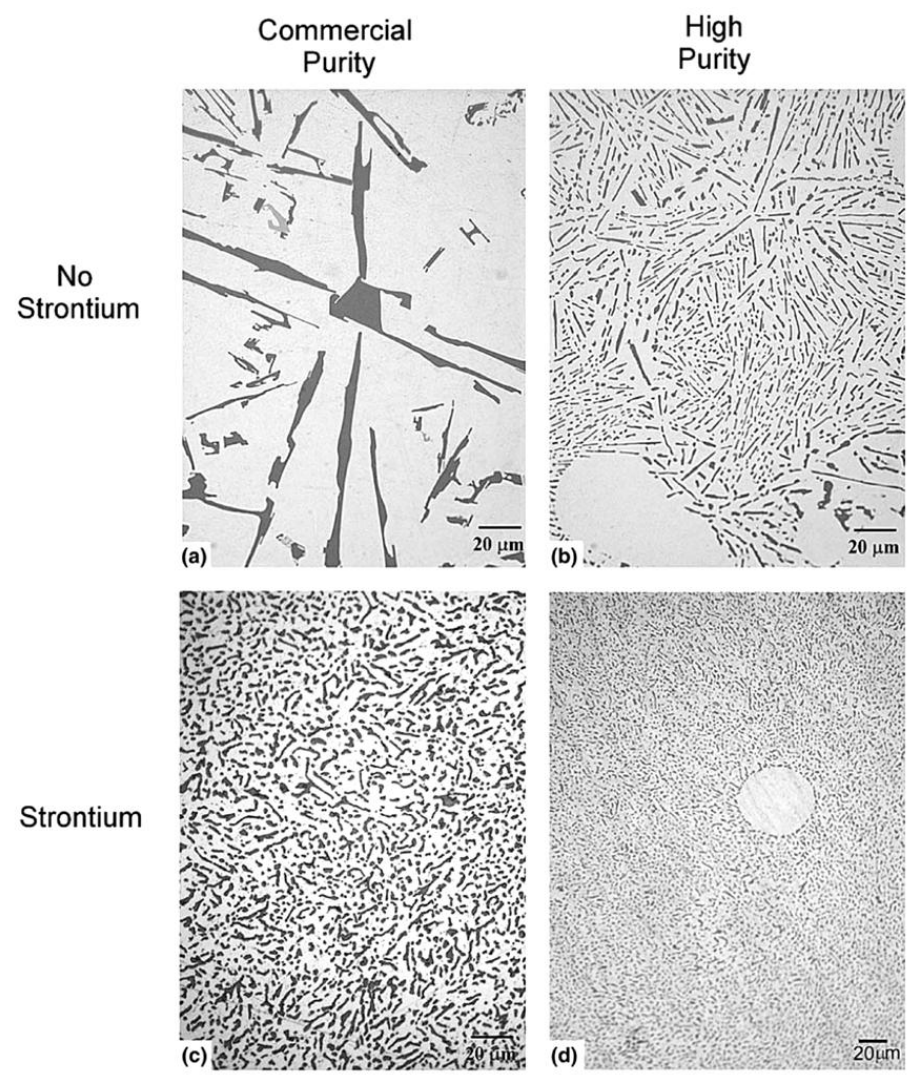

Figure 5.9: Eutectic microstructures: unmodified alloys with (a) commercial purity, and (b) high purity; strontium modified alloys with (c) commercial purity, and (d) high purity [123]

The decrease in eutectic nucleation frequency is accompanied by changes in the nucleation mode. Dahle et al [140] showed three solidification modes (figure 5.10): (a) nucleation at or adjacent to the wall, and growth opposite to thermal gradient; (b) nucleation of the eutectic phase on primary aluminum dendrites; and (c) heterogeneous eutectic nucleation on nucleant-particles in the interdendritic liquid. Quenched samples showed growth type (b) in hypoeutectic unmodified alloys with the eutectic phase formed close to the tips of the dendrites (figure 5.10(b)). In this case, primary and eutectic aluminum had the same crystallographic orientation [122,124,135,140,141]. In contrast, alloys with 70 and $110 \mathrm{ppm}$ Sr showed eutectic grains starting solidification at the center of interdendritic channels in an "independent" nucleation as depicted in figure 5.10 (c) 
$[122,124,135,140]$. Small eutectic aluminum grains in these modified samples showed no orientation relationship to the surrounding aluminum dendrites [141]. Interestingly, a sample modified with $500 \mathrm{ppm} \mathrm{Sr}$ exhibited growth associated to the dendrites, like unmodified alloys (figure 5.10 (b)). The authors argue that strontium containing particles such as $\mathrm{Al}_{2} \mathrm{Si}_{2} \mathrm{Sr}$ in samples with a low strontium level, might promote independent nucleation, while these particles become too large at higher strontium levels causing the reversion in nucleation mode [140].

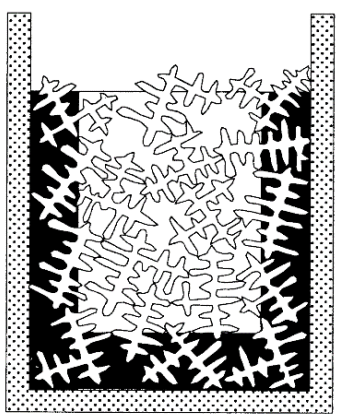

(a)

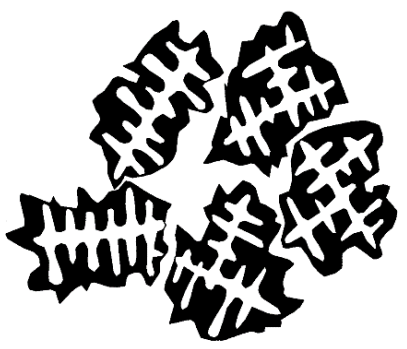

(b)

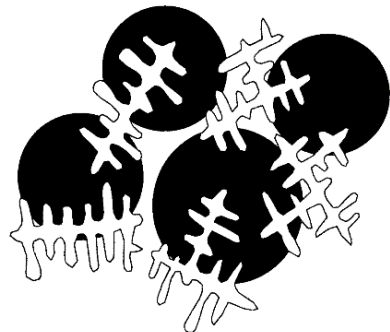

(c)

Figure 5.10: Possible eutectic growth modes in Al-Si alloys (eutectic phase illustrated in black): (a) front growth opposite to the thermal gradient; (b) nucleation on primary aluminum dendrites; and (c) independent heterogeneous nucleation in interdendritic spaces. [140]

In summary, it has been shown by several studies, that the nucleation of the eutectic phase is inhibited by the addition of a modifying element. Considering the following equation:

$$
q=\bar{V} A L
$$

where $q$ is the total rate of heat extraction, $\bar{V}$ the average interface velocity, $A$ the solidification interface area and $L$ the latent heat of fusion per unit volume. If fewer eutectic grains are nucleated in a modified alloy, the solid / liquid interface area $(A)$ will be smaller than in the unmodified case. In order to maintain a constant rate of heat extraction $(q)$, the interface velocity $(\bar{V})$ of the modified alloy will increase to compensate for the decrease in area $(A)$. The higher interface velocity has been accounted in literature for the refinement of the structure inside the eutectic grains. Several elements, for example all rare earths (except for europium) only refine the eutectic microstructure but are not able to produce the coral-like growth of silicon [20]. The plate-to-coral transition 
is believed to be independent of the change in the nucleation mode [123,131,140] and it is rather a consequence of the additional effect of the modifier during growth.

\subsubsection{Recent developments}

Efforts to reveal the distribution of the modifier elements in the eutectic phase show submicrometer strontium-rich intermetallics (most likely $\mathrm{Al}_{2} \mathrm{Si}_{2} \mathrm{Sr}$ ) adjacent to eutectic silicon crystals [100,142]. A relatively homogeneous distribution of strontium and sodium is shown to be exclusively incorporated into the silicon phase [100,142,143]. Although these studies were able to confirm the relevance of the modifier in the silicon phase, the reported lateral resolutions of about $50 \mathrm{~nm}$ are not enough to disclose how crystallographic defects in this phase are formed.

The first APT results showing the local distribution of the modifying element in the Al-Si eutectic showed segregations of strontium together with aluminum and silicon [144147]. These studies showed segregations with varying compositions of 2.6-2.8 at\% $\mathrm{Sr}$, 6.2-11 at\% $\mathrm{Al}$ and 86.4-91 at\% $\mathrm{Si}$, and proposed the formation of $\mathrm{SrAl}_{4} \mathrm{Si}_{33}$ or $\mathrm{SrAl}_{2} \mathrm{Si}_{88}$ intermetallic phases to cause the multiplication of twins and restrict silicon growth. These phases have never been shown for the Al-Si-Sr system, although several ternary phases were calculated [148]. Nevertheless, these early investigations proved the potential of APT to study eutectic modification. 


\section{Sample preparation and Characterization}

A combination of characterization techniques has been used in this thesis for the study of the eutectic modification in Al-Si alloys. This chapter gives a basic description of the sample preparation and the methods used including: mechanical polishing, SEM, EDX, EBSD, FIB, (S)TEM and APT.

\subsection{Al-Si alloys}

The compositions of the analyzed alloys are summarized in Table 6.1.

Table 6.1: List of the alloys analyzed in this thesis.

\begin{tabular}{|l|c|c|c|c|}
\hline Modification & Si (wt\%) & $\begin{array}{c}\mathrm{X}=\mathrm{Sr}, \mathrm{Na}, \mathrm{Eu}, \\
\mathrm{Yb} \text { (wt. ppm) }\end{array}$ & $\mathrm{Al}$ & \\
\hline Unmodified & 7 & -- & Balance & $\begin{array}{c}\text { Directional } \\
\text { solidification }\end{array}$ \\
\hline Unmodified & 5 & -- & Balance & Conventional casting \\
\hline Strontium & 7 & 150 & Balance & $\begin{array}{c}\text { Directional } \\
\text { solidification }\end{array}$ \\
\hline Sodium & 5 & 19 & Balance & Conventional casting \\
\hline Sodium & 5 & 160 & Balance & Conventional casting \\
\hline Europium & 5 & 500 & Balance & Conventional casting \\
\hline Ytterbium & 5 & 6100 & Balance & Conventional casting \\
\hline
\end{tabular}

\subsubsection{Al - 7 wt\% Si}

Al-7 wt.\% Si with and without 150 wt. ppm Sr were produced at the Foundry Institute at RWTH Aachen by directional solidification in a Bridgman furnace at a cooling rate of $0.25 \mathrm{~K} / \mathrm{s}$ and a temperature gradient of $15 \mathrm{~K} / \mathrm{mm}$. High purity silicon and aluminum $\left(\mathrm{Al}_{5} \mathrm{~N}_{5}\right)$ were melted at the corresponding proportions. An aluminum master alloy containing $15 \mathrm{wt} \% \mathrm{Sr}$ was added to modify the samples with 150 wt. ppm Sr.

\subsubsection{Al - 5 wt\% Si}

$\mathrm{Al}-5$ wt\% Si with no additions and with 19 wt. ppm Na, 160 wt. ppm Na, 500 wt. ppm Eu and 6100 wt. ppm $\mathrm{Yb}$ were manufactured with high purity silicon chips $(5 \mathrm{~N})$ and $\mathrm{Al}$ $(5 \mathrm{~N})$. Sodium was added using elemental sodium $(2 \mathrm{~N} 8,99.8)$ supplied in vacuum- 
packed aluminum foils. Europium and Ytterbium were added by the aluminum master alloys $\mathrm{Al}-2 \mathrm{wt} \% \mathrm{Eu}$ and $\mathrm{Al}-5 \mathrm{wt} \% \mathrm{Yb}$.

Conventional casting samples were produced by electric resistance melting of the charge material in a boron-nitride coated clay-graphite crucible at $720{ }^{\circ} \mathrm{C}-750{ }^{\circ} \mathrm{C}$ and then casted using gravity die casting. Prior to casting, no degassing treatment was performed. The average cooling rate was about $20 \mathrm{~K} / \mathrm{min}(20 \mathrm{C} / \mathrm{min})$.

\subsection{Scanning electron microscopy - SEM}

Scanning electron microscopy (SEM) is a standard technique to characterize alloys from nanometer to micrometer length scales. The sample is irradiated with a high energy (1 $30 \mathrm{kV}$ ) focused electron beam that interacts with the electrons of the atoms in the sample analyzed. Secondary electron, backscattered electrons and characteristic x-rays are produced from the interaction of the primary electron beam with the sample [149]. For this investigation, a FIB / SEM Dual-station Helios 600 (FEI company) was used.

\subsubsection{Secondary electron imaging - SE}

Secondary electrons (SE) are generated from a narrow volume near the primary beam impact area and, therefore, the imaging resolution can approximate the size of the focused electron beam. Secondary electrons are loosely bound outer shell electrons from the specimen atoms that are excited by the inelastic scattering of beam electrons. They have low energy of less than $50 \mathrm{eV}$, with $90 \%$ of them emitted with less than $10 \mathrm{eV}$. The important consequence of their low kinetic energy is the shallow escape depth in the order of few nanometers [149]. SE imaging was performed at a voltage of $5 \mathrm{kV}$ and currents in the range of $86 \mathrm{pA}$ to $1.4 \mathrm{nA}$. Two secondary electrons detectors were used during this investigation: an Everhart-Thornley detector (ETD) and a through-the-lens detector (TTL).

ETD uses a scintillator to convert electrons to light and transmit them through reflection in a light guide to a photomultiplier. Photons are then transformed back into electrons multiplied in a cascade until they reach the final collector. The face of the scintillator is metal coated with a bias positive potential to accelerate the SE to a sufficient energy to generate light in the scintillator. The scintillator is surrounded with a Faraday cage with a separate bias potential to increase the collection of SE with higher geometric efficiency.

The TTL detector is a scintillator with a high bias positioned above the objective lens. Only the SE that pass through the lens bore are detected. The disposition of the detector 
completely eliminates the SE coming from remotely produced electrons from BSE colliding with the bottom of the lens and chamber walls. The TTL detector is especially advantageous when used together with the "snorkel"-type lens. The strong magnetic field of this lens extends from the polepiece directly to the specimen below the physical lens. Lens aberrations are small due to the reduced working distance (reduced focal length) and, therefore, high-resolution images are possible [149].

\subsubsection{Backscattered electron imaging - BSE}

Backscattered electrons (BSE) are beam electrons that interacted with the electrical field of the specimen atoms and were elastically scattered along new trajectories with small or no loss of kinetic energy. The beam electron can suffer several deflections before leaving the specimen backscattered. Because of these repeated deflections, the interaction volume from which BSE emerge is larger than the size of the incident beam and, consequently, the resolution lower than SE. However, the important characteristic of BSE is that the probability of elastic scattering increases with the atomic number $(Z)$ by a relationship of approximately $\mathrm{Z}^{2}$. Primary electrons interact strongly with the positive charge of the nucleus of heavy atoms. This characteristic allows for compositional contrast or also called $\mathrm{Z}$ contrast. Due to their penetration depth, BSE can carry information from subsurface features of the specimen and therefore, this signal is generally not considered surface-sensitive [149]. BSE imaging was performed at voltages of 5 and $10 \mathrm{kV}$ and currents in the range of 0.34 to $1.4 \mathrm{nA}$.

A high sensitivity solid state backscattered detector was used for this investigation (lowvoltage / high-contrast detector - vCD). Silicon diode detectors operate on the principle of electron-holes production induced in a semiconductor by energetic electrons. They have the form of a thin wafer placed parallel to the surface of the specimen below the electron column.

Figure 6.1 compares SE and BSE contrasts for the eutectic phase in unmodified and strontium modified Al- 7 wt\% Si-0.3 wt\% Mg alloys. The compositional and channeling contrasts of BSE electron allows for the clear identification of eutectic $\mathrm{Al}_{2} \mathrm{Si}_{2} \mathrm{Sr}$ ternary phases and twin boundaries in silicon. 


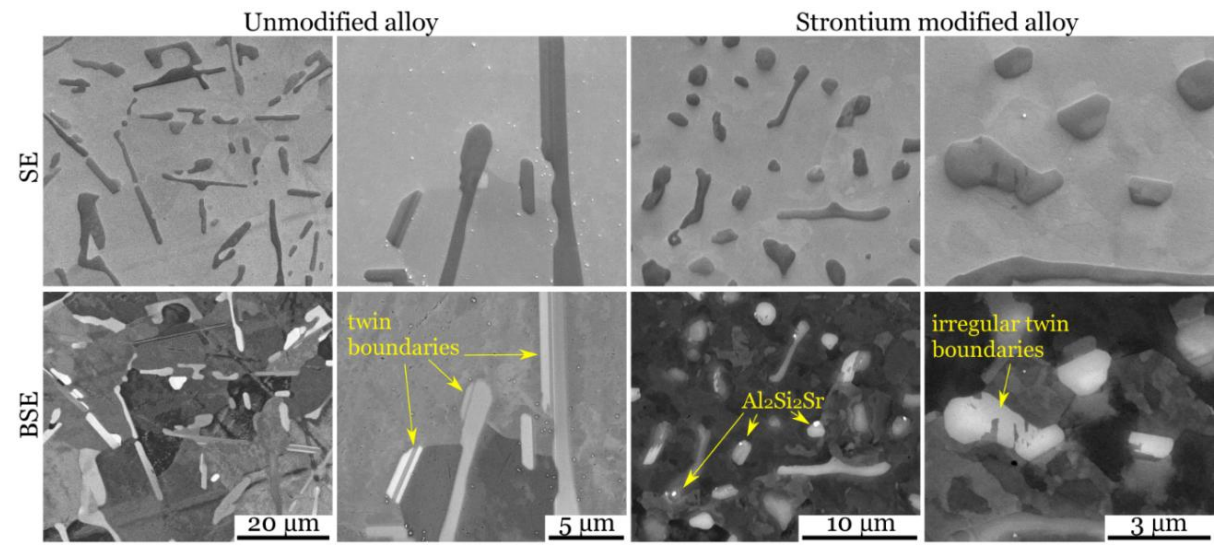

Figure 6.1: Scanning electron microscopy images of unmodified and strontium modified Al-7 wt\% Si-0.3 wt\% Mg alloys. Comparison of secondary electron (SE) and backscattered electrons (BSE) contrasts.

\subsubsection{Energy dispersive X-ray spectroscopy - EDX}

Beam electrons can interact with the specimen atoms and eject inner shell electrons. The atom is left in an excited state and to go back to the ground state, an electron of an outer shell can transition to fill the inner-shell vacancy. This energy difference between electron shells is a characteristic value for each element and it can be released as a photon of electromagnetic radiation called characteristic x-ray [149]. Characteristic xrays emitted from the sample were used in energy-dispersive x-ray spectroscopy (EDX) as a routine analytical technique for qualitative elemental detection and phase assignment. For this investigation, an Apolo XV detector (EDAX Company) was used for EDX measurements at voltages of 15 and $20 \mathrm{kV}$ and currents of 5.5 and $11 \mathrm{nA}$.

The compositional information in EDX comes from a region $\sim 1 \mu \mathrm{m}$ in both diameter and depth with accuracy of approximately $1-2 \%$ in composition. At the typical beam currents in SEM, EDX spectrometers are capable of detecting x-rays of all elements above an atomic number of 4 . Figure 6.2 shows an example of $\mathrm{Al}_{2} \mathrm{Si}_{2} \mathrm{Eu}$ phase recognition in an $\mathrm{Al}$ 5 wt\% Si with 500 ppm Eu. 


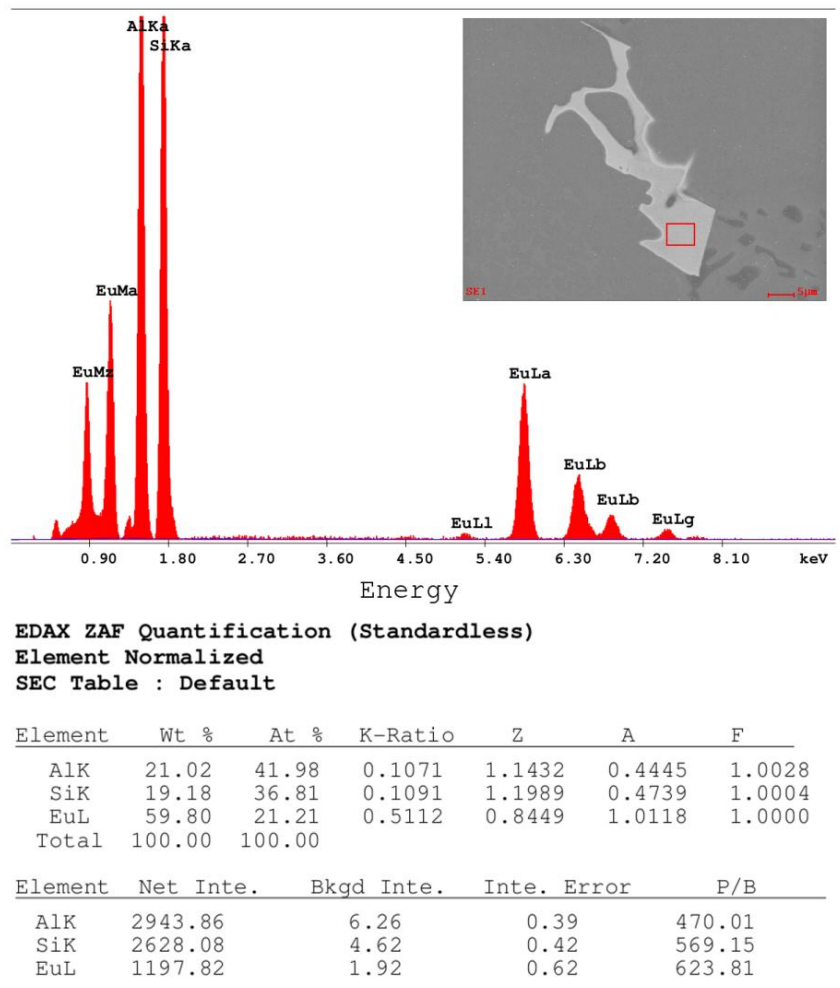

Figure 6.2: $\mathrm{Al}_{2} \mathrm{Si}_{2} \mathrm{Eu}$ phase identification by energy dispersive X-ray (EDX) spectroscopy in an Al-5 wt\% Si hypoeutectic alloy with 500 ppm Eu. Acquisition with $11 \mathrm{nA}$ and $15 \mathrm{kV}$ electron beam.

\subsubsection{Electron backscattered diffraction - EBSD}

In EBSD, the last elastic scattering event of BSE at the last plane before escaping the specimen is analyzed. To get a maximal intensity in the diffraction patterns, the surface of the specimen is tilted $70^{\circ}$ from the horizontal. Primary electrons do not penetrate as deeply in the strongly tilted specimen and electrons with small scattering angles can escape the surface and be backscattered, increasing the backscattering coefficient. For every plane in the specimen, BSE fulfill the Bragg diffraction condition in all directions and Kossel-cones are formed. The so-called Kikuchi lines, are a section of the Kosselcone wall on the detector's screen. For every plane in the specimen there are two Kikuchi-lines and the distance between them is determined by the crystallographic structure. A large part of the stereographic triangle is imaged at the same time which facilitates the determination of the crystal orientation. Kikuchi lines are transformed into 
points by a Hough transformation. Hough peaks are detected and back-transformed to index the Kikuchi lines. The relative orientation of the grains and phases in the specimen is determined with respect to a reference orientation. A charge-coupled-device (CCD) camera is used for the acquisition and a specialized software makes an automated indexing of the backscattered Kikuchi patterns received from the sample [149].

Transmission Kikuchi diffraction (TKD) was also used in this study. This is a similar technique to EBSD but uses scattered electron that are forward transmitted from a TEM sample for the diffraction analysis. The advantage of this alternative is the improved resolution due to the small interaction volume in an approximately $50 \mathrm{~nm}$ thick TEM lamella $[150,151]$. Because transmitted electrons are used, the tilt of the specimen is of $45^{\circ}$ in the opposite direction of the $70^{\circ}$ used for EBSD. The working distance is of 4-5 $\mathrm{mm}$ in comparison to the $9-11 \mathrm{~mm}$ used for EBSD [151].

For the analysis of results in this work, the data was presented in two ways: pole figures (PFs) and inverse pole figures (IPFs). PFs represent a stereographic projection of the crystallographic directions in the analyzed sample. A stereographic projection is a twodimensional projection of the three-dimensional unit cell such that the angular relationship between planes and directions in the crystal can be read from the projection. Each pole shows the direction of the crystal plane normal with respect to a sample reference frame. An (hkl) pole figure shows the distribution of the $\{\mathrm{hkl}\}$ poles in the sample. IPFs are orientation maps that show the distribution of crystallographic orientations in relationship to a reference sample direction [152].

In this investigation, an EDAX Hikari detector within the FIB/SEM workstation was used to record EBSD and TKD data using an electron beam of $20 \mathrm{kV} / 22 \mathrm{nA}$ and $30 \mathrm{kV} / 5.5$ $\mathrm{nA}$, respectively; and post-processing was performed using the OIM Analysis software (EDAX). IPFs were used to identify twin boundaries and $\Sigma 9$ boundaries in eutectic silicon for different samples (figure 6.3(b)); and PFs from silicon and neighboring $\mathrm{Al}_{2} \mathrm{Si}_{2} \mathrm{X}$ $(\mathrm{X}=\mathrm{Eu}, \mathrm{Yb})$ phases were used to find parallel orientations during the growth of these phases as evidence of heterogeneous epitaxial growth. $\mathrm{Al}_{2} \mathrm{Si}_{2} \mathrm{X}$ crystal structures from literature [153-155] were added to OIM Data Collection 7 database by means of the builtin structure creation wizard. Figure 6.3 shows an example in the Al- 5 wt\% Si with 500 ppm Eu. For the calculation of pole figures, data points from the intermetallic compound and neighboring silicon were extracted using the grain highlighting feature of OIM Data Analysis 7 software. This feature allows a point-and-click selection of data points which belong to continuous grains based on a predefined tolerance angle (here $5^{\circ}$ ) (figure 6.3 (c, d)). Selected data points were then used for pole figure calculation. In contrast to 
classic cleanup techniques which involve a more or less severe data modification, the highlighting technique is no more than an orientation based selection of data points.

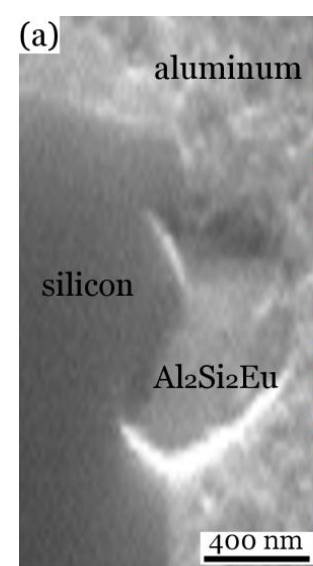

(e) $\mathrm{Al}_{2} \mathrm{Si}_{2} \mathrm{Eu}$
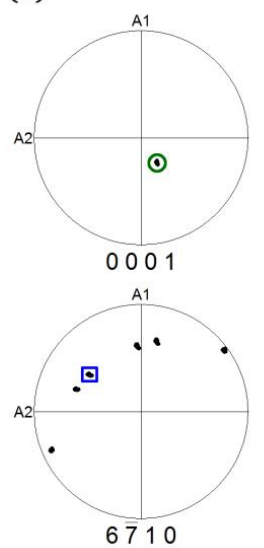
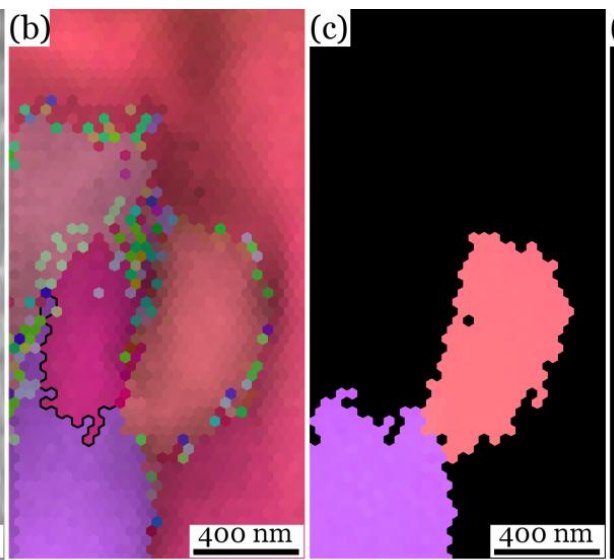

Si in (d)
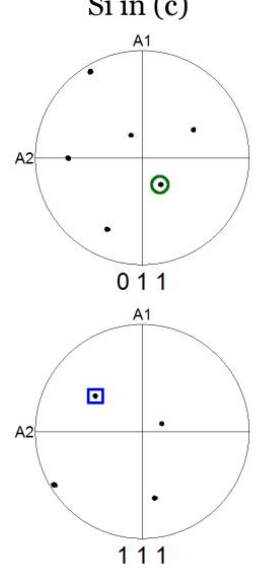
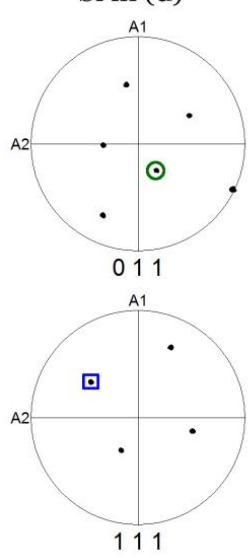

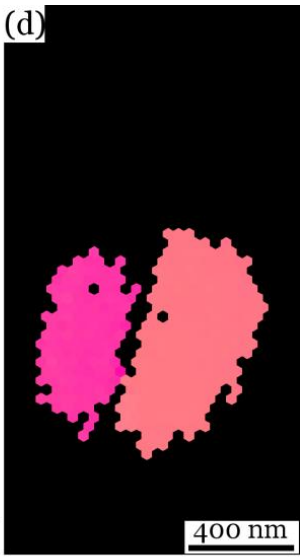

Silicon

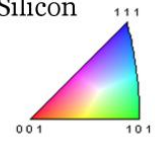

$\mathrm{Al}_{2} \mathrm{Si}_{2} \mathrm{Eu}$

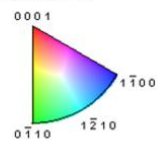

Figure 6.3: EBSD analysis in an Al-5 wt\% Si with 500 ppm Eu. Crystal orientation relationship between silicon and $\mathrm{Al}_{2} \mathrm{Si}_{2} \mathrm{Eu}$ : (a) SEM image of $\mathrm{Al}_{2} \mathrm{Si}_{2} \mathrm{Eu}$ in contact with silicon and aluminum. (b) Overlaid IPF (color) and image quality (IQ) (brightness) maps of region in (a). Uncleaned raw data, step size $30 \mathrm{~nm}$. Black line depicts a $\sum 3$ twin boundary between the silicon orientations. (c,d) Orientation-based extracted IPF maps of neighboring silicon and $\mathrm{Al}_{2} \mathrm{Si}_{2} \mathrm{Eu}$. (e) $\mathrm{PFs}$ of $\mathrm{Al}_{2} \mathrm{Si}_{2} \mathrm{Eu}$ and both silicon orientations in (c) and (d). Circles and squares highlight parallel plane normals in the crystals.

\subsection{Focused ion beam - FIB}

A focused ion beam (FIB) with a liquid metal ion source (LMIS) allows the controlled sputtering of small volumes of material in a sample and for this reason, is especially useful for site-specific sample preparation for TEM and APT. In this work, a SEM / FIB 
dual-beam station Helios Nanolab 600 (FEI Company) with a gallium $\left(\mathrm{Ga}^{+}\right)$source was used.

\subsubsection{Sample preparation for TEM}

An in-situ lift-out procedure in the SEM/FIB dual station was used for site-specific TEM sample preparation. The region of interest (ROI) can be chosen by surface inspection with SE or BSE and the orientation of the lamella can be determined by surface EBSD. Figure 6.4 shows an example of preparation in the Al-Si eutectic phase. Electron and ion induced platinum were deposited on the ROI to protect the region from gallium implantation and avoid later curtain effect during thinning. A script was used to automatically cut-out an approximately $1 \mu \mathrm{m}$ thick lamella and the specimen was liftedout and transferred to a $3 \mathrm{~mm}$ TEM grid with an Omniprobe micromanipulator. Cleaning cross-section patterns with progressively decreasing currents are used for thinning on both sides. A last low voltage cleaning step with $2 \mathrm{kV}$ is done to minimize artifacts like amorphization, ion implantation and creation of atomic defects in the lamella after thinning with $30 \mathrm{kV}$.
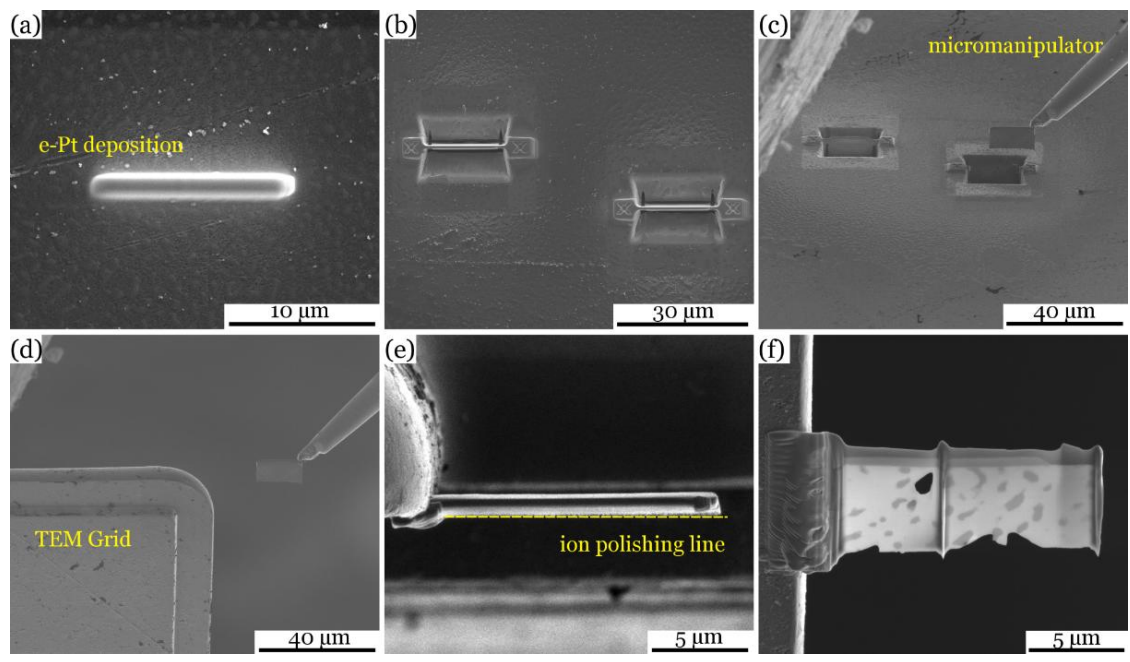

Figure 6.4: FIB sample preparation for TEM lamella. (a) Electron induced platinum

deposition. (b) Lamellas after TEM-Wizard. (c) In-situ lift-out of a lamella with a micromanipulator. (d) Transfer to a TEM Grid for thinning. (e) Lamella perpendicular to the ion beam for thinning. (f) Thinned lamella ready for analysis. 


\subsubsection{Sample preparation for APT}

APT requires a high electric field on the specimen to field evaporate atoms from its surface. For this reason, the specimen needs to be needle-shaped with an end radius smaller than $100 \mathrm{~nm}$. If it is assumed that the specimen ends in a hemispherical cap of radius $\mathrm{R}$ and a high voltage $(\mathrm{V})$ is applied, the electric field $(\mathrm{F})$ at the apex of the specimen can be estimated by the idealized equation of a charged sphere:

$$
F=\frac{V}{k_{f} R}
$$

where $k_{f}$ is a field factor between 3 and 5 accounting for the specimen shape and the electrostatic environment [156]. The end radius of the specimen is practically limited by the required evaporation fields of around 10 to $50 \mathrm{~V} / \mathrm{nm}$, and a maximal applied voltages of up to around $10 \mathrm{kV}$.
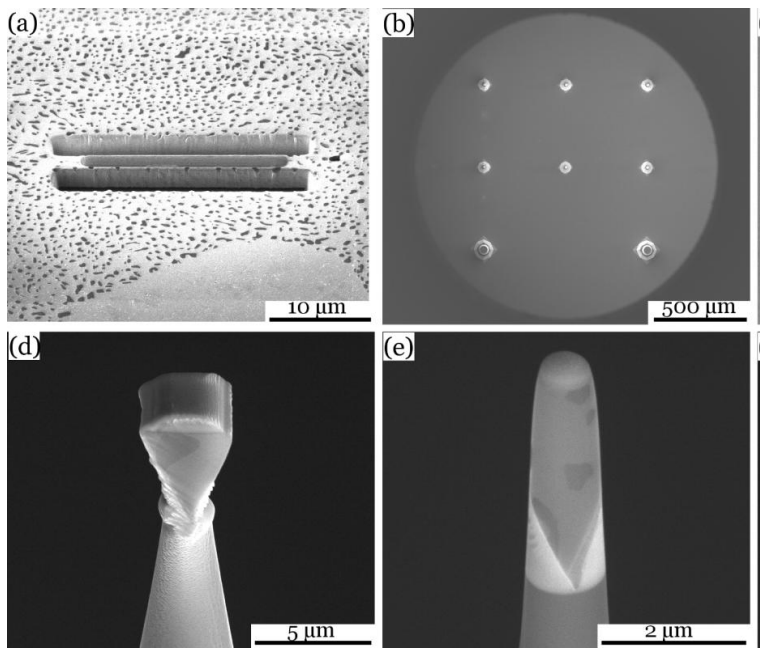

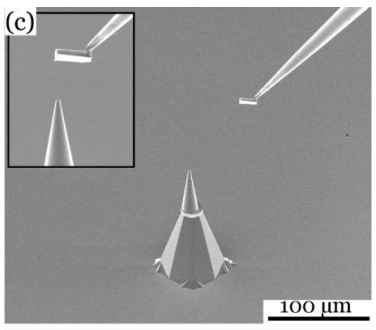

(f)

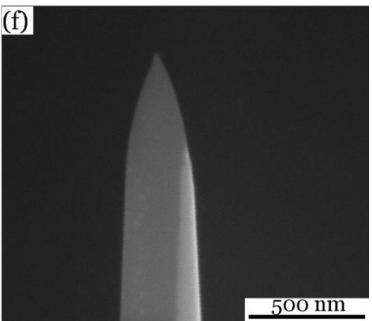

Figure 6.5: FIB sample preparation for APT. (a) Cut-out of a triangular wedge in the eutectic phase. (b) Array of micro-posts to mount the lift-out. (c) Triangular wedge attached to a micromanipulator being transferred to one of the posts shown in (b). (d)

Cut piece attached by platinum deposition to the holder. (e) First thinning steps by annular milling. (f) APT specimen ready to run.

Needle-shaped specimens for APT can be prepared in two ways: electro-chemical polishing and FIB-assisted methods. The main advantages of electro-chemical polishing are avoiding the implantation of gallium ions and its low-cost; however, no site-specific preparation is possible. For Al-Si alloys, a further problem of electro-polishing is the 
selective etching that leads to inhomogeneities in the form of the specimen. For these reasons, FIB methods were used in this work. The lift-out method described by Thompson et al [157] was used to prepare specimens of very fine eutectic structure and to study eutectic aluminum. Figure 6.5 shows the main steps of this method: a $20 \mu \mathrm{m}$ long triangular wedge is cut-out from the sample and transferred to an APT sample holder with an array of 36 posts. The wedge is then divided into 6 to 8 pieces attached to single posts and an annular milling process is then used to gradually thin the specimens up to the final required size. A last low-energy milling step with $2 \mathrm{kV}$ is used to minimize gallium induced damage.

Since this work specially focuses on the analysis of eutectic silicon, a phase-selective sample preparation method was developed to prepare silicon specimens. In this method, aluminum was deep etched and single silicon branches or plates were lifted out by FIB. Details concerning this method can be found in Paper $\boldsymbol{V}$ of this thesis.

\subsection{Transmission electron microscopy - TEM}

In transmission electron microscopy (TEM) and scanning transmission electron microscopy (STEM), a high-energy electron beam interacts with a thin specimen. If the specimen is thin enough to be electron transparent ( 20-100 $\mathrm{nm})$, beam electrons are transmitted through the specimen and collected after interacting with its atoms. Due to the small interaction volume, (S)TEM resolution is significantly increased with respect to SEM. TEM can be used to observe the crystal structure, crystal defects or grain boundaries down to the atomic scale. TEM's high-resolution makes it an adequate technique for correlation with APT. In this investigation, TEM and STEM were used to characterize the crystal defects in modified silicon. Since stacking faults (SF) / nanotwins and $\Sigma 3$ twin boundaries, all of them on $(111)_{\text {Si }}$ planes, are the most frequent defects, selected area electron diffraction (SAED) patterns were used to align the specimens in $<110\rangle_{\text {Si }}$ zone axes to see the defects on edge (figure 6.6).

TEM and STEM imaging and analysis in this work were performed in a Tecnai G2 TF 20 UT FEG (FEI Company) in micro and nanoprobe modes, an image-side aberrationcorrected JEOL 2100F microscope and a JEM - ARM 200 F Cold FEG TEM/STEM equipped with a spherical aberration (Cs) probe and image correctors. All of them operated at $200 \mathrm{kV}$. 

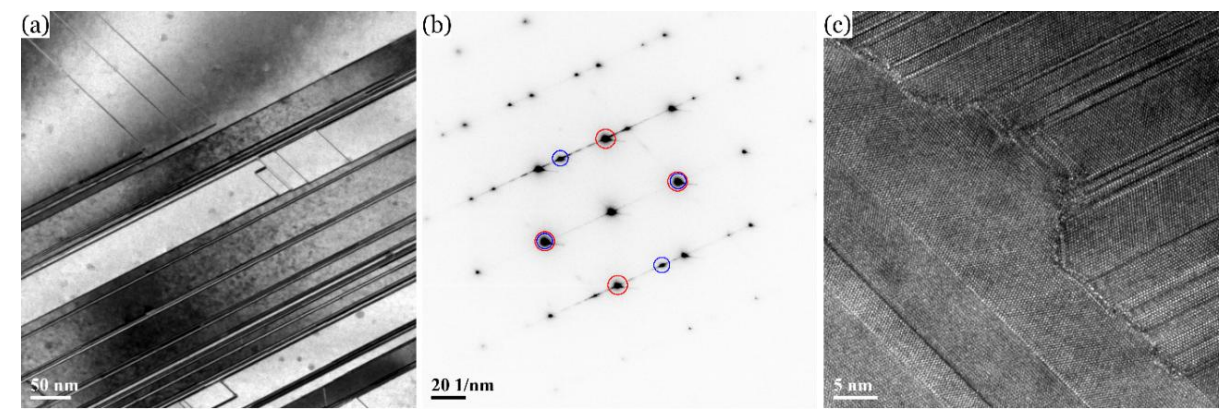

Figure 6.6: Eutectic silicon in an $\mathrm{Al}-7 \mathrm{Si}-0.3 \mathrm{Mg}$ with $250 \mathrm{ppm} \mathrm{Sr}$. (a) Twinned silicon imaged with bright field diffraction contrast. Signal through a $20 \mu \mathrm{m}$ objective aperture.

(b) Selected area electron diffraction (SAED) pattern aligned in $\langle 110\rangle_{\mathrm{Si}}$ zone axis. Red and blue circles highlight $\{111\}_{\text {Si }}$ reflections for the two mutually twinned silicon crystals

in the specimen. (c) High resolution image showing twins, nanotwins and a grain boundary in detail.

\subsection{Atom probe tomography - APT}

APT is an analytical technique that provides three-dimensional mapping of materials with atomic resolution. Surface atoms from a needle-shaped specimen are ionized, removed from the material and accelerated towards a detector. The removal of atoms from their own lattice, is field-induced by the combined effect of a standing electrostatic field and either high-voltage or laser pulses. In this investigation a LEAP 3000X HR (CAMECA Company) was used. Measurements were performed at repetition rates of 200 - $250 \mathrm{kHz}$, pressure lower than $1.33 \times 10-8 \mathrm{~Pa}$, evaporation rate of 5 atoms per 1000 pulses and temperatures between 40 and $60 \mathrm{~K}$. Laser-pulsed APT was applied to measure silicon specimens using a laser with a wavelength of $532 \mathrm{~nm}$, pulse length of 10 ps, and a pulse energy of $0.3^{-0.4} \mathrm{~nJ}$. Voltage measurements were use to measure aluminum specimens at 20\% pulse fraction. Datasets were reconstructed and analyzed with IVAS $^{\mathrm{TM}} 3.6 .8$ sofware (CAMECA)

\subsubsection{Working principle and experimental setup}

Müller [158] explained field evaporation by the image hump model. In this model, a sufficiently strong electric field fully ionizes a surface atom and lowers the energy barrier of the ion to escape the surface. Later, Gomer [159,160] proposed the alternative chargeexchange model that assumes that ionization and escape take place simultaneously while the atom is desorbing. In any case, the energy barrier that bonds the atom to the surface 
is overcome by thermal activation energy, although it is possible that in low-temperature regime, ion tunneling through the energy barrier also plays a role. One further model worth mentioning is the post-ionization theory [161,162]. The early models, assumed the direct transition of the surface atom into an $n$-charged ion. However, in the 1980s, it was shown that the ion leaves the surface with a single charge and is then subjected to one or more field ionization processes as it moves away from the surface. The number of postionization events increase with field. This theory was used to calculate the relative frequency of charge-states as a function of field for several elements in the periodic system. The resultant curves are called Kingham curves and are used nowadays as a rough estimation of the evaporation field during a measurement. For a deeper review about field evaporation theories refer to [163].

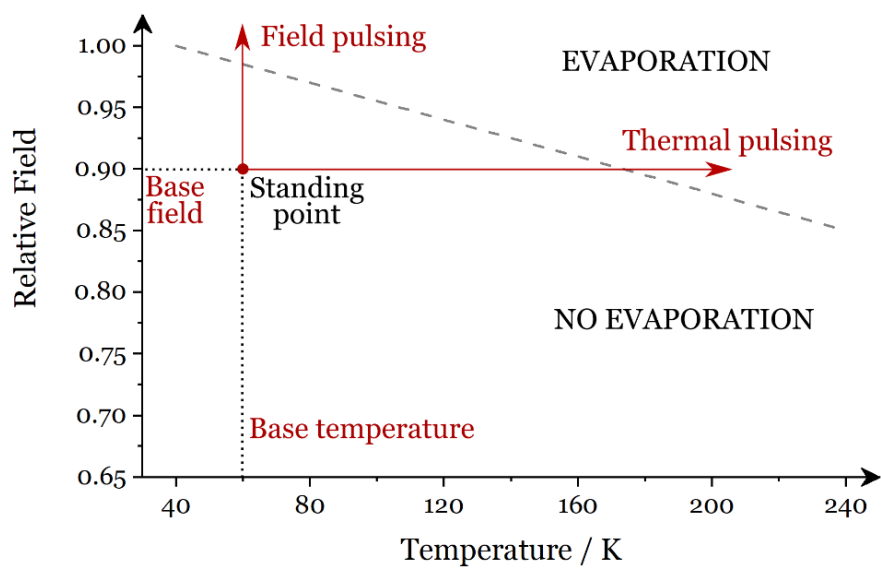

Figure 6.7: Schematic of the required electric field to evaporate as a function of temperature (thermal activation energy). Pulsing modes are depicted by arrows starting from a standing point.

In a practical sense, the removal of atoms from the specimen is a function of the applied field and temperature. Each element exhibits a characteristic behavior and a slope as shown schematically in figure 6.7. To achieve a controlled evaporation atom-by-atom, two mechanisms can be used: field-pulsing and thermal-pulsing. Starting from a standing point at a DC field (base field) and base temperature, the electric field can be increased by high-voltage pulses at a constant temperature or, on the contrary, temperature can be increased by laser pulses at a constant field. In both cases, enough energy is transferred to the specimen to evaporate an atom from the surface (figure 6.7).

Figure 6.8 shows the basic experimental setup of an atom probe. The needle-shaped specimen is mounted on a three-axis translation stage and cooled to cryogenic 
temperatures between 20 to $80 \mathrm{~K}$. The base electrostatic field is generated by a highvoltage (HV) supply connected to the specimen and the voltage pulses are applied to a local electrode positioned in front of the specimen. The system operates under ultra-high vacuum (UHV) below $10^{-8} \mathrm{~Pa}$.

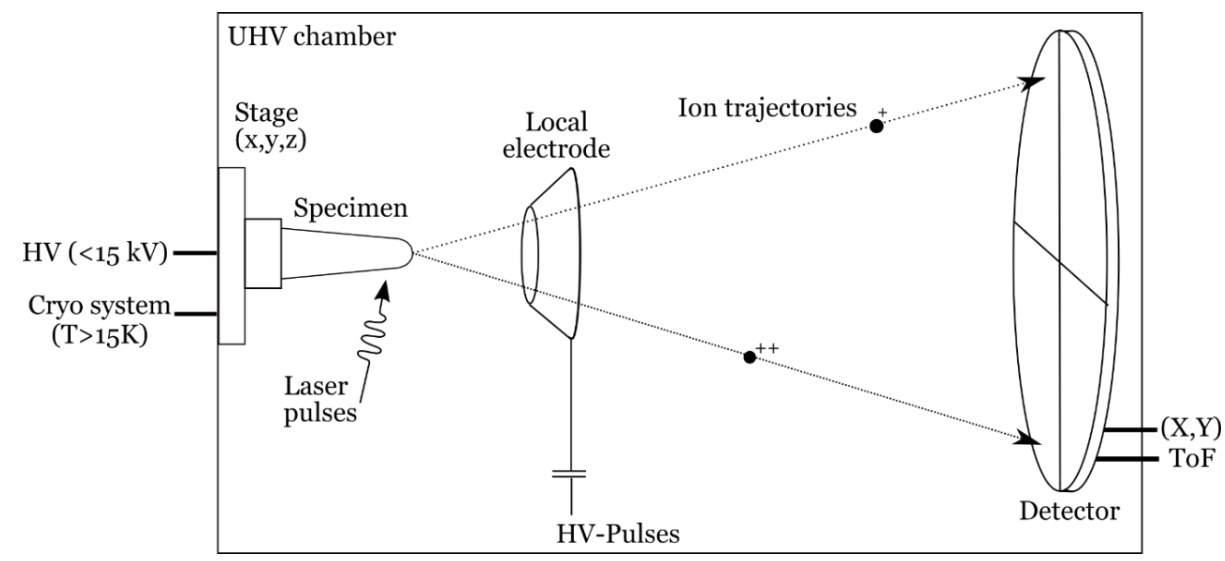

Figure 6.8: Basic experimental setup of an atom probe. [UHV: ultra-high vacuum; HV: high voltage; ToF: time of flight].

The detection system is able to record the position of impact of each ion. Ions are converted into electrons and multiplied in a stack of microchannel plates (MCP). The electrons then come to a delay-line position-sensitive detector, where they are focused on two or three polarized conductive lines. The electrons induce electric signals on all lines and are propagated along them till the end of the line. Using the time and distance covered, the $\mathrm{X}$ and $\mathrm{Y}$ coordinates of the impact on the detector are calculated.

The chemical nature of the ions is determined by a time-of-flight (ToF) spectrometer. The time of flight of an ion ( $\mathrm{t}_{\text {flight }}$ ) is defined as the time between its departure from the specimen -given by the pulse that triggers evaporation- and its arrival, when the ion impacts the detector. The ion will be accelerated in the electrostatic field by the potential energy available $E_{p}=n e V$, where $V$ is the total voltage and ne, the charge of the ion. The total kinetic energy after departure $E_{k}=\frac{1}{2} m v^{2}$ will be equal to the potential energy, and the velocity can be defined as $v=\frac{L}{t_{\text {flight }}}$, where $L$ is the flight length between the specimen and the detector [164]. The mass-to-charge ratio $\left(\frac{m}{n}\right)$ of the ion can be then directly determined by:

$$
n e V=\frac{1}{2} m v^{2} \rightarrow \frac{m}{n}=2 e V\left(\frac{t_{\text {flight }}}{L}\right)^{2}
$$


By knowing the mass-to-charge ratio of each ion, it is possible to identify their chemical nature. All mass-to-charge values in a measurement are showed in a single spectrum, where the natural isotopic abundance ratios assist in the assignment of the peaks. The peaks were ranged at the full width tenth maximum (FWTM) in this investigation. Figure 6.9 shows a mass-to-charge spectrum from a eutectic silicon specimen of an $\mathrm{Al}-7 \mathrm{wt} \% \mathrm{Si}$ with $150 \mathrm{ppm}$ Sr.

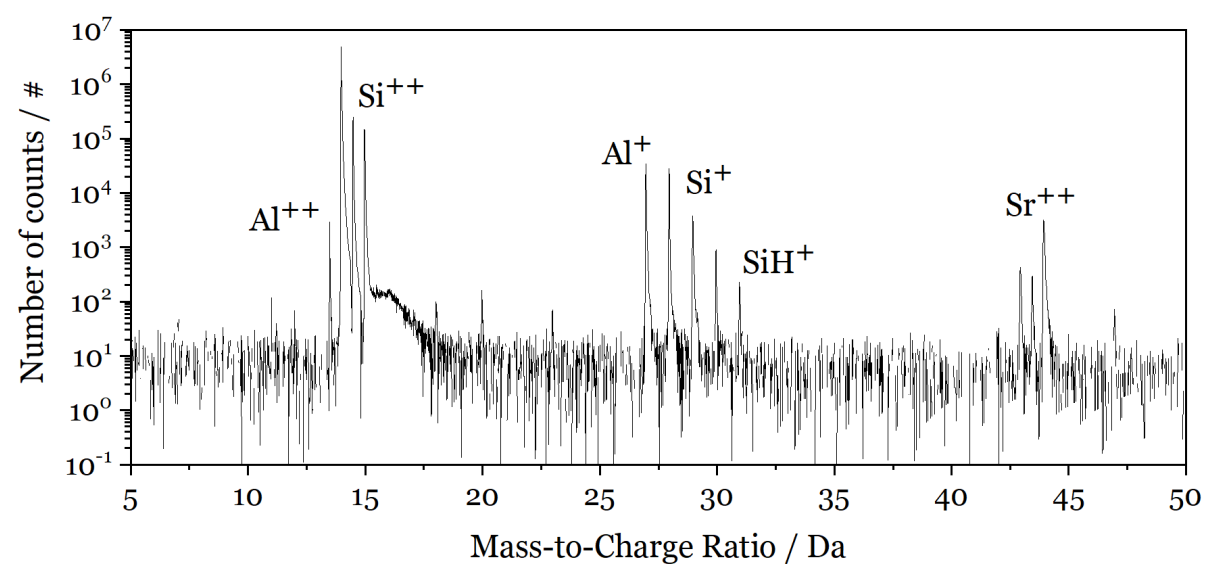

Figure 6.9: Mass-to-charge spectrum of eutectic silicon in Al- 7 wt\% Si with 150 ppm Sr.

\subsubsection{Data reconstruction, visualization and analysis}

After acquisition, the raw data is reconstructed and analyzed in the dedicated software IVAS 3.6.8 (CAMECA). This software uses an algorithm that calculates the position of the ions by assuming that they fly in a straight line from the surface of the specimen, with these lines originating from a single projection-point along the axis of the specimen [165]. The position of the projection-point depends on the compression of the field lines during evaporation, which is related to the distribution of the field at the surface of the specimen and its shape. It is also assumed that the atoms are evaporated layer-by-layer from the outermost surface inwards. This means that the sequence of detection reveals the depth position of the atoms in the specimen, the z-coordinate. This information together with the lateral position $(x, y)$ deduced from the reverse projection of the impact coordinates given by the position-sensitive detector determine the $(\mathrm{x}, \mathrm{y}, \mathrm{z})$ coordinates for each atom in the volume [166].

Four parameters are set by the operator during reconstruction: the evaporation field $\mathrm{F}_{\mathrm{e}}$, image compression factor ICF, field factor $\mathrm{k}_{\mathrm{f}}$ (section 6.3.2) and detection efficiency. In this investigation, the detection efficiency of $37 \%$ given for the LEAP 3000 XR system 
was used. Silicon specimens were reconstructed with $\mathrm{F}_{\mathrm{e}}$ of $30-33 \mathrm{~V} / \mathrm{nm}$, ICF of 1.65 and $\mathrm{k}_{\mathrm{f}}$ of 3.3. For aluminum specimens $\mathrm{F}_{\mathrm{e}}$ of $19 \mathrm{~V} / \mathrm{nm}$, ICF of 1.5 and $\mathrm{k}_{\mathrm{f}}$ of 3.3 were adopted.

The tools used for visualization and analysis of the data in this investigation are isoconcentration surfaces, one-dimensional (1D) concentration profiles, proximity histograms and background corrected compositions in regions of interest (ROI).

An iso-concentration surface is a $3 \mathrm{D}$ representation of a threshold value. Concentrations are interpolated from average voxel values and connected triangles build an interface for a set value [167]. This is a powerful means of visualization and also the first step for the construction of proximity histograms. Proximity histograms represent concentration profiles with respect to distance from an interface allowing the analysis of sophisticated features in a reconstruction. Compositions are computed normal to the iso-surface for each point and, therefore, independent from the interface geometry [168].

1D concentration profiles are an alternative method to show the evolution of composition. Concentrations are plotted along the length of a rectangular or cylindrical ROI across a feature in the reconstruction. A fixed number of counts was used in this work to divide the ROI into slices called blocks. Concentrations in each block are calculated and displayed as a function of length. The block size was optimized to maximize the signal-to-noise ratio. In principle, proximity histograms might seem as a more advanced representation of the data, but in cases where iso-concentration surfaces are difficult to obtain, for example due to low solute concentrations, 1D profiles are a better choice.

To count the amount of solute atoms in small clusters from one to a couple of lattice distances in size, tight ROI around each cluster were constructed and exported. The solute atoms were counted after a time-independent background subtraction included in IVAS software.

\subsubsection{Trajectory aberrations and local magnification effects}

Differences between the original structure and the reconstructed data may arise from a number of reasons in APT [164]. In the samples analyzed in this work, the main concern was trajectory aberrations. The deflection in the flight of the ions is related to the distribution of the electric field at the surface of the specimen. Localized variations of the electric field can induce undesirable lateral displacement of the ion just after evaporation, which induces zones of high or low density of ions in the reconstruction $[169,170]$. 
When a precipitate requires a considerably different field to evaporate than the matrix, trajectory aberrations may occur. In this work, clusters with a high content of aluminum need a significantly lower field than the silicon matrix around them. This produces a flattening of the surface and an inward deflection of the ion trajectories that causes an increased density of hits in the detector. Low-evaporation field solutes may also be evaporated prematurely, i.e. before more protruding atoms, which would result in an artefact in the depth coordinate. When considering $2-4$ nanometer clusters, a convolution of the matrix with the precipitate may occur resulting in an overestimation of the matrix element [171-173]. Because of this uncertainty, relative solute ratios $\mathrm{Al}: \mathrm{M}$ ( $\mathrm{M}=\mathrm{Sr}, \mathrm{Na}$ or $\mathrm{Eu}$ ) rather than absolute concentrations were considered in this work. The standard deviations in the $\mathrm{Al}: \mathrm{M}$ ratios are attributed to the combined effect of the limited number of solute atoms in the small clusters and the detection efficiency of APT ( $37 \%)$. 


\section{Summary of included papers and contribution to the field}

This investigation contributes to understand the growth change of eutectic silicon when small concentrations of modifying elements are added to hypoeutectic Al-Si alloys. Figure 7.1 shows a graphical summary of the three cases of alloys studied in this research revealing the structure and atomic distribution in the silicon phase. A model explaining the multiplication of crystal defects in silicon and its microstructural change is proposed as the outcome of this thesis.

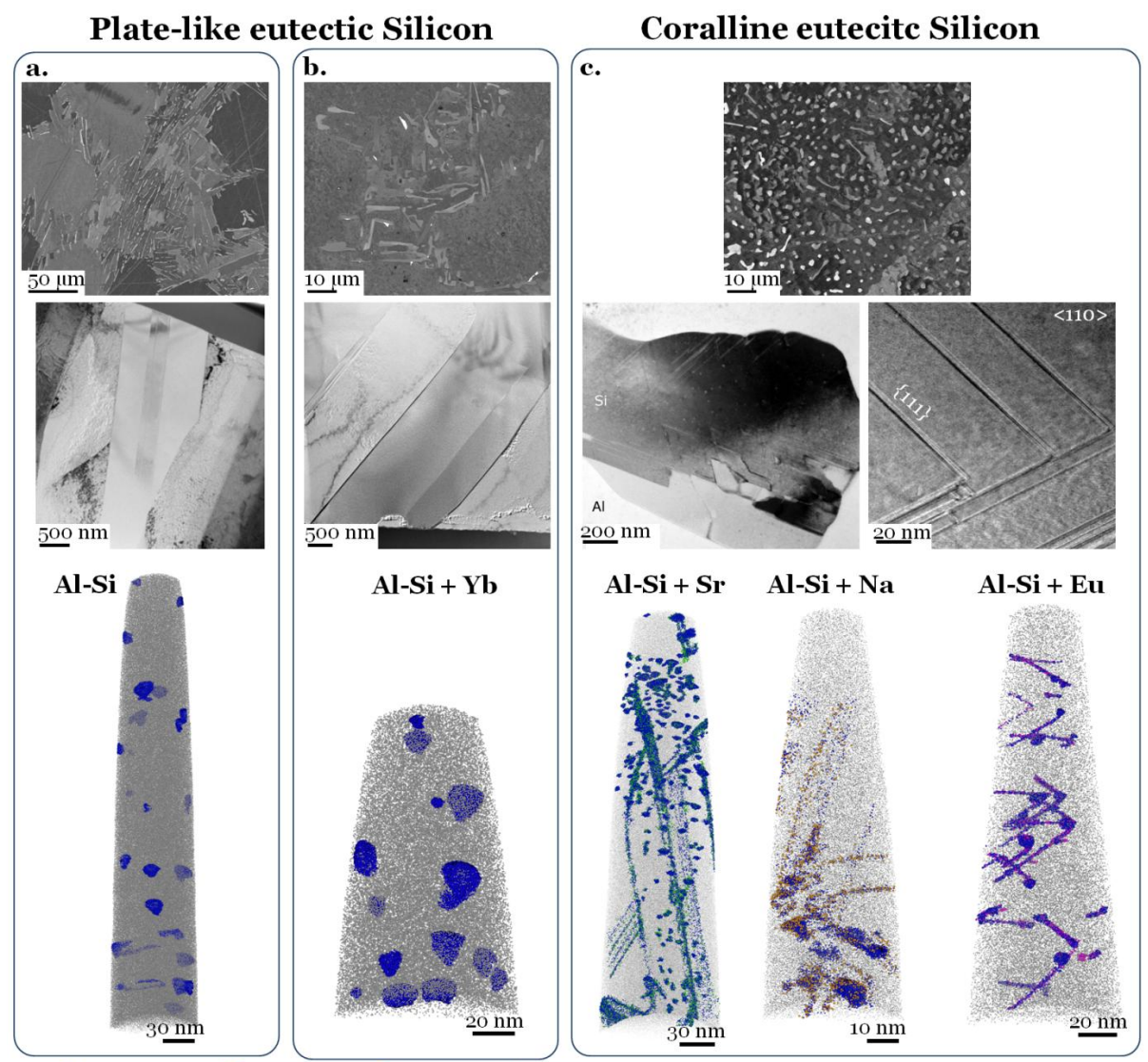

- Aluminium $\bigcirc$ Strontium O Sodium $\bigcirc$ Europium

Figure 7.1: Overview of the cases studied: (a) Al-Si alloy with no addition of modifier as a reference structure; (b) Alloy with ytterbium addition. Refined plates, but no coralline 
structure; (c) Alloys with addition of the three most powerful modifiers known to date: sodium, strontium and europium. Coral-like structure.

\section{Paper I. Comparison of segregations formed in unmodified and Sr-modified Al- Si alloys studied by atom probe tomography and transmission electron microscopy}

The atomic distribution of solutes in eutectic silicon of an $\mathrm{Al}-7 \mathrm{wt} \% \mathrm{Si}$ alloy with and without strontium addition was studied by APT and (S)TEM.

The silicon phase in the unmodified alloy showed straight twins across the plates and spherical coherent particles. APT depicted small particles (5 to $10 \mathrm{~nm}$ ) with 5-15 at\% Al, larger particles (13-18 nm) with a core-shell structure with 40-50 at\% $\mathrm{Al}$ in the shell, and a ring-segregation decorated with 6 at\% Al. These aluminum enrichments are small pockets of liquid entrapped during solidification and impurity clouds on silicon defects such as dislocation loops.

The modified alloy with $150 \mathrm{ppm}$ Sr showed irregular twin boundaries and a high density of crystal lattice defects correlated to Al-Sr-Si segregations. Depending on their morphology, the segregations were divided into three categories: rod-like, planar and particle-like (rounded). Rod-like segregations have one dimension significantly larger than the other two and often show a v-shape arrangement with precipitates at their intersection. They are responsible for changes in the silicon lattice stacking sequence and contribute to the irregular growth and smoothening of the boundary between eutectic aluminum and silicon. Planar segregations are the result of the progressive accumulation of aluminum and strontium at the silicon solid-liquid interface and favor the formation of grain boundaries and irregular twin boundaries. Rounded segregations are also found in the modified alloy, with the distinction that all contained strontium atoms together with aluminum and regions with high density of small segregations responsible for the silicon growth obstruction.

The amount of aluminum and strontium in solid solution in silicon was of $430 \pm 160$ atppm and $40 \pm 10$ at-ppm, respectively. The total content of aluminum trapped in silicon was nearly 4 times higher in the modified alloy and most of the strontium in the alloy segregated to the silicon phase. Based on the $\mathrm{Al}$ :Sr content ratio in the rod-like and planar segregations a local ternary reaction is proposed to assist in the formation and pinning of crystal defects. 


\section{Paper II. Cluster formation at the Si / liquid interface in $\mathrm{Sr}$ and Na modified Al- Si alloys}

Atom probe tomography was used to compare the effect of strontium and sodium additions in the eutectic silicon phase of hypoeutectic Al-Si alloys. Spherical precipitates, stacking faults (SFs) and twin lamellas (TLs) depicted with TEM in both alloys show oneto-one correlation with APT results showing spherical, rod-like and planar clusters in silicon. The silicon growth is obstructed in both cases by the formation of crystal defects with solute-enriched clusters. However, the solute ratios $\mathrm{Al}: \mathrm{M}(\mathrm{M}=\mathrm{Sr}$ or $\mathrm{Na})$ in the clusters were $2.92 \pm 0.46$ in the case of strontium and $1.07 \pm 0.23$ for sodium, showing a distinctly different interaction of aluminum with each of the modifiers. The heterogenous formation of clusters of the ternary compounds $\mathrm{AlSiNa}$ and $\mathrm{Al}_{2} \mathrm{Si}_{2} \mathrm{Sr}$ at the silicon / liquid interface is proposed to alter the silicon microstructure by imparting growth flexibility. These ternary compounds are reported in literature for ternary invariant reactions in Al$\mathrm{Si}-\mathrm{Sr}$ and $\mathrm{Al}-\mathrm{Si}-\mathrm{Na}$ systems at nearly the same temperature and composition as the $\mathrm{Al}-\mathrm{Si}$ binary eutectic reaction. The efficiency of a modifier is suggested to be closely related to its ability to form ternary compound clusters at the faceted silicon solidification front during growth.

\section{Paper III. Eutectic modification by ternary compound cluster formation in Al- Si alloys}

The effects of europium and ytterbium additions in hypoeutectic Al-Si alloys were studied. The addition of europium modifies the eutectic silicon to a coral-like structure, while ytterbium yields a refined plate-like silicon structure. Backscattered electron images showed that both alloys form pre-eutectic and eutectic $\mathrm{Al}_{2} \mathrm{Si}_{2} \mathrm{Eu}$ and $\mathrm{Al}_{2} \mathrm{Si}_{2} \mathrm{Yb}$ phases. A substantial difference was found when comparing the silicon phases with APT. The alloy with europium addition presented numerous clusters containing europium and aluminum with the three morphologies consistent with Paper I and II: spherical, rod-like and planar. The average of the Al:Eu ratio for 35 rod-like and 4 planar clusters was of $2.25 \pm 0.42$, which agrees with the formation of $\mathrm{Al}_{2} \mathrm{Si}_{2} \mathrm{Eu}$ clusters at the crystallographic defects. On the contrary, no ytterbium was found in the silicon phase and only aluminum segregations similar to the unmodified alloy were present. It is proposed that the difference between these alloys is their ability to form early stage $\mathrm{Al}_{2} \mathrm{Si}_{2} \mathrm{X}$ clusters on the facets of silicon. The formation of clusters obstructs the silicon growth and increases growth flexibility causing a coral-like silicon structure. The crystallographic orientation relationship between silicon and $\mathrm{Al}_{2} \mathrm{Si}_{2} \mathrm{Eu}$ or $\mathrm{Al}_{2} \mathrm{Si}_{2} \mathrm{Yb}$ was studied by EBSD / TKD. The parallel plane normals: $111_{\mathrm{Si}} / / 6 \overline{7} 1 \mathrm{O}_{\mathrm{Al} 2 \mathrm{Si} 2 \mathrm{Eu}}, 011_{\mathrm{Si}} / / 6 \overline{7} 1 \mathrm{O}_{\mathrm{Al} 2 \mathrm{Si} 2 \mathrm{Eu}}$ and $011_{\mathrm{Si}} / / 0001_{\mathrm{Al} 2 \mathrm{Si} 2 \mathrm{Eu}}$ 
with misfits of the d-spacings smaller than $6 \%$ were found between silicon and $\mathrm{Al}_{2} \mathrm{Si}_{2} \mathrm{Eu}$, while no consistent orientation relationship was found between silicon and $\mathrm{Al}_{2} \mathrm{Si}_{2} \mathrm{Yb}$. The interplanar spacing misfits between the $\mathrm{d}(\mathrm{OOOO2})_{\mathrm{Al} 2 \mathrm{Si2X}}$ and $\mathrm{d}(110)_{\mathrm{Si}}$ are $5.79 \%$ for $\mathrm{Al}_{2} \mathrm{Si}_{2} \mathrm{Eu}$ and $10.50 \%$ for $\mathrm{Al}_{2} \mathrm{Si}_{2} \mathrm{Yb}$. The higher mismatch of the ytterbium phase adds strain energy to its nucleation, what makes $\mathrm{Al}_{2} \mathrm{Si}_{2} \mathrm{Yb}$ clusters less stable than $\mathrm{Al}_{2} \mathrm{Si}_{2} \mathrm{Eu}$ clusters on silicon facets. Based on these results, it is postulated that $\mathrm{Al}_{2} \mathrm{Si}_{2} \mathrm{Yb}$ needs a higher energy to heterogeneously form sub-critical clusters on silicon than $\mathrm{Al}_{2} \mathrm{Si}_{2} \mathrm{Eu}$.

\section{Paper IV. Nucleation and growth of eutectic Si in Al-Si alloys with Na addition}

The nucleation and growth of sodium modified Al-Si alloys was studied in controlled sand casting and melt spun samples. TEM and APT analyses of controlled sand casting alloys showed a high density of twins and rod-like and spherical clusters containing sodium and aluminum atoms with $\mathrm{Al}: \mathrm{Na}$ ratios of about 1-1.5. It is proposed that the spherical clusters might agree with the impurity induced twinning idea changing the silicon stacking sequence and promoting twin formation. The rod-like clusters can be related to the poisoning of twin plane re-entrant edges as proposed by previous models. The rejection of sodium ahead of the solidification front was confirmed by a sodium enrichment of about 0.25 at\% at the interface between eutectic aluminum and silicon.

Melt spun samples were used to study eutectic nucleation for sodium addition. DSC was used to measure the undercooling for nucleation of entrained droplets. Al-5 wt\% $\mathrm{Si}$ without sodium showed an undercooling of $24{ }^{\circ} \mathrm{C}$, while the addition of $19 \mathrm{ppm}$ Na lead to a significant depression of the nucleation temperature $\left(\Delta \mathrm{T}=49^{\circ} \mathrm{C}\right)$. This depression can be explained by the removal of AlP nucleation sites by the formation of the competing phase $\mathrm{Na}_{3} \mathrm{P}$. However, the entrained droplet undercooling for the alloy with $160 \mathrm{ppm} \mathrm{Na}$ decreased to $29^{\circ} \mathrm{C}$, indicating that the formation of $\mathrm{Na}_{3} \mathrm{P}$ alone is not enough to explain the effect of sodium on nucleation.

\section{Paper V. Phase selective sample preparation of Al-Si alloys for atom probe tomography}

A method to selectively prepare eutectic silicon specimens for APT is presented. It is often said that in APT, the specimen itself is the "lens" of the microscope. The trajectory of the ions removed from the surface determine the magnification and are responsible for the later $3 \mathrm{D}$-image formation. To obtain long and stable measurements of the silicon phase with a high quality mass-spectrum, aluminum eutectic surrounding the silicon branches was deep etched and silicon pieces were lifted-out attached to a 
micromanipulator in the SEM / FIB dual station. This specimens were transferred to an APT sample holder for final thinning. Two slightly adapted methods are given for rounded modified silicon branches and coarser unmodified silicon plates. Specimens prepared by this method had an extremely high success rate and yield during APT measurements. Density fluctuations and preferential retention due to the large difference between the evaporation field of aluminum and silicon were minimized.

\subsection{Contribution to the field}

The present investigation shows that all three elements that induce silicon plate-to-coral morphology transition - strontium, sodium and europium - contain nanometer sized clusters of solute atoms at the defects in silicon. The clusters have stoichiometries corresponding to compounds formed in the ternary eutectic reaction of each system. In contrast, the addition of ytterbium, which only refines the silicon plates but do not form corals, is unable to form ternary compound clusters in silicon.

The evidence of clusters containing aluminum apart from the modifying element, falsified the impurity induced twinning model which assumed the adsorption of single modifying atoms at the silicon growth interface, but confirmed the idea that the modifier is responsible for the multiplication of crystallographic defects in silicon.

We propose that the formation of ternary compounds clusters $\mathrm{AlSiNa}, \mathrm{Al}_{2} \mathrm{Si}_{2} \mathrm{Sr}$ and $\mathrm{Al}_{2} \mathrm{Si}_{2} \mathrm{Eu}$ at the silicon / liquid interface during solidification restrict the silicon growth. The formation of ternary compound clusters on silicon facets create growth steps and increase growth direction diversity. The incorporation of clusters onto the silicon surface explains the high density of crystallographic defects in silicon and the modification from plates to corals.

The parallel lattice plane-normals $011_{\mathrm{Si}} / / 0001_{\mathrm{Al} 2 \mathrm{Si} 2 \mathrm{Eu}}, 011_{\mathrm{Si}} / / 6 \overline{7} 1 \mathrm{O}_{\mathrm{Al} 2 \mathrm{Si} 2 \mathrm{Eu}}$ and $111_{\mathrm{Si}} / /$ $6 \overline{7} 1 \mathrm{O}_{\mathrm{Al} 2 \mathrm{Si} 2 \mathrm{Eu}}$ were found between $\mathrm{Al}_{2} \mathrm{Si}_{2} \mathrm{Eu}$ and silicon, and absent between $\mathrm{Al}_{2} \mathrm{Si}_{2} \mathrm{Yb}$ and silicon. We propose a favorable heterogeneous formation of $\mathrm{Al}_{2} \mathrm{Si}_{2} \mathrm{Eu}$ on $\mathrm{Si}$. The misfit between $011_{\mathrm{Si}}$ and $0002_{\mathrm{Al} 2 \mathrm{Si} 2 \mathrm{X}}$ interplanar spacings shows a consistent trend with the potency of modification for several elements such as strontium, sodium, europium, calcium, barium, ytterbium and yttrium.

\subsection{Outlook and future work}

Based on the results obtained in this thesis some ideas for further work are presented. 


\subsubsection{APT analysis of modified Al-Si eutectic phase}

APT proved to be a powerful analytical tool in the study of eutectic modification in $\mathrm{Al}-\mathrm{Si}$ alloys. Continuing with the results in this thesis, the analysis of the silicon phase in high purity alloys with additions of calcium, yttrium and barium will give a complete outlook of the interaction of the modifying elements with aluminum and silicon at the solidification front and the formation of clusters and defects.

Further APT analysis of the Al / Si boundary in the eutectic phase for the different modification elements is also of interest. Paper IV shows an enrichment of sodium at the $\mathrm{Al} / \mathrm{Si}$ interface. The comparison with additions of other modifying elements would enable a deeper understanding of the role that this enrichment plays during growth.

\subsubsection{Calculation of phase diagrams and simulations}

The results in this work show the relevance of phase formation in the ternary systems Al$\mathrm{Si}-\mathrm{X}$, with $\mathrm{X}=\mathrm{Sr}, \mathrm{Na}$, Eu or $\mathrm{Yb}$. To the best of our knowledge, the Al-Si-Sr [115] and Al$\mathrm{Si}-\mathrm{Na}[114]$ phase diagrams were reported in literature, but $\mathrm{Al}-\mathrm{Si}-\mathrm{Eu}$ and $\mathrm{Al}-\mathrm{Si}-\mathrm{Yb}$ are still missing. These phase diagrams, particularly the liquidus surfaces, will assist in the interpretation of phase formation and solidification pathways during eutectic reaction.

Atomistic simulations of the crystallization at the eutectic solidification front are also needed. These simulations will unravel the structure of the melt just ahead of the crystallization interface and the cluster formation process. Li et al [99] performed calculations based on density functional theory with europium atoms placed in four different positions of a silicon twin boundary. However, in these calculations no aluminum atoms where considered, which differs with the experimental results shown in Paper III. Using another approach, Suzuki-Yamamoto et al [174] studied the stability of the crystal structure of the ternary intermetallics $\mathrm{Al}_{2} \mathrm{Si}_{2} \mathrm{X}(\mathrm{X}=\mathrm{Ca}, \mathrm{Sr}, \mathrm{Ba}, \mathrm{Eu}, \mathrm{Y}, \mathrm{Yb}$ ) over a wide range of temperatures showing their stability and proposing their possible relevance for modification, but no calculation in the silicon lattice was performed. Moreover, no simulations were performed to visualize the undercooled melt in addition to the solid, with atomic-scale resolution. Force-field based molecular-dynamics (MD) simulations can be employed as an option to facilitate this [175]. Force field based simulations, rather than density-functional theory (DFT) would give access to relevant number of atoms over sufficiently large times to "equilibrate" the slightly undercooled melt close to the crystalline surface. An example of the potential of force field based simulations can be found in the work of Gao et al [176], who studied the moving crystallization front of $\mathrm{CuZr}$ from a high viscous melt. 


\subsubsection{Correlative characterization of the solidification front}

The heterogeneous formation of clusters of ternary compounds on the eutectic solidification front is proposed to be one of the keys of modification. This hypothesis is based on "post-mortem" analysis, i.e. on completely solidified alloys. As a further study, we propose the comparison of the topology, crystal structure and concentration profile at the solidification front of unmodified and modified alloys in samples quenched during eutectic solidification. The study of the three-dimensional $(3 \mathrm{D})$ "frozen" solidification front at various length scales will allow the comparison of the eutectic growth modes and the clarification of the role of aluminum together with the modifier agent in the silicon crystal. Nano-CT (X-Ray computer tomography) or plasma FIB are techniques capable of giving $3 \mathrm{D}$ images to unveil the microstructural evolution and show the change of morphology of the solidification front. This analysis enables the study of the growth restriction due to the presence of the modifier at the growth front. EDX maps can give a rough idea of the concentration profile at both sides of the solidification front and help to recognize the exact position of the front. APT specimens at the growth front and at increasing distances from it can be used to determine the accumulation of the modifying element at the front during solidification. TEM can provide the structure of the crystallographic defects in the silicon structure and at the solidification front. The correlation of the atomic evolution at the growth front with the evolution at the micrometer scale leads to a global understanding of the solidification process and the formation of the coralline structure.

\subsubsection{Interaction of modifying elements in Al-Si alloys with magnesium and iron}

In this thesis, high purity binary $\mathrm{Al}-\mathrm{Si}$ alloys were studied to understand the interaction between the modifying agent and silicon avoiding the effects of further impurities or alloying elements. The next step is to analyze more complex alloys such as $\mathrm{Al}-\mathrm{Si}-\mathrm{Mg}$ and $\mathrm{Al}-\mathrm{Si}-\mathrm{Cu}-\mathrm{Mg}$. These alloys are industrially relevant and the interaction between the modifier agent and these ternary and quaternary elements has not been studied at the atomic scale. APT analysis of the $\mathrm{Mg}_{2} \mathrm{Si}$ and $\mathrm{Al}_{2} \mathrm{Cu}$ phases and its boundary with eutectic aluminum and silicon would reveal whether a part of the modifying element is consumed by these phases. Additionally, the interaction of iron and its phases with the modifying elements has also not been studied at the atomic level. 


\section{References}

[1] J.G. Kaufman, E.L. Rooy, Aluminum Alloy Castings: Properties , Processes , and Applications., 2004.

[2] M.M. Makhlouf, Solidification of Eutectic Alloys - Aluminum-Silicon, in: ASM Handbook, Vol. 15 Cast., 2008: pp. 312-316. doi:10.1361/asmhba0o05212.

[3] S. Khan, R. Elliott, Solidification kinetics of the unmodified aluminium-silicon flake structure, Acta Metall. Mater. 41 (1993) 2433-2439. doi:10.1016/o9567151(93)90323-K.

[4] W. Kurz, R. Trivedi, Overview No. 87 Solidification microstructures: Recent developments and future directions, Acta Metall. Mater. 38 (1990) 1-17. doi:10.1016/0956-7151(90)90129-5.

[5] M.G. Day, A. Hellawell, The Microstructure and Crystallography of AluminiumSilicon Eutectic Alloys, Proc. R. Soc. A Math. Phys. Eng. Sci. 305 (1968) 473-491. doi:10.1098/rspa.1968.0128.

[6] A. Hellawell, The growth and structure of eutectics with silicon and germanium, Prog. Mater. Sci. 15 (1970) 3-78. doi:10.1016/0079-6425(70)90001-0.

[7] J.E. Gruzleski, B. Closset, The treatment of liquid Aluminum-Silicon alloys, American Foundrymens Society, 1990.

[8] A. Pacz, Alloy, 1,387,900, 1921.

[9] V.L. Davies, J.M. West, Factors affecting the modification of the aluminiumsilicon eutectic, J. Inst. Met. 92 (1963) 175-180.

[10] H. Fredriksson, M. Hillert, N. Lange, The modification of aluminium-silicon alloys by sodium, J. Inst. Met. 101 (1973) 285-299.

[11] D.C. Jenkinson, L.M. Hogan, The modification of aluminium-silicon alloys with strontium, J. Cryst. Growth. 28 (1975) 171-187. doi:10.1016/00220248(75)90233-X.

[12] M. Shamsuzzoha, L.M. Hogan, The crystal morphology of fibrous silicon in strontium-modified Al-Si eutectic, Philos. Mag. A. 54 (1986) 459-477. doi:10.1080/01418618608243605.

[13] J.H. Li, X.D. Wang, T.H. Ludwig, Y. Tsunekawa, L. Arnberg, J.Z. Jiang, P. Schumacher, Modification of eutectic $\mathrm{Si}$ in $\mathrm{Al}-\mathrm{Si}$ alloys with Eu addition, Acta Mater. 84 (2015) 153-163. doi:10.1016/j.actamat.2014.10.064.

[14] T.H. Ludwig, E. Schonhovd Dæhlen, P.L. Schaffer, L. Arnberg, The effect of Ca and $\mathrm{P}$ interaction on the $\mathrm{Al}-\mathrm{Si}$ eutectic in a hypoeutectic $\mathrm{Al}-\mathrm{Si}$ alloy, J. Alloys Compd. 586 (2014) 180-190. doi:10.1016/j.jallcom.2013.09.127. 
[15] T.H. Ludwig, P.L. Schaffer, L. Arnberg, Influence of Some Trace Elements on Solidification Path and Microstructure of Al-Si Foundry Alloys, Metall. Mater. Trans. A. 44 (2013) 3783-3796. doi:10.1007/s11661-013-1694-y.

[16] A. Knuutinen, K. Nogita, S.D. Mcdonald, A.K. Dahle, Modification of Al - Si alloys with $\mathrm{Ba}, \mathrm{Ca}, \mathrm{Y}$ and $\mathrm{Yb}$, J. Light Met. 1 (2002) 229-240. doi:10.1016/S14715317(02)00004-4.

[17] K. Nogita, H. Yasuda, M. Yoshiya, S.D. McDonald, K. Uesugi, a. Takeuchi, Y. Suzuki, The role of trace element segregation in the eutectic modification of hypoeutectic Al-Si alloys, J. Alloys Compd. 489 (2010) 415-420. doi:10.1016/j.jallcom.2009.09.138.

[18] J.H. Li, S. Suetsugu, Y. Tsunekawa, P. Schumacher, Refinement of Eutectic Si Phase in Al-5Si Alloys with $\mathrm{Yb}$ Additions, Metall. Mater. Trans. A. 44 (2012) 669681. doi:10.1007/s11661-012-1410-3.

[19] K. Nogita, J. Drennan, A.K. Dahle, Evaluation of Silicon Twinning in HypoEutectic Al-Si Alloys, Mater. Trans. 44 (2003) 625-628. doi:10.2320/matertrans.44.625.

[20] K. Nogita, S.D. McDonald, A.K. Dahle, Eutectic Modification of Al-Si Alloys with Rare Earth Metals, Mater. Trans. 45 (2004) 323-326. doi:10.2320/matertrans.45.323.

[21] R.N. Lumley, Introduction to aluminum metallurgy, in: R. Lumley (Ed.), Fundam. Alum. Metall. Prod. Process. Appl., First Edit, Woodhead Publishing, Cambridge, UK, 2011: pp. 1-20.

[22] S. Otarawanna, A.K. Dahle, Casting of aluminium alloys, in: L. R.N. (Ed.), Fundam. Alum. Metall. Prod. Process. Appl., Woodhead Publishing, Cambridge, UK, 2011: pp. 141-154.

[23] R.B.C. Cayless, Alloy and Temper Designation System for Aluminum and Aluminum Alloys, in: ASM Handbook, Vol. 2 Prop. Sel. Nonferrous Alloy. Spec. Mater., ASM International, 1990: pp. 15-28. doi:10.1361/asmhbaoo01058.

[24] K. Kirgin, Feeling the domino effect, Mod. Cast. 99 (2009) 34-36.

[25] European Aluminium Association. The Aluminium automotive manual - Cast alloys and products, (2002). https://www.europeanaluminium.eu/media/1544/aam-products-6-cast-alloys-and-products.pdf (accessed November 15, 2018).

[26] W. Kurz, D.J. Fisher, Fundamentals of Solidification, Third Edit, Trans Tech Publications, Switzerland, 1992.

[27] S. Shankar, Eutectic Solidification - An Introduction, in: ASM Handbook, Vol. 15 Cast., ASM International, 2008: pp. 307-311. doi:10.1361/asmhbaoo05211.

[28] M.N. Croker, R.S. Fidler, R.W. Smith, The Characterization of Eutectic Structures, Proc. R. Soc. A Math. Phys. Eng. Sci. 335 (1973) 15-37. doi:10.1098/rspa.1973.0111.

[29] M.N. Croker, D. Baragar, R.W. Smith, Anomalous eutectic growth, J. Cryst. Growth. 30 (1975) 198-212. doi:10.1016/0022-0248(75)90090-1.

[30] K.A. Jackson, Liquid metals and solidification, American Society for metals, 
Cleveland, Ohio, 1958.

[31] R. Elliott, Eutectic solidification, Int. Mater. Rev. 22 (1977) 161-186. doi:10.1179/095066077791100363.

[32] D.M. Stefanescu, Science and Engineering of Casting Solidification, Second Ed., Springer, New York, 2009.

[33] M.R. Taylor, R.S. Fidler, R.W. Smith, Broken lamellar eutectic growth; Structure of the silver-bismuth eutectic, J. Cryst. Growth. 3-4 (1968) 666-673. doi:10.1016/0022-0248(68)90242-X.

[34] J.L. Murray, A.J. McAlister, The Al-Si (Aluminum-Silicon) system, Bull. Alloy Phase Diagrams. 5 (1984) 74-84. doi:10.1007/BFo2868729.

[35] J. Barrirero, M. Engstler, N. Ghafoor, N. de Jonge, M. Odén, F. Mücklich, Comparison of segregations formed in unmodified and $\mathrm{Sr}$-modified $\mathrm{Al}-\mathrm{Si}$ alloys studied by atom probe tomography and transmission electron microscopy, J. Alloys Compd. 611 (2014) 410-421. doi:10.1016/j.jallcom.2014.05.121.

[36] M.M. Makhluf, Solidification of Eutectic Alloys - Aluminum-Silicon, in: ASM Handbook, Vol. 15 Cast., ASM International, 2008: pp. 312-316. doi:10.1361/asmhbaooo5212.

[37] H.A.. Steent, A. Hellawell, Structure and properties of aluminium-silicon eutectic alloys, Acta Metall. 20 (1972) 363-370. doi:10.1016/0001-6160(72)90030-2.

[38] M. Shamsuzzoha, L.M. Hogan, Twinning in fibrous eutectic silicon in modified AlSi Alloys, J. Cryst. Growth. 72 (1985) 735-737. doi:10.1016/0022-0248(85)902295 .

[39] S. Lu, A. Hellawell, Growth mechanisms of silicon in Al-Si alloys, J. Cryst. Growth. 73 (1985) 316-328. doi:10.1016/0022-0248(85)90308-2.

[40] S. Lu, A. Hellawell, The mechanism of silicon modification in aluminum-silicon alloys: Impurity induced twinning, Metall. Trans. A. 18 (1987) 1721-1733. doi:10.1007/BFo2646204.

[41] M. Shamsuzzoha, L.M. Hogan, The twinned growth of silicon in chill-modified Al-Si eutectic, J. Cryst. Growth. 82 (1987) 598-610. doi:10.1016/Soo220248(87)80004-0.

[42] R.S. Wagner, On the growth of germanium dendrites, Acta Metall. 8 (1960) 57-60. doi:10.1016/0001-6160(60)90145-0.

[43] D.R. Hamilton, R.G. Seidensticker, Propagation Mechanism of Germanium Dendrites, J. Appl. Phys. 31 (1960) 1165. doi:10.1063/1.1735796.

[44] M. Shamsuzzoha, L.M. Hogan, D.J. Smith, P.A. Deymier, A transmission and high-resolution electron microscope study of cozonally twinned growth of eutectic silicon in unmodified Al-Si alloys, J. Cryst. Growth. 112 (1991) 635-643. doi:10.1016/0022-0248(91)90119-P.

[45] K.F. Kobayashi, L.M. Hogan, The crystal growth of silicon in Al-Si alloys, J. Mater. Sci. 20 (1985) 1961-1975. doi:10.1007/BFo1112278.

[46] M. Shamsuzzoha, L.M. Hogan, Crystal morphology of unmodified aluminiumsilicon eutectic microstructures, J. Cryst. Growth. 76 (1986) 429-439. doi:10.1016/0022-0248(86)90390-8. 
[47] X. Liu, Y. Zhang, B. Beausir, F. Liu, C. Esling, F. Yu, X. Zhao, L. Zuo, Twincontrolled growth of eutectic Si in unmodified and Sr-modified Al-12.7\%Si alloys investigated by SEM/EBSD, Acta Mater. 97 (2015) 338-347. doi:10.1016/j.actamat.2015.06.041.

[48] E. and P.J.H. Billig, Some observations on growth and etching of crystals with the diamond or zincblende structure, Acta Crystallogr. 8 (1955) 353-354. doi:10.1107/So365110X55001084.

[49] E. Billig, P.J. Holmes, New Observations on the Structure Germanium Dendrites, Acta Metall. 5 (1957) 53-54.

[50] M. Kitamura, S. Hosoya, I. Sunagawa, Re-investigation of the re-entrant corner effect in twinned crystals, J. Cryst. Growth. 47 (1979) 93-99. doi:10.1016/00220248(79)90162-3.

[51] F. Lasagni, a. Lasagni, E. Marks, C. Holzapfel, F. Mücklich, H.P. Degischer, Threedimensional characterization of 'as-cast' and solution-treated AlSi12(Sr) alloys by high-resolution FIB tomography, Acta Mater. 55 (2007) 3875-3882. doi:10.1016/j.actamat.2007.03.004.

[52] F. Lasagni, A. Lasagni, C. Holzapfel, F. Mücklich, H.P. Degischer, Three Dimensional Characterization of Unmodified and Sr-Modified Al-Si Eutectics by FIB and FIB EDX Tomography, Adv. Eng. Mater. 8 (2006) 719-723. doi:10.1002/adem.200500276.

[53] A.M. Samuel, E.M. Elgallad, H.W. Doty, S. Valtierra, F.H. Samuel, Effect of metallurgical parameters on the microstructure, hardness impact properties, and fractography of Al-(6.5-11.5) wt\% Si based alloys, Mater. Des. 107 (2016) 426-439. doi:10.1016/j.matdes.2016.06.051.

[54] S. Joseph, S. Kumar, A systematic investigation of fracture mechanisms in Al-Si based eutectic alloy-Effect of Si modification, Mater. Sci. Eng. A. 588 (2013) 111124. doi:10.1016/j.msea.2013.09.019.

[55] F. Lasagni, a. Lasagni, M. Engstler, H.P. Degischer, F. Mücklich, Nanocharacterization of Cast Structures by FIB-Tomography, Adv. Eng. Mater. 10 (2008) 62-66. doi:10.1002/adem.200700249.

[56] F. Mao, G. Yan, Z. Xuan, Z. Cao, T. Wang, Effect of trace Eu addition on the microstructures and mechanical properties of A356, J. Alloys Compd. 650 (2015) 896-906. doi:10.1016/j.jallcom.2015.06.266.

[57] A.M. Samuel, G.H. Garza-Elizondo, H.W. Doty, F.H. Samuel, Role of modification and melt thermal treatment processes on the microstructure and tensile properties of Al-Si alloys, Mater. Des. 80 (2015) 99-108. doi:10.1016/j.matdes.2015.05.013.

[58] C.H. Caceres, J.R. Griffiths, Damage by the cracking of silicon particles in an Al7Si-0.4Mg casting alloy, Acta Mater. 44 (1996) 25-33. doi:10.1016/13596454(95)00172-8.

[59] Q.G. Wang, C.H. Caceres, J.R. Griffiths, Damage by eutectic particle cracking in aluminum casting alloys A356/357, Metall. Mater. Trans. A Phys. Metall. Mater. Sci. 34 (2003) 2901-2912. doi:10.1007/s11661-003-0190-1.

[6o] A.M.A. Mohamed, F.H. Samuel, A.M. Samuel, H.W. Doty, Influence of additives on the impact toughness of $\mathrm{Al}-10.8 \% \mathrm{Si}$ near-eutectic cast alloys, Mater. Des. 30 (2009) 4218-4229. doi:10.1016/j.matdes.2009.04.041. 
[61] J.F. Su, X. Nie, V. Stoilov, Characterization of fracture and debonding of $\mathrm{Si}$ particles in AlSi alloys, Mater. Sci. Eng. A. 527 (2010) 7168-7175. doi:10.1016/j.msea.2010.07.106.

[62] A. Kruglova, M. Roland, S. Diebels, T. Dahmen, P. Slusallek, F. Mücklich, Modelling and characterization of ductile fracture surface in Al-Si alloys by means of Voronoi tessellation, Mater. Charact. 131 (2017) 1-11. doi:10.1016/j.matchar.2017.06.013.

[63] M. Riestra, E. Ghassemali, T. Bogdanoff, S. Seifeddine, Interactive effects of grain refinement, eutectic modification and solidification rate on tensile properties of Al-10Si alloy, Mater. Sci. Eng. A. 703 (2017) 270-279. doi:10.1016/j.msea.2017.07.074.

[64] S.M. Jigajinni, K. Venkateswarlu, S.A. Kori, Effect of a grain refiner cum modifier on mechanical properties of $\mathrm{Al}-7 \mathrm{Si}$ and $\mathrm{Al}-11 \mathrm{Si}$ alloys, Met. Mater. Int. 19 (2013) 171-181. doi:10.1007/s12540-013-2006-1.

[65] S. Tao, Y. Pan, T. Lu, Y. Chen, J. Wu, Microstructures and mechanical properties of $\mathrm{La}$ added $\mathrm{Al}-\mathrm{Si}$ casting alloys and mechanism of grain refinement, Int. J. Cast Met. Res. 28 (2015) 375-381. doi:10.1179/1743133615Y.oooooooo11.

[66] A.M. Samuel, H.W. Doty, S. Valtierra, F.H. Samuel, Effect of grain refining and Srmodification interactions on the impact toughness of $\mathrm{Al}-\mathrm{Si}-\mathrm{Mg}$ cast alloys, Mater. Des. 56 (2014) 264-273. doi:10.1016/j.matdes.2013.10.029.

[67] S. Shivkumar, S. Ricci, J.C. Keller, D. Apelian, Influence of Solution Treatment on Tensile Properties of Cast Aluminum Alloys, J. Heat Treat. 8 (1990) 63-70.

[68] D.L. Zhang, L.H. Zheng, D.H. StJohn, Effect of a short solution treatment time on microstructure and mechanical properties of modified Al-7wt.\%Si-0.3wt.\%Mg alloy, J. Light Met. 2 (2002) 27-36. doi:10.1016/S1471-5317(02)ooo10-X.

[69] D.L. Zalensas, ed., Aluminum Casting Technology, 2nd ed., American Foundrymens Society, 1993.

[70] W. Khalifa, F.H. Samuel, J.E. Gruzleski, Iron intermetallic phases in the Al corner of the Al-Si-Fe system, Metall. Mater. Trans. A Phys. Metall. Mater. Sci. 34 (2003) 807-825. doi:10.1007/s11661-003-1009-9.

[71] T.O. Mbuya, B.O. Odera, S.P. Ng'ang'a, Influence of iron on castability and properties of aluminium silicon alloys: Literature review, Int. J. Cast Met. Res. 16 (2003) 451-465. doi:10.1080/13640461.2003.11819622.

[72] L. Lu, A.K. Dahle, Iron-rich intermetallic phases and their role in casting defect formation in hypoeutectic Al-Si alloys, Metall. Mater. Trans. A. 36 (2005) 819835. doi:10.1007/s11661-005-1012-4.

[73] M. Timpel, N. Wanderka, B.S. Murty, J. Banhart, Three-dimensional visualization of the microstructure development of $\mathrm{Sr}$-modified $\mathrm{Al}-15 \mathrm{Si}$ casting alloy using FIBEsB tomography, Acta Mater. 58 (2010) 6600-6608. doi:10.1016/j.actamat.2010.08.021.

[74] C.M. Dinnis, J.A. Taylor, A.K. Dahle, As-cast morphology of iron-intermetallics in Al-Si foundry alloys, Scr. Mater. 53 (2005) 955-958. doi:10.1016/j.scriptamat.2005.06.028.

[75] J.A. Taylor, Iron-Containing Intermetallic Phases in Al-Si Based Casting Alloys, 
Procedia Mater. Sci. 1 (2012) 19-33. doi:10.1016/j.mspro.2012.06.004.

[76] S.-N. Yie, S.-L. Lee, Y.-H. Lin, L. Jing-Chie, Mechanical Properties of Al-11\%Si Casting Alloys Containing Trace Be and Sr, Mater. Trans. JIM. 40 (1999) 294300 .

[77] M. Tash, F.H. Samuel, F. Mucciardi, H.W. Doty, Effect of metallurgical parameters on the hardness and microstructural characterization of as-cast and heat-treated 356 and 319 aluminum alloys, Mater. Sci. Eng. A. 443 (2007) 185-201. doi:10.1016/j.msea.2006.08.054.

[78] F.H. Samuel, P. Ouellet, A.M. Samuel, H.W. Doty, Effect of Mg and Sr additions on the formation of intermetallics in AI-6 Wt Pet Si-3.5 Wt Pet Cu-(0.45) to (o.8) Wt Pet Fe 319-Type Alloys, Metall. Mater. Trans. A Phys. Metall. Mater. Sci. 29 (1998) 2871-2884. doi:10.1007/s11661-998-0194-y.

[79] M.H. Mulazimoglu, A. Zaluska, F. Paray, J.E. Gruzleski, The effect of strontium on the Mg2Si precipitation process in 6201 aluminum alloy, Metall. Mater. Trans. A. 28 (1997) 1289-1295. doi:10.1007/s11661-997-0265-5.

[80] B. Otani, Silumin and its structure, J. Inst. Met. (1926) 243-267.

[81] C.E. Ransley, H. Neufeld, The solubility relationship in the aluminium-sodium and aluminium-silicon-sodium systems, J. Inst. Met. (1950) 25-46.

[82] B.M. Thall, B. Chalmers, Modification in Aluminum-Silicon Alloys, J. Inst. Met. 77 (1949) 79-97.

[83] R.C. Plumb, J.E. Lewis, The modification of Aluminium-Silicon alloys by Sodium, J. Inst. Met. 86 (1958) 393-400.

[84] V.L. Davies, J.M. West, Influence of small additions of sodium on the Surface tension of aluminium and aluminium-silicon alloys, J. Inst. Met. 92 (1963) 208210.

[85] S.C. Flood, J.D. Hunt, Modification of Al-Si eutectic alloys with Na, Met. Sci. 15 (1981) 287-294. doi:10.1179/030634581790426813.

[86] S.M.D. Glenister, R. Elliott, Strontium modification of AI-12.7wt-\%Si alloys, Met. Sci. 15 (1981) 181-184. doi:10.1179/030634581790426732.

[87] L. Clapham, R.W. Smith, Segregation behaviour of strontium in modified and unmodified Al-Si alloys, J. Cryst. Growth. 92 (1988) 263-270. doi:10.1016/oo220248(88)90458-7.

[88] M. Shamsuzzoha, L.M. Hogan, The role of non-cozonal twinning in the growth of fibrous silicon in strontium-modified Al-Si eutectic, J. Mater. Sci. 24 (1989) 2849-2859. doi:10.1007/BFo2385637.

[89] B. Closset, H. Dugas, M. Pekguleryuz, J.E. Gruzleski, The Aluminum-Strontium Phase Diagram, Metall. Trans. A. 17A (1986) 1250-1253.

[9o] S.-M. Liang, M. Engstler, V. Groten, J. Barrirero, F. Mücklich, A. Bührig-Polaczek, R. Schmid-Fetzer, Key experiments and thermodynamic revision of the binary AlSr system, J. Alloys Compd. 610 (2014) 443-450. doi:10.1016/j.jallcom.2014.05.018.

[91] K. Nogita, A. Knuutinen, S.D. McDonald, A.K. Dahle, Mechanisms of eutectic solidification in Al-Si alloys modified with $\mathrm{Ba}, \mathrm{Ca}, \mathrm{Y}$ and $\mathrm{Yb}$, J. Light Met. 1 (2001) 
219-228. doi:10.1016/S1471-5317(02)oooo5-6.

[92] S.S.S. Kumari, R.M. Pillai, B.C. Pai, Role of calcium in aluminium based alloys and composites, Int. Mater. Rev. 50 (2005) 216-238. doi:10.1179/174328005X14366.

[93] S.S.S. Kumari, R.M. Pillai, B.C. Pai, Structure and properties of calcium and strontium treated Al-7Si-0.3Mg alloy: A comparison, J. Alloys Compd. 460 (2008) 472-477. doi:10.1016/j.jallcom.2007.05.085.

[94] T.H. Ludwig, J. Li, P.L. Schaffer, P. Schumacher, L. Arnberg, Refinement of Eutectic Si in High Purity Al-5Si Alloys with Combined Ca and P Additions, Metall. Mater. Trans. A Phys. Metall. Mater. Sci. 46 (2015) 362-376. doi:10.1007/s11661014-2585-6.

[95] T. Kobayashi, J.H. Kim, M. Niinomi, Effect of calcium on mechanical properties of recycled aluminium casting alloys, Mater. Sci. Technol. 13 (1997) 497-502. doi:10.1179/mst.1997.13.6.497.

[96] S.S. Sreeja Kumari, R.M. Pillai, B.C. Pai, A study on the structural, age hardening and mechanical characteristics of $\mathrm{Mn}$ and $\mathrm{Ca}$ added $\mathrm{Al}-7 \mathrm{Si}-0.3 \mathrm{Mg}-0.6 \mathrm{Fe}$ alloy, J. Alloys Compd. 453 (2008) 167-173. doi:10.1016/j.jallcom.2006.11.145.

[97] S.S. Sreeja Kumari, R.M. Pillai, K. Nogita, A.K. Dahle, B.C. Pai, Influence of calcium on the microstructure and properties of an Al-7Si-O.3Mg-xFe Alloy, Metall. Mater. Trans. A Phys. Metall. Mater. Sci. 37 (2006) 2581-2587. doi:10.1007/BFo2586230.

[98] A. Abdollahi, J.E. Gruzleski, An evaluation of calcium as a eutectic modifier in A357 alloy, Int. J. Cast Met. Res. 11 (1998) 145-155. doi:10.1080/13640461.1998.11819269.

[99] J. Li, F. Hage, M. Wiessner, L. Romaner, D. Scheiber, B. Sartory, Q. Ramasse, P. Schumacher, The roles of Eu during the growth of eutectic Si in Al-Si alloys, Sci. Rep. 5 (2015) 13802. doi:10.1038/srep13802.

[100] K. Nogita, H. Yasuda, K. Yoshida, K. Uesugi, a. Takeuchi, Y. Suzuki, a. K. Dahle, Determination of strontium segregation in modified hypoeutectic Al-Si alloy by micro X-ray fluorescence analysis, Scr. Mater. 55 (2006) 787-790. doi:10.1016/j.scriptamat.2006.07.029.

[101] G.K. Sigworth, Modification of Aluminum-Silicon Alloys, in: ASM Handbook, Vol. 15 Cast., 2008: pp. 240-254. doi:10.1361/asmhbaooo5301.

[102] A. Knuutinen, K. Nogita, S.D. McDonald, A.K. Dahle, Porosity formation in aluminium alloy A356 modified with $\mathrm{Ba}, \mathrm{Ca}, \mathrm{Y}$ and $\mathrm{Yb}$, J. Light Met. 1 (2001) 241249. doi:10.1016/S1471-5317(02)0ooo6-8.

[103] S.D. Mcdonald, A.K. Dahle, J.A. Taylor, D.H. Stjohn, A.H. Effects, ModificationRelated Porosity Formation in Hypoeutectic Aluminum-Silicon Alloys, 35 (2004) 1097-1106.

[104] L. Lu, K. Nogita, S.D. McDonald, A.K. Dahle, Eutectic solidification and its role in casting porosity formation, Jom. 56 (2004) 52-58. doi:10.1007/s11837-004-02548.

[105] L. Liu, A.M. Samuel, F.H. Samuel, H.W. Doty, S. Valtierra, Influence of oxides on porosity formation in Sr-treated alloys, Int. J. Met. 11 (2017) 729-742. doi:10.1007/s40962-016-0118-3. 
[106] N.S. Tiedje, J.A. Taylor, M.A. Easton, Feeding and distribution of porosity in cast Al-Si alloys as function of alloy composition and modification, Metall. Mater. Trans. A Phys. Metall. Mater. Sci. 43 (2012) 4846-4858. doi:10.1007/s11661-0121308-0.

[107] D. Emadi, Porosity Formation in Sr-Modified Al-Si Alloys, 1995.

[108] Z. Zhang, X. Bian, X. Liu, Effect of strontium addition on hydrogen content and porosity shape of Al-Si alloys, Int. J. Cast Met. Res. 14 (2001) 31-35. doi:10.1080/13640461.2001.11819422.

[109] D. Emadi, J.E. Gruzleski, J.M. Toguri, The effect of na and Sr modification on surface tension and volumetric shrinkage of A356 alloy and their influence on porosity formation, Metall. Trans. B. 24 (1993) 1055-1063. doi:10.1007/BFo2660997.

[110] M. De Giovanni, J.M. Warnett, M.A. Williams, P. Srirangam, 3D imaging and quantification of porosity and intermetallic particles in strontium modified Al-Si alloys, J. Alloys Compd. 727 (2017) 353-361. doi:10.1016/j.jallcom.2017.08.146.

[111] C.M. Dinnis, M.O. Otte, A.K. Dahle, J.A. Taylor, The influence of strontium on porosity formation in Al-Si alloys, Metall. Mater. Trans. A Phys. Metall. Mater. Sci. 35 A (2004) 3531-3541. doi:10.1007/s11661-004-0190-9.

[112] M.M. Makhlouf, H.V. Guthy, The aluminum-silicon eutectic reaction: mechanisms and crystallography, J. Light Met. 1 (2001) 199-218. doi:10.1016/S1471-5317(02)oooo3-2.

[113] A.G.C. Gwyer, H.W.L. Phillips, The constitution and structure of the commercial aluminium-silicon alloys, J. Inst. Met. 36 (1923) 283-324.

[114] N. Bochvar, P. Budberg, F. Hayes, Y. Liberov, R. Schmid-Fetzer, Al-Na-Si Ternary Phase Diagram, MSI, Materials Science International Services GmbH, Stuttgart, 1993.

[115] R. Ferro, O. Kubaschewski, H. Hubert, G. Ibe, Aluminium-Silicon-Strontium, VCH. 8 (1993) 270-278.

[116] J.A.E. Bell, W.C. Winegard, Structure of Pure Aluminium-Silicon Eutectics, J. Inst. Met. 93 (1964) 318-319.

[117] M.G. Day, A. Hellawell, The Structure of Modified Aluminium-Silicon Eutectic Alloy, J. Inst. Met. 95 (1967) 377.

[118] H.A.H. Steen, A. Hellawell, The growth of eutectic silicon-contributions to undercooling, Acta Metall. 23 (1975) 529-535. doi:10.1016/0001-6160(75)90093o.

[119] M.D. Hanna, S.-Z. Lu, A. Hellawell, Modification in the aluminum silicon system, Metall. Trans. A. 15 (1984) 459-469. doi:10.1007/BFo2644969.

[120] F. Yilmaz, O.A. Atasoy, R. Elliott, Growth structures in aluminium-silicon alloys II. The influence of strontium, J. Cryst. Growth. 118 (1992) 377-384. doi:10.1016/0022-0248(92)90086-X.

[121] J.H. Li, M.Z. Zarif, G. Dehm, P. Schumacher, Influence of impurity elements on the nucleation and growth of $\mathrm{Si}$ in high purity melt-spun Al-Si-based alloys, Philos. Mag. 92 (2012) 3789-3805. doi:10.1080/14786435.2012.687840. 
[122] S.D. McDonald, A.K. Dahle, J.A. Taylor, D.H. StJohn, Eutectic grains in unmodified and strontium-modified hypoeutectic aluminum-silicon alloys, Metall. Mater. Trans. A. 35 (2004) 1829-1837. doi:10.1007/s11661-004-0091-y.

[123] S.D. McDonald, K. Nogita, A.K. Dahle, Eutectic nucleation in Al-Si alloys, Acta Mater. 52 (2004) 4273-4280. doi:10.1016/j.actamat.2004.05.043.

[124] A.K. Dahle, K. Nogita, S.D. McDonald, C. Dinnis, L. Lu, Eutectic modification and microstructure development in Al-Si Alloys, Mater. Sci. Eng. A. 413-414 (2005) 243-248. doi:10.1016/j.msea.2005.09.055.

[125] D.M. Stefanescu, ed., Modification of Aluminum-Silicon Alloys, in: ASM Met. Handb. - Vol. 15, Fourth pri, ASM INternational, 1998: pp. 1052-1064.

[126] S.-Z. Lu, A. Hellawell, Modification of Al-Si Alloys: Microstructure, Thermal Analysis, and Mechanisms, JOM. (1995) 38-40.

[127] C.R. Ho, B. Cantor, Modification of hypoeutectic Al-Si alloys, J. Mater. Sci. 30 (1995) 1912-1920. doi:10.1007/BFoo353013.

[128] T.H. Ludwig, P.L. Schaffer, L. Arnberg, Influence of phosphorus on the nucleation of eutectic silicon in Al-Si alloys, Metall. Mater. Trans. A Phys. Metall. Mater. Sci. 44 (2013) 5796-5805. doi:10.1007/s11661-013-1945-y.

[129] S.-M. Liang, R. Schmid-Fetzer, Phosphorus in Al-Si cast alloys: Thermodynamic prediction of the AlP and eutectic ( $\mathrm{Si}$ ) solidification sequence validated by microstructure and nucleation undercooling data, Acta Mater. 72 (2014) 41-56. doi:10.1016/j.actamat.2014.02.042.

[130] S.M. Liang, R. Schmid-Fetzer, Validated thermodynamic prediction of AlP and eutectic (Si) solidification sequence in Al-Si cast alloys, IOP Conf. Ser. Mater. Sci. Eng. 117 (2016). doi:10.1088/1757-899X/117/1/012003.

[131] J. Eiken, M. Apel, S.-M. Liang, R. Schmid-Fetzer, Impact of P and Sr on solidification sequence and morphology of hypoeutectic Al-Si alloys: Combined thermodynamic computation and phase-field simulation, Acta Mater. 98 (2015) 152-163. doi:10.1016/j.actamat.2015.06.056.

[132] D.L. Zhang, B. Cantor, Heterogeneous nucleation of solidification of Si by solid AI in hypoeutectic Al-Si alloy, Metall. Trans. A. 24 (1993) 1195-1204. doi:10.1007/BFo2657251.

[133] M. Zarif, B. Mckay, P. Schumacher, Study of Heterogeneous Nucleation of Eutectic $\mathrm{Si}$ in High-Purity Al-Si Alloys with Sr Addition, Metall. Mater. Trans. A. 42 (2010) 1684-1691. doi:10.1007/s11661-010-0553-3.

[134] J.H. Li, M.Z. Zarif, M. Albu, B.J. McKay, F. Hofer, P. Schumacher, Nucleation kinetics of entrained eutectic Si in Al-5Si alloys, Acta Mater. 72 (2014) 80-98. doi:10.1016/j.actamat.2014.03.030.

[135] C.M. Dinnis, A.K. Dahle, J.A. Taylor, Three-dimensional analysis of eutectic grains in hypoeutectic Al-Si alloys, Mater. Sci. Eng. A. 392 (2005) 440-448. doi:10.1016/j.msea.2004.10.037.

[136] P. Srirangam, S. Chattopadhyay, a. Bhattacharya, S. Nag, J. Kaduk, S. Shankar, R. Banerjee, T. Shibata, Probing the local atomic structure of $\mathrm{Sr}$-modified $\mathrm{Al}-\mathrm{Si}$ alloys, Acta Mater. 65 (2014) 185-193. doi:10.1016/j.actamat.2013.10.060. 
[137] Y.H. Cho, H.-C. Lee, K.H. Oh, a. K. Dahle, Effect of Strontium and Phosphorus on Eutectic Al-Si Nucleation and Formation of $\beta-\mathrm{Al}_{5} \mathrm{FeSi}$ in Hypoeutectic Al-Si Foundry Alloys, Metall. Mater. Trans. A. 39 (2008) 2435-2448. doi:10.1007/s11661-008-9580-8.

[138] S. Shankar, Y.W. Riddle, M.M. Makhlouf, Nucleation mechanism of the eutectic phases in aluminum-silicon hypoeutectic alloys, Acta Mater. 52 (2004) 44474460. doi:10.1016/j.actamat.2004.05.045.

[139] S. Shankar, Y.W. Riddle, M.M. Makhlouf, Eutectic solidification of aluminumsilicon alloys, Metall. Mater. Trans. A. 35 (2004) 3038-3043. doi:10.1007/s11661004-0048-1.

[140] A.K. Dahle, K. Nogita, S.D. McDonald, J.W. Zindel, L.M. Hogan, Eutectic nucleation and growth in hypoeutectic $\mathrm{Al}-\mathrm{Si}$ alloys at different strontium levels, Metall. Mater. Trans. A. 32 (2001) 949-960. doi:10.1007/s11661-001-0352-y.

[141] K. Nogita, A.K. Dahle, Eutectic solidification in hypoeutectic Al-Si alloys: Electron backscatter diffraction analysis, Mater. Charact. 46 (2001) 305-310. doi:10.1016/S1044-5803(00)00109-1.

[142] J. Manickaraj, A. Gorny, Z. Cai, S. Shankar, X-ray nano-diffraction study of Sr intermetallic phase during solidification of Al-Si hypoeutectic alloy, Appl. Phys. Lett. 104 (2014). doi:10.1063/1.4865496.

[143] C.J. Simensen, Ø. Nielsen, F. Hillion, J. Voje, NanoSIMS Analysis of Trace Element Segregation during the Al-Si Eutectic Reaction, Metall. Mater. Trans. A. 38 (2007) 1448-1451. doi:10.1007/s11661-007-9165-y.

[144] M. Timpel, N. Wanderka, G.S. Vinod Kumar, J. Banhart, Microstructural investigation of Sr-modified Al-15 wt\%Si alloys in the range from micrometer to atomic scale., Ultramicroscopy. 111 (2011) 695-700. doi:10.1016/j.ultramic.2010.12.023.

[145] M. Timpel, N. Wanderka, R. Schlesiger, T. Yamamoto, N. Lazarev, D. Isheim, G. Schmitz, S. Matsumura, J. Banhart, The role of strontium in modifying aluminium-silicon alloys, Acta Mater. 60 (2012) 3920-3928. doi:10.1016/j.actamat.2012.03.031.

[146] M. Timpel, N. Wanderka, R. Schlesiger, T. Yamamoto, D. Isheim, G. Schmitz, S. Matsumura, J. Banhart, Sr-Al-Si co-segregated regions in eutectic Si phase of Srmodified Al-10Si alloy., Ultramicroscopy. $132 \quad$ (2013) 216-21. doi:10.1016/j.ultramic.2012.10.006.

[147] J. Barrirero, M. Engstler, F. Mücklich, Atom Probe analysis of Sr distribution in AlSi foundry alloys, in: Light Met. 2013 - TMS, 2013: pp. 291-296. doi:10.1002/9781118663189.ch50.

[148] A.M. Garay-Tapia, A.H. Romero, G. Trapaga, R. Arróyave, First-principles investigation of the $\mathrm{Al}-\mathrm{Si}-\mathrm{Sr}$ ternary system: Ground state determination and mechanical properties, Intermetallics. 21 (2012) 31-44. doi:10.1016/j.intermet.2011.09.001.

[149] J.I. Goldstein, C.E. Lyman, D.E. Newbury, E. Lifshin, P. Echlin, L. Sawyer, D.C. Joy, J.R. Michael, Scanning Electron Microscopy and X-Ray Microanalysis, Third Edit, Kluwer Academic / Plenum Publishers, New York, NY, 2003.

[150] R.R. Keller, R.H. Geiss, Transmission EBSD from $10 \mathrm{~nm}$ domains in a scanning 
electron microscope, J. Microsc. 245 (2012) 245-251. doi:10.1111/j.13652818.2011.03566.x.

[151] S. Suzuki, Features of transmission EBSD and its application, Jom. 65 (2013) 1254-1263. doi:10.1007/s11837-013-0700-6.

[152] S. Suwas, R.K. Ray, Crystallographic Texture of Materials, Eng. Mater. Process. 88 (2014) 151-177. doi:10.1007/978-1-4471-6314-5.

[153] C. Kranenberg, D. Johrendt, A. Mewis, R. Pöttgen, G. Kotzyba, C. Rosenhahn, B.D. Mosel, Structure and properties of the compounds LnAl2X2 ( $\mathrm{Ln}=\mathrm{Eu}, \mathrm{Yb} ; \mathrm{X}=\mathrm{Si}$, Ge ), Solid State Sci. 2 (2000) 215-222. doi:10.1016/S1293-2558(oo)00135-7.

[154] S. Bobev, P.H. Tobash, V. Fritsch, J.D. Thompson, M.F. Hundley, J.L. Sarrao, Z. Fisk, Ternary rare-earth alumo-silicides - Single-crystal growth from Al flux, structural and physical properties, J. Solid State Chem. 178 (2005) 2091-2103. doi:10.1016/j.jssc.2005.04.021.

[155] P. Villars, K. Cenzual, eds., YbAl2Si2 Crystal Structure: Datasheet from "PAULING FILE Multinaries Edition - 2012" in SpringerMaterials (https://materials.springer.com/isp/crystallographic/docs/sd_1210515), (2016).

[156] R. Gomer, Field emission, field ionization, and field desorption, Surf. Sci. 299300 (1994) 129-152. doi:10.1016/0039-6028(94)90651-3.

[157] K. Thompson, D. Lawrence, D.J. Larson, J.D. Olson, T.F. Kelly, B. Gorman, In situ site-specific specimen preparation for atom probe tomography., Ultramicroscopy. 107 (2007) 131-9. doi:10.1016/j.ultramic.2006.06.008.

[158] E. Müller, Field Desorption, Phys. Rev. 102 (1956) 618-624. doi:10.1103/PhysRev.102.618.

[159] R. Gomer, Field desorption, J. Chem. Phys. 31 (1959) 341-345. doi:10.1063/1.1730354.

[160] R. Gomer, L.W. Swanson, Theory of field desorption, J. Chem. Phys. 38 (1963) 1613-1629. doi:10.1063/1.1776932.

[161] R. Haydock, D.R. Kingham, Post-Ionization of Field-Evaporated Ions, Phys. Rev. Lett. 44 (1980) 1520-1523. doi:10.1103/PhysRevLett.44.1520.

[162] D.R. Kingham, The post-ionization of field evaporated ions: A theoretical explanation of multiple charge states, Surf. Sci. 116 (1982) 273-301. doi:10.1016/0039-6028(82)90434-4.

[163] R. Forbes, Field evaporation theory: a review of basic ideas, Appl. Surf. Sci. 87-88 (1995) 1-11. doi:10.1016/0169-4332(94)00526-5.

[164] B. Gault, M.P. Moody, J.M. Cairney, S.P. Ringer, Atom Probe Microscopy, Springer New York, New York, NY, 2012. doi:10.1007/978-1-4614-3436-8.

[165] P. Bas, A. Bostel, B. Deconihout, D. Blavette, A general protocol for the reconstruction of 3D atom probe data, Appl. Surf. Sci. 87-88 (1995) 298-304. doi:10.1016/0169-4332(94)00561-3.

[166] D. Blavette, A. Bostel, J.M. Sarrau, B. Deconihout, A. Menand, An atom probe for three-dimensional tomography, Nature. $363 \quad$ (1993) 432-435. doi:10.1038/363432ao. 
[167] D.J. Larson, T.J. Prosa, R.M. Ulfig, B.P. Geiser, T.F. Kelly, Local Electrode Atom Probe Tomography, Springer New York, New York, NY, 2013. doi:10.1007/978-14614-8721-0.

[168] O.C. Hellman, J.A. Vandenbroucke, J. Rüsing, D. Isheim, D.N. Seidman, Analysis of Three-dimensional Atom-probe Data by the Proximity Histogram, Microsc. Microanal. 6 (2000) 437-444. doi:10.1007/s100050010051.

[169] W. Lefebvre, F. Danoix, G. Da Costa, F. De Geuser, H. Hallem, A. Deschamps, M. Dumont, 3DAP measurements of Al content in different types of precipitates in aluminium alloys, Surf. Interface Anal. 39 (2007) 206-212. doi:10.1002/sia.2516.

[170] F. Vurpillot, A. Bostel, D. Blavette, Trajectory overlaps and local magnification in three-dimensional atom probe, Appl. Phys. Lett. $76 \quad$ (2000) 3127. doi:10.1063/1.126545.

[171] B. Gault, F. de Geuser, L. Bourgeois, B.M. Gabble, S.P. Ringer, B.C. Muddle, Atom probe tomography and transmission electron microscopy characterisation of precipitation in an Al-Cu-Li-Mg-Ag alloy., Ultramicroscopy. 111 (2011) 683-9. doi:10.1016/j.ultramic.2010.12.004.

[172] G. Sha, H. Möller, W.E. Stumpf, J.H. Xia, G. Govender, S.P. Ringer, Solute nanostructures and their strengthening effects in $\mathrm{Al}-7 \mathrm{Si}-0.6 \mathrm{Mg}$ alloy $\mathrm{F} 357$, Acta Mater. 60 (2012) 692-701. doi:10.1016/j.actamat.2011.10.029.

[173] J. Rüsing, J.T. Sebastian, O.C. Hellman, D.N. Seidman, Three-dimensional Investigation of Ceramic / Metal Heterophase Interfaces by Atom-probe Microscopy, Microsc. Microanal. 6 (2000) 445-451. doi:10.1007/s100050010050.

[174] Y. Suzuki-Yamamoto, R. Ozaki, M. Yoshiya, T. Nagira, H. Yasuda, Yet Another Marked Difference among Impurities as Modifier Elements for Refinement of Eutectic Si in Al-Si Alloys, 56 (2015) 1475-1483. doi:10.2320/matertrans.MA201576.

[175] M.A. González, Force fields and molecular dynamics simulations, École Thématique La Société Française La Neutron. 12 (2011) 169-200. doi:10.1051/sfn/201112009.

[176] X.Z. Gao, M.H. Müser, L.T. Kong, J.F. Li, Atomic structure and energetics of amorphous-crystalline CuZr interfaces: A molecular dynamics study, Model. Simul. Mater. Sci. Eng. 22 (2014). doi:10.1088/0965-0393/22/6/065007. 


\section{Papers}

The papers associated with this thesis have been removed for copyright reasons. For more details about these see:

http://urn.kb.se/resolve?urn=urn:nbn:se:liu:diva-160235 


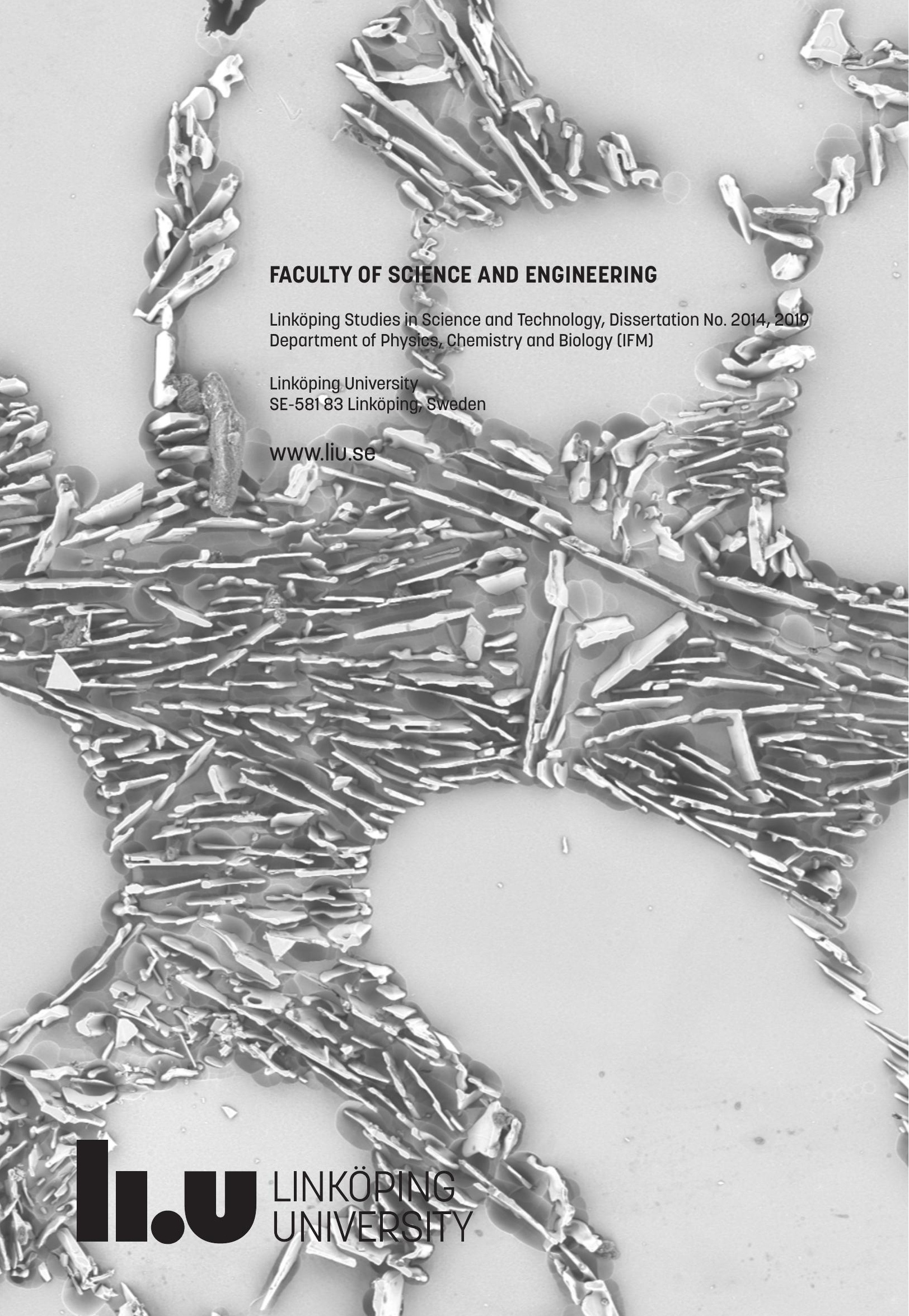

